Paulo Henrique Martins

\title{
Projeto robusto e análise de incertezas em dispositivos ressonantes para coleta de energia
}

São Carlos 

Paulo Henrique Martins

\section{Projeto robusto e análise de incertezas em dispositivos ressonantes para coleta de energia}

Dissertação apresentada à Escola de Engenharia de São Carlos da Universidade de São Paulo como parte dos requisitos para a obtenção do título de Mestre em Engenharia Mecânica.

Área de concentração: Dinâmica das Máquinas e Sistemas.

Orientador: Prof. Dr. Marcelo Areias Trindade DA VERSÃO CORRIGIDA. A VERSÃO ORIGINAL ENCONTRA-SE DISPONÍVEL JUNTO AO DEPARTAMENTO DE ENGENHARIA MECÂNICA DA EESC-USP. 
AUTORIZO A REPRODUÇÃO E DIVULGAÇ̃̃O TOTAL OU PARCIAL DESTE TRABALHO, POR QUALQUER MEIO CONVENCIONAL OU ELETRÔNICO, PARA FINS DE ESTUDO E PESQUISA, DESDE QUE CITADA A FONTE.

Ficha catalográfica preparada pela Seção de Atendimento ao Usuário do Serviço de Biblioteca

"Prof. Dr. Sérgio Rodrigues Fontes" da EESC/USP

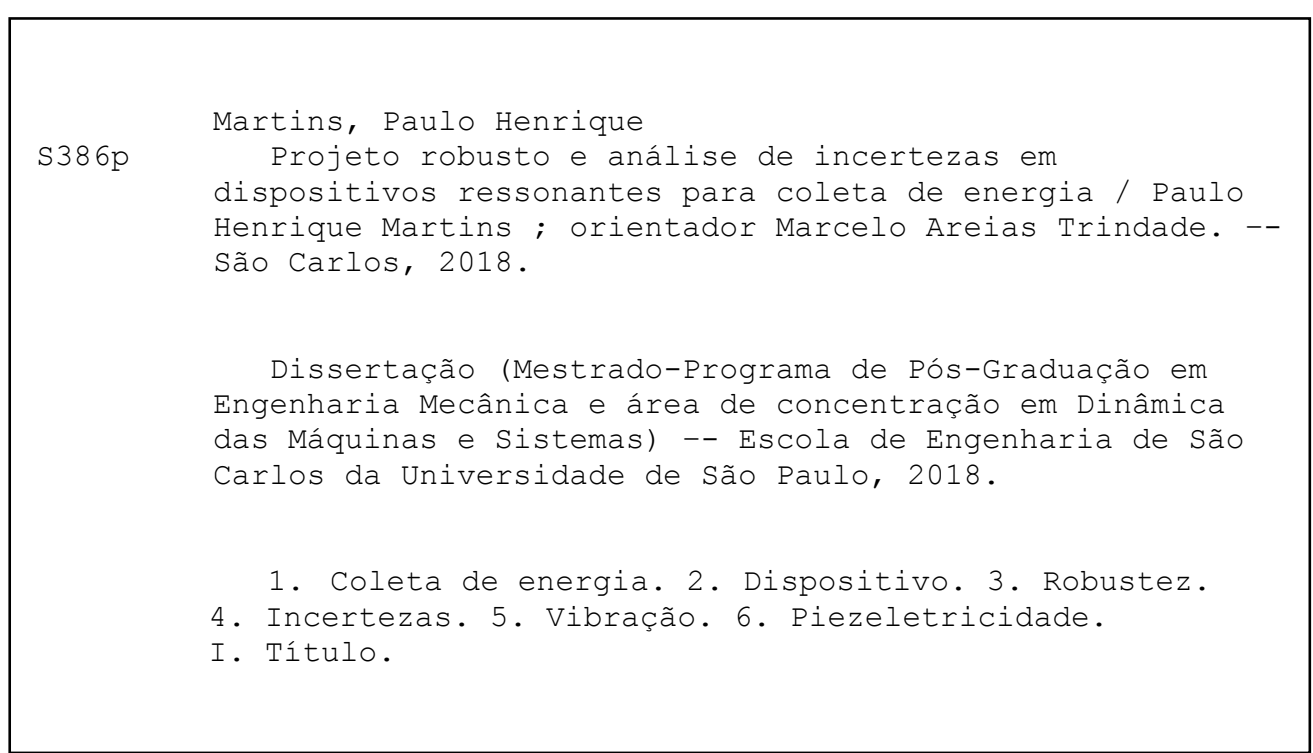

Elaborado por Flávia Helena Cassin - CRB-8/5812 


\section{FOLHA DE JULGAMENTO}

Candidato: Engenheiro PAULO HENRIQUE MARTINS.

Título da dissertação: "Projeto robusto e análise de incertezas em dispositivos ressonantes para coleta de energia".

Data da defesa: 22/02/2018.

Comissão Julgadora:

Prof. Associado Marcelo Areias Trindade

(Orientador)

(Escola de Engenharia de São Carlos/EESC)

Prof. Associado André Teófillo Beck

(Escola de Engenharia de São Carlos/EESC)

Prof. Dr. Vitor Ramos Franco

(Universidade Federal de São Carlos/UFSCar)
Resultado:

APROVADO

Coordenador do Programa de Pós-Graduação em Engenharia Mecânica: Prof. Associado Gherhardt Ribatski

Presidente da Comissão de Pós-Graduação:

Prof. Associado Luis Fernando Costa Alberto 

Dedico este trabalho em especial a minha irmã Elenice que sempre me ajudou em meus estudos. 



\section{Agradecimentos}

Agradeço primeiramente a Deus, sem o qual nada sou, o qual me deu forças para continuar nos momentos difíceis.

Agradeço ao meu orientador Marcelo Trindade pela oportunidade concedida, por toda orientação, conselhos e auxílios durante esse tempo do curso de mestrado. Pela grande pessoa que é e por sempre me orientar em muitas situações, com grande profissionalismo.

A minha irmã por tudo que me ajudou durante muito tempo, em todos os sentidos, propiciando as condições para que eu pudesse terminar minha graduação e, hoje, ter realizado o curso de mestrado.

A toda minha família que estiveram comigo em todos os momentos, minha mãe, em especial, e todos meus irmãos que sempre me ampararam.

Ao meu amigo Enrico e sua esposa Elaine pelo auxílio e orientação nas escolhas durante esse tempo.

Aos meu amigos, em especial, Jelder e Augusto que por fazerem parte da mesma área de pesquisa puderam contribuir no dia a dia no laboratório, compartilhando do conhecimento e auxiliando em algumas questões práticas.

A todos os amigos do laboratório de dinâmica que estiveram juntos durante os bons momentos de estudos, alegria e diversões, o que contribui para o bom desenvolvimento dos estudos.

Aos professores que ministraram as disciplinas de mestrado, ajudando-me sempre que precisei e aos funcionários dos departamentos pela simpatia diante das dificuldades.

Agradeço ao Conselho Nacional de Desenvolvimento Científico e Tecnológico (CNPq) pela bolsa concedida de mestrado que propiciou o desenvolvimento do curso nesses anos.

Aos professores que fizeram parte da banca examinadora e contribuíram para o meu crescimento.

A todos que de alguma forma estiveram presente durante esse tempo e aqueles que um dia vão ler esse trabalho. Desejo que esse projeto possa lhes ser útil. 

"As cousas árduas e lustrosas

Se alcançam com trabalho e com fadiga.

(Camões) 



\section{Resumo}

MARTINS, P.H. Projeto robusto e análise de incertezas em dispositivos ressonantes para coleta de energia. 112 p. Dissertação (Mestrado) - Escola de Engenharia de São Carlos, Universidade de São Paulo, São Carlos, 2018.

O estudo das vibrações é importante para prevenir danos em equipamentos ou mesmo evitar catástrofes de grande natureza. Nesse sentido, aproveitar a energia que seria dissipada na vibração e contribuir no controle do sistema representa um grande avanço tecnológico. O termo Energy Harvesting (Colheita de Energia) está relacionado ao contexto do aproveitamento energético, utilizando sistema de conversão para transformação da energia em eletricidade. Através de um dispositivo com viga engastada e massa inercial na extremidade, é possível realizar o estudo de vibração e coleta de energia, ao se considerar uma estrutura piezelétrica acoplada na viga e conectada a um circuito elétrico com resistor. Estruturas inteligentes que atuam na conversão de energia mecânica em elétrica, ou vice-versa, são fundamentais para esse estudo, o que motiva a inclusão dos sensores piezelétricos no projeto de dispositivos estudados e sujeitos a vibrações. Por outro lado, otimizar parâmetros de projeto é fundamental para aumentar a amplitude de vibração e tornar o processo com maior desempenho, tendo em vista maior captação de energia. Ainda, parâmetros otimizados podem estar sujeitos a incertezas do projeto e variações, devido a flutuações ambientais, como temperatura, pressão, propriedades dos materiais, geometria, etc. Por isso, técnicas robustas que tornem os projetos menos sensíveis a variações são interessantes para serem abordadas. Embora métodos de projetos robustos sejam eficientes, poucas pesquisas têm sido feitas na área da dinâmica de vibrações e alguns processos podem demandar tempo computacional dependendo do estudo ou projeto. Este trabalho tem como propósito abordar um método específico de projeto robusto focado em uma metodologia com matrizes chamadas ortogonais. Além disso, o método determinístico via algoritmo de Programação Sequencial Quadrático (SQP) é utilizado. O trabalho consiste numa abordagem para coleta de energia em um modelo de viga engastada, otimizando parâmetros e inserindo incertezas no sistema para análise de robustez e verificação de comprimentos adequados de vigas para os dispositivos. Os resultados mostram um aumento da energia coletada, analisando funções de resposta em frequências para saída de potência, diante de uma entrada de deslocamento no engaste do dispositivo, projetado via otimização determinística, além de aumento de robustez de acordo com certos critérios considerando circuito elétrico com resistência corretamente selecionada.

Palavras chave: coleta de energia, dispositivo, robustez, incertezas, vibração, piezeletricidade. 



\section{Abstract}

MARTINS, P.H. Robust design and uncertainty analysis in resonant energy harvesting devices. 112 p. Dissertation (Master) - São Carlos School of Engineering, University of São Paulo, São Carlos, 2018.

The study of vibrations is important to prevent damage to equipment or even prevent major catastrophes. In this sense harvesting the energy that would otherwise be dissipated in vibration and contributing to the control of the system represents a great technological advance. The term Energy Harvesting is related to the context of energy use, using a conversion system to transform energy into electricity. Through a device with clamped beam and inertial mass at the end, it is possible to study the vibration and energy harvesting, considering a piezoelectric structure coupled to the beam and connected to a resistance electric circuit. Smart structures that act in the conversion of mechanical energy to electrical energy, or vice versa, are fundamental for this study, which motivates the inclusion of piezoelectric sensors in the design of studied devices and subject to vibrations. On the other hand, optimizing design parameters is fundamental to increase the amplitude of vibration and increase process performance, in view of greater power uptake. Furthermore, optimized parameters may be subject to design uncertainties and variations due to environmental fluctuations such as temperature, pressure, material properties, geometry, etc. Therefore, robust techniques that make designs less sensitive to variations are interesting to be addressed. Although robust design methods are efficient, few researches have been done in the area of vibration dynamics and some processes may require computational time depending on the study or project. This work aims to address a specific method of robust design focused on a methodology with matrices called orthogonal. In addition, the deterministic method using Sequential Quadratic Programming (SQP) algorithm is used. The work consists of an approach to harvest energy in a clamped beam model, optimizing parameters and inserting uncertainties in the system for robustness analysis and verification of adequate beam lengths for the devices. The results show an increase in the harvested energy, analyzing frequency response functions for power output, in the face of a displacement input in the device clamp, designed through deterministic optimization, besides increasing robustness according to certain criteria considering electric circuit with correctly selected resistance.

Palavras chave: Energy harvesting, device, robustness, uncertainties, vibration, piezoelectricity. 



\section{Lista de ilustrações}

Figura 1 - Placas de material piezelétrico fixada sobre o pavimento. . . . . . . . 27

Figura 2 - (a) Dipolos desorientados (b) Orientação de dipolos conforme sentido de aplicação do campo elétrico (c) Direção dos dipolos após retirada do campo elétrico. . . . . . . . . . . . . . . . . . . . . . . 28

Figura 3 - Polarização do material piezelétrico conforme direção da carga aplicada: (a) Polarização no mesmo sentido da carga (b) Polarização transversal à carga. . . . . . . . . . . . . . . . . . . . . . . . . . . . . . . . . . 29

Figura 4 - Modelo esquemático de dispositivos para estudo de coleta de energia. . 30

Figura 5 - Sistemas de vigas excitadas para alcance da frequência natural. . . . . 31

Figura 6 - Modelos para vigas cantilevers com um grau de liberdade. . . . . . . . 33

Figura 7 - Curvas de níveis para restrições e função objetivo. . . . . . . . . . . . 35

Figura 8 - Diagramas de variabilidade e alvo a ser alcançado. . . . . . . . . 36

Figura 9 - Metodologia de robustez baseada no conceito de sensibilidade. . . . . . 37

Figura 10 - Dispositivo modelo para estudo da coleta de energia. . . . . . . . . . . 39

Figura 11 - Modelo do dispositivo para coleta de energia. . . . . . . . . . . . . . . 41

Figura 12 - Deslocamentos para uma viga sanduíche considerando as hipóteses de Timoshenko para camada central e Bernoulli-Euler para camadas externas. . . . . . . . . . . . . . . . . . . . 4 43

Figura 13 - Elemento e graus de liberdades considerados (SANTOS, 2008). . . . . 45

Figura 14 - Funções perda de qualidade. . . . . . . . . . . . . . . . 58

Figura 15 - Diagrama de blocos para o sistema ou produtos. . . . . . . . . . . . 61

Figura 16 - Matriz ortogonal do tipo $L_{32}\left(2^{1} \times 4^{9}\right)$. . . . . . . . . . . . . . . 63

Figura 17 - Gráfico de efeito. . . . . . . . . . . . . . . . . . . . 69

Figura 18 - Gráfico de efeito com tipos de iterações. . . . . . . . . . . . . . . 70

Figura 19 - Gráficos lineares de interação. . . . . . . . . . . . . . . . . . . . 71

Figura 20 - Formação de quatro níveis através de pares de dois níveis. . . . . . . . 73

Figura 21 - Divisão de etapas desenvolvidas para otimização do projeto robusto. . . 75

Figura 22 - Dispositivo prático utilizado em coleta de energia. . . . . . . . . . 78

Figura 23 - Modelo do dispositivo para coleta de energia. . . . . . . . . . . . . 78

Figura 24 - Diagrama de bloco para o sistema. . . . . . . . . . . . . . . 82

Figura 25 - Gráfico linear para matriz ortogonal do tipo $L_{50}\left(2^{1} \times 5^{11}\right)$. . . . . . . 84

Figura 26 - Viga em elementos finitos de $50 \mathrm{~mm}$ de comprimento. . . . . . . . . . . 90

Figura 27 - Resposta para primeiro modo de vibração em função da rigidez linear para viga de $50 \mathrm{~mm} \ldots \ldots$. . . . . . . . . . . . . . . . 91

Figura 28 - Resposta para primeiro modo de vibração em função da rigidez torcional para viga de $50 \mathrm{~mm}$. . . . . . . . . . . . . . . 91 
Figura 29 - Resposta para primeiro modo de vibração em função da rigidez linear para viga de $75 \mathrm{~mm}$. . . . . . . . . . . . . . . . . . . . . 92

Figura 30 - Resposta para primeiro modo de vibração em função da rigidez torcional para viga de $75 \mathrm{~mm}$. . . . . . . . . . . . . . . . . . 92

Figura 31 - Resposta para saída de tensão dos dispositivos projetados. . . . . . . . 95

Figura 32 - Resposta para saída de potência elétrica dos dispositivos projetados. 95

Figura 33 - Resposta para saída de tensão em função da rigidez linear para os dispositivos. . . . . . . . . . . . . . . . . . . . . 97

Figura 34 - Resposta para saída de tensão em função da rigidez torcional para os dispositivos. . . . . . . . . . . . . . . . . . . . . 997

Figura 35 - Resposta para saída de potência versus resistência para os dispositivos na frequência de $100 \mathrm{~Hz}$. . . . . . . . . . . . . . . . . . . . . . . . 99

Figura 36 - Efeito com $k_{w}=1500 \mathrm{kN} / \mathrm{m}, k_{\theta}=2,5 \mathrm{kNm} / \mathrm{rad}$ e $\zeta$ com $10 \%$ de tolerância. . . . . . . . . . . . . . . . . . . 101

Figura 37 - Efeito com $k_{w}=2000 \mathrm{kN} / \mathrm{m}, k_{\theta}=4,2 \mathrm{kNm} / \mathrm{rad}$ e $\zeta$ com $10 \%$ de tolerância. . . . . . . . . . . . . . . . . . 102

Figura 38 - Efeito com $k_{w}=3000 \mathrm{kN} / \mathrm{m}, k_{\theta}=5,8 \mathrm{kNm} / \mathrm{rad}$ e $\zeta$ com $10 \%$ de tolerância. . . . . . . . . . . . . . . . . . 102

Figura 39 - Valor de média e intervalo de confiança com $6 \sigma$ para saída de potência dos cinco dispositivos para energy harvesting quando usando (a) Valor de resistência ótima e (b) Valor menor de resistência. . . . . . . . . . . 105

Figura 40 - Gráfico de interação. . . . . . . . . . . . . . . . . . . . . . 106 


\section{Lista de tabelas}

Tabela 1 - Matrizes de parâmetros de controle e fatores de ruído com média e variância . . . . . . . . . . . . . . . . . 64 64

Tabela 2 - modelo para ANOVA. . . . . . . . . . . . . . . . . 69

Tabela 3 - Matriz Ortogonal $L_{8}\left(2^{7}\right) \ldots \ldots \ldots \ldots \ldots \ldots$

Tabela 4 - Formação de quatro níveis através de pares de dois níveis . . . . . . . 73

Tabela 5 - Limites para cada fator de ruído . . . . . . . . . . . . . 74

Tabela 6 - Formação de níveis para fatores de ruído e resistência com tolerâncias . 82

Tabela 7 - Matriz ortogonal $L_{8}\left(2^{7}\right)$ para fatores de ruído e resistência . . . . . 83

Tabela 8 - Matriz $L_{50}\left(2^{1} \times 5^{11}\right)$ para parâmetros de controle . . . . . . . . 86

Tabela 9 - Matrizes de controle associada com matriz de ruído . . . . . . . . 87

Tabela 10 - Condições para projetos de dispositivos via otimização . . . . . . . . 93

Tabela 11 - Intervalos e parâmetros otimizados . . . . . . . . . . . . . . 95

Tabela 12 - Regiões de análise para rigidez linear . . . . . . . . . . . . . 98

Tabela 13 - Valores limites e tolerâncias para $k_{\theta} \ldots \ldots$. . . . . . . . 98

Tabela 14 - Parâmetros de controle . . . . . . . . . . . . . . . . . . . 100

Tabela 15 - Fatores de ruídos . . . . . . . . . . . . . . . . . . . . . 100

Tabela 16 - Valores média, variância e sensibilidade para os níveis dos parâmetros . 103

Tabela 17 - ANOVA para média $\left(m W / g^{2}\right) \ldots \ldots \ldots \ldots$

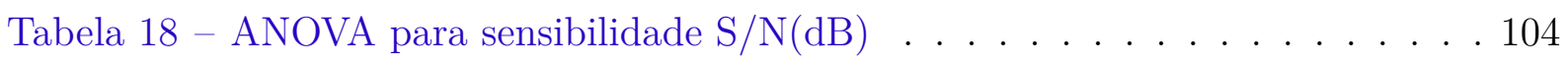

Tabela 19 - Parâmetros de controle para análise de interação . . . . . . . . . . . 106 



\section{Lista de abreviaturas e siglas}

$\begin{array}{ll}\text { ANOVA } & \text { Analysis of variance, ou análise de variância } \\ \text { EESC } & \text { Escola de Engenharia de São Carlos } \\ \text { FRF } & \text { Função de resposta em frequência } \\ \text { STB } & \text { Smaller-the-better, ou "quanto menor melhor" } \\ \text { NTB } & \text { Nominal-the-best, ou "nominal é melhor" } \\ \text { LTB } & \text { Larger-the-better, ou "quanto maior melhor" } \\ \text { PZT } & \text { Titanato Zirconato de Chumbo } \\ \text { GL } & \text { Graus de Liberdade } \\ \text { SQ } & \text { Soma dos Quadrados } \\ \text { QM } & \text { Quadrados Médios } \\ \text { MCS } & \text { Simulação Monte Carlo } \\ \text { USP } & \text { Universidade de São Paulo } \\ \text { S/N } & \text { Signal-to-noise, ou razão sinal-ruído } \\ \text { SQP } & \text { Sequencial Quadratic Programmming, ou Programação Quadrática Se- } \\ & \text { quencial }\end{array}$





\section{Lista de símbolos}

$\varepsilon$

D

E

$\sigma$

$c^{D}$

$h$

$\boldsymbol{\beta}^{\varepsilon}$

$u$

$w$

$w^{\prime}$

$\delta W^{c}$

$\delta W^{i n}$

$\delta W^{e x}$

$\delta H_{m}$

$\delta H_{m e}$

$\delta H_{e}$

$\rho_{i}$

$A_{i}$

$I_{i}$

$M$

$M_{r r}$

$\boldsymbol{K}_{m}$

$\boldsymbol{K}_{r r}$

$\boldsymbol{K}_{m e}$

vetor de deformação mecânica

vetor de deslocamento elétrico

vetor de campo elétrico

vetor de tensão mecânica

matriz de constante elástica para deslocamentos elétrico constante

matriz de constantes piezelétricas

matriz de constantes dielétricas para deformações constantes

deslocamentos em relação ao eixo x da camada do modelo

deslocamentos em relação ao eixo z da camada do modelo

ângulo de rotação da seção da camada do modelo

trabalho virtual para força de inercias

trabalho virtual para força internas

trabalho virtual para força externas

energia potencial para camadas mecânicas do modelo

energia potencial para camadas eletromecânicas do modelo

energia potencial para camadas dielétricas do modelo

densidade da i-ésima camada do modelo

área da i-ésima camada do modelo

momento de inércia da i-ésima camada do modelo

matriz de massa sem a massa sísmica

matriz de massa para o modelo com a massa sísmica

matriz de rigidez mecânica sem molas no engaste

matriz de rigidez mecânica para o modelo com molas no engaste

matriz de rigidez eletromecânica para o modelo 


\begin{tabular}{|c|c|}
\hline $\boldsymbol{K}_{e}$ & matriz dielétrica para o modelo \\
\hline $\boldsymbol{F}_{p}$ & vetor de força elástica no modelo \\
\hline $\boldsymbol{R}_{c}$ & matriz de resistência elétrica \\
\hline $\boldsymbol{q}_{c}$ & vetor de carga elétrica \\
\hline$\eta$ & função de sensibilidade $(\mathrm{S} / \mathrm{N})$ \\
\hline$z$ & vetor de fatores de ruído \\
\hline $\boldsymbol{x}$ & vetor de parâmetros de controle \\
\hline $\mathbf{x}_{p}$ & vetor de parâmetros de projeto \\
\hline$S S_{X}$ & soma dos quadrados para um determinado parâmetro $X$ \\
\hline$S_{X}^{2}$ & quadrado médio para um determinado parâmetro $X$ \\
\hline$S S T$ & soma dos quadrados total \\
\hline$S S E$ & soma dos quadrados do erro \\
\hline$S S T_{G}$ & soma geral de quadrados \\
\hline$S S_{\bar{m}}$ & soma dos quadrados devido a média geral \\
\hline$\sigma_{e}^{2}$ & variância devido ao erro \\
\hline$\omega_{0}$ & deslocamento imposto \\
\hline$\Omega$ & frequência do deslocamento imposto \\
\hline$k_{w}$ & rigidez linear do engaste \\
\hline$k_{\theta}$ & rigidez de torção do engaste \\
\hline$h_{v}$ & espessura da viga \\
\hline$h_{p}$ & espessura da camada piezelétrica \\
\hline$h_{c}$ & espessura da camada adesiva \\
\hline$d_{p}$ & distância do engaste até a camada piezelétrica \\
\hline$l_{p}$ & comprimento do sensor piezelétrico \\
\hline$l_{v}$ & comprimento da viga \\
\hline$m_{b}$ & massa sísmica \\
\hline & amortecimento \\
\hline
\end{tabular}




\section{Sumário}

INTRODUÇÃ̃O .......................... 25

$1.1 \quad$ Motivação . . . . . . . . . . . . . . . . . 25

1.2 Energy Harvesting . . . . . . . . . . . . . . . . 25

1.3 Materiais Piezelétricos . . . . . . . . . . . . . . 27

$1.4 \quad$ Coleta de energia usando vigas cantilever . . . . . . . . . . . . 30

1.5 Otimização e projeto robusto . . . . . . . . . . 33

$1.6 \quad$ Justificativas . . . . . . . . . . . . . . . . . 38

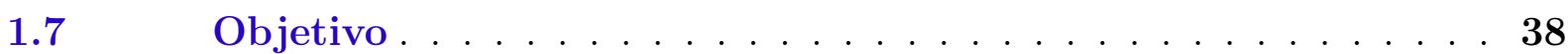

$2 \quad$ MODELO DE VIGA EM ELEMENTOS FINITOS $\ldots \ldots$

2.1 Modelo cinemático e constitutivo para vigas com camadas pi-

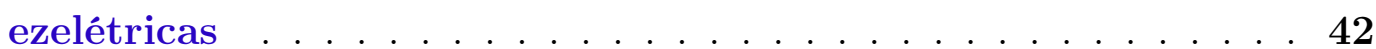

2.2 Formulação Variacional . . . . . . . . . . . . . . . . . . . 44

2.3 Formulação em elementos finitos . . . . . . . . . . . . . 45

2.4 Discretização das expressões de trabalho virtual . . . . . . . . 46

2.5 Modelagem do Dispositivo . . . . . . . . . . . . 48

2.6 Resposta em Frequência . . . . . . . . . . . . . . 53

$3 \quad$ PROJETO ROBUSTO E MATRIZES ORTOGONAIS $\ldots \ldots$

$3.1 \quad$ Função Perda de Qualidade . . . . . . . . . . . . . 57

3.2 Parâmetros de Análises na Função Perda de Qualidade . . . . . 59

3.3 Matrizes Ortogonais .................. 61

$3.4 \quad$ Análises Estatísticas . . . . . . . . . . . . . . . . 65

3.5 Interações entre Parâmetros de Controle . . . . . . . . . . . . . 69

3.6 Modificação de Matrizes Ortogonais . . . . . . . . . . . . . 72

$3.7 \quad$ Análises de Robustez e Matrizes Ortogonais . . . . . . . . . . . 73

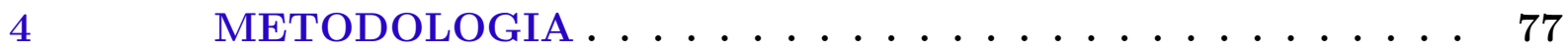

4.1 Introdução . . . . . . . . . . . . . . . . . . 77

$4.2 \quad$ Análise paramétrica . . . . . . . . . . . . . 78

4.3 Otimização do dispositivo . . . . . . . . . . . 79

$4.4 \quad$ Análise de Robustez . . . . . . . . . . . . . . . . . 81

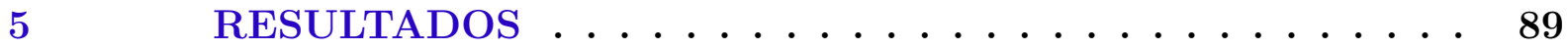

$5.1 \quad$ Análise paramétrica de rigidez do engaste . . . . . . . . . 89

5.2 Projeto do dispositivo . . . . . . . . . . . . 93 
5.3 Projeto robusto e análise de incertezas dos dispositivos . . . . . 96

5.4 Análise de Interações . . . . . . . . . . . . . . . . . 105

6 CONSIDERAÇÕES FINAIS E CONCLUSÕES . . . . . . 107

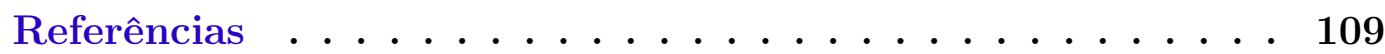




\section{Introdução}

\subsection{Motivação}

Atualmente existe um crescente número de dispositivos portáteis que utilizam energia através de fontes recarregáveis como bateria, que ocupam um espaço significativo nos dispositivos, além de possuírem um tempo de vida útil limitado. Além disso, alguns sistemas necessitam de alimentação plena de energia, e que deveriam ser auto alimentados, como marcapassos, celulares, sensores e câmeras. Sendo assim, muitos estudos têm sido conduzidos com a finalidade de se averiguar a possibilidade de utilização de energia disponível de diversas fontes, tal que se consiga maximizar o tempo de vida para operação dos dispositivos, sem necessidade de recarregamento ou utilização de fontes secundárias (ABDELKEFI, 2016). Com esta exigência o conceito de Energy Harvesting (colheita de energia) vem sendo pesquisado, uma vez que o termo está relacionado justamente com o aproveitamento de energia das diversas fontes ambientais.

Vibrações podem causar efeitos indesejáveis em sistemas e equipamentos, como ruído, fadiga, degradação, aumento do consumo de energia e problemas de segurança em determinados ambientes. Sabendo desse fato, atenuar vibrações é de suma importância, por isso métodos de controle podem ser utilizados e muitos estudos são desenvolvidos nesse sentido (LESIEUTRE; OTTMAN; HOFMANN, 2004). Estabelecer o controle de uma estrutura e aproveitar a energia que seria dissipada na vibração pode ser feito através de controle passivo, utilizando materiais piezelétricos, que são utilizados como sensores, associados a circuitos shunts. Para o controle adequado de uma estrutura também é importante garantir que a conversão de energia seja eficiente; assim projetos de dispositivos com materiais, geometria e dimensões apropriados são fundamentais para abordagem do presente trabalho. Por isso, análise de projetos robusto é imprescindível ao se considerar as incertezas inerentes ao sistema, que diminuiriam a qualidade da estrutura ou dispositivo analisado, bem como o aproveitamento da energia disponível através da vibração.

\subsection{Energy Harvesting}

O conceito de Energy Harvesting está diretamente relacionado a coleta e armazenamento de energia das fontes existentes no meio ambiente. Através de fontes térmicas, eólicas, químicas, mecânicas, eletromagnéticas e luminosas, a energia pode ser aproveitada de alguma maneira, por meio de armazenamento ou conversão em eletricidade. Dessa maneira, o termo Energy Harvesting também está associado ao processo de conversão da energia em eletricidade a partir de muitas fontes (GONÇALVES, 2011; STEPHEN, 2006; 


\section{ROUNDY, 2005).}

Na atualidade, o termo Energy Harvesting faz referência a sistemas ou dispositivos que convertem baixa quantidade de energia disponível (ABDELKEFI, 2016; SODANO; INMAN; PARK, 2004; BEEBY; TUDOR; WHITE, 2006). Considerando essa pequena quantidade para coleta em alguns sistemas, é importante que a conversão em energia elétrica seja eficiente, assim a utilização de materiais adequados, estruturas com geometria e projetos apropriados, além de análises computacionais para dispositivos e sistemas, devem ser criteriosamente investigados para melhor resultado final daquilo que se pretende alcançar (CHEN et al., 2014). Em se tratando da conversão de energia mecânica proveniente de vibrações, materiais chamados piezelétricos estão sendo adotados, por satisfazerem os requisitos citados (GODOY; TRINDADE, 2012). Esses materiais podem ser utilizados como sensores ou atuadores dependendo da finalidade. Alguns estudos estão sendo realizados para otimização da posição desses materiais, com o intuito de melhorar a extração da energia disponível no sistema estudado (OSTASEVICIUS et al., 2015; GODOY; TRINDADE; DEÜ, 2012).

Pelo fato da energia coletada proveniente de vibrações mecânicas ter a possibilidade de conversão em eletricidade através da utilização de materiais piezelétricos, muitos estudos e pesquisas estão sendo realizados. Assim, alguns casos podem ser introduzidos, relatando a associação entre coleta de energia e utilização de materiais piezelétricos para uma melhor compreensão do assunto.

Um estudo em tubulações de condução de fluido em poços de petróleo, utilizando sensores piezelétricos dispostos no interior da tubulação, para conversão do movimento natural de escoamento em eletricidade, foi elaborado (LEE et al., 2015). Neste caso, análises de vibrações são citadas devido ao movimento do fluido nas tubulações, bem como gerações de desprendimento de vórtices, batimentos e pressão hidráulica.

Análise do comportamento aerodinâmico, quando a estrutura é submetida a fluxos de ventos, considerando o fenômeno aeroelástico para aplicação na coleta de energia e utilizando modelos de vigas engastadas com estruturas piezelétricas associadas a circuitos elétricos pode ser citado (ABDELKEFI, 2016). Nesta pesquisa, abordagem sobre indução de vortex, flutter e fenômenos conhecidos como galloping são considerados.

Um desenvolvimento de estrutura flexível, com material piezelétrico para ser inserido em uma luva, de tal maneira que o movimento mecânico de um dos dedos da mão possa ser convertido em energia elétrica, também é introduzido em (GUIDO et al., 2016). Dessa forma, o estudo reforça a importância do desenvolvimento de estruturas que capturem o movimento de alguma parte do corpo humano e converta em eletricidade para alimentação de dispositivos portáteis e acumuladores de energia, muitos que possam ser utilizados na biomedicina. Além disso, uma abordagem de sistemas microeletromecânicos e microgeradores piezelétricos é levantada para a compreensão de pequenos movimentos 
realizados na conversão elétrica.

Vários exemplos podem ser citados de sistemas que consideram a coleta de energia como técnica de eficiência e conversão energética. Através de sensores piezelétricos a energia da vibração mecânica está sendo aproveitada para muitas aplicações, ao invés de ser rejeitada por dissipação de calor. Movimentos humanos podem gerar vibração ou pressionar estruturas, permitindo a conversão da energia. Além disso, sistemas de transportes e estruturas civis também são meios que possibilitam a coleta de energia utilizando materiais piezelétricos. Como exemplos, podem ser citados rodovias, que possuem atualmente esse tipo de material implantado no pavimento para converter o movimento das rodas de veículos em energia elétrica, boates, aeroportos ou locais onde existe grande aglomerado de pessoas que ao caminhar, pular ou dançar interagem com o piso e possibilitam a geração de energia, que é aproveitada para outras finalidades. Na figura 1, está um pavimento onde pessoas estão caminhando, sendo que existem placas piezelétricas fixadas sobre o mesmo, possibilitando que o movimento seja convertido em eletricidade, para posterior utilização (KALYANI; PIAUS; VYAS, 2015).

Figura 1 - Placas de material piezelétrico fixada sobre o pavimento.

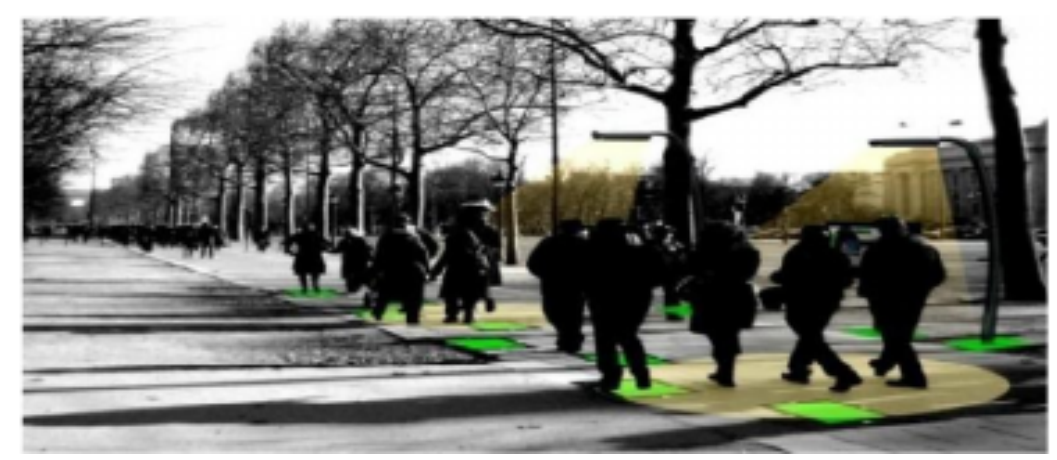

Fonte: Kalyani, Piaus e Vyas (2015).

\subsection{Materiais Piezelétricos}

Piezoeletricidade é a característica eletromecânica que determinados materiais têm de acumularem carga elétrica quando submetidos a aplicação de esforço mecânico, conhecido também como efeito direto, ou de se deformarem quando submetidos a campos elétricos, efeito inverso, sendo descoberta em 1880 pelos físicos franceses Jacques e Pierre Curie. Os materiais piezelétricos são do grupo dos ferromagnéticos, os quais se magnetizam quando submetidos a campo magnético, devido a orientação de dipolos. Alguns exemplos de materiais que exibem propriedades piezelétricas são o quartzo, o titanato de bário, o titanato zirconato de chumbo, conhecido como PZT, e a turmalina. Com estas propriedades é possível a utilização dos materiais piezelétricos como sensores ou atuadores. 
As cerâmicas com propriedades piezelétricas possuem dipolos randomicamente distribuídos e quando devidamente manufaturadas através de um processo chamado polarização, por aquecimento acima de determinada temperatura, chamada temperatura de Curie, e sob aplicação de um forte campo elétrico têm seus dipolos alinhados. Após rápida redução da temperatura e retirada do campo elétrico os dipolos são orientados todos na mesma direção, permitindo a utilização para diversas finalidades (LEO, 2007). Na figura 2, há uma representação do exposto anteriormente para exemplificação.

Figura 2 - (a) Dipolos desorientados (b) Orientação de dipolos conforme sentido de aplicação do campo elétrico (c) Direção dos dipolos após retirada do campo elétrico.

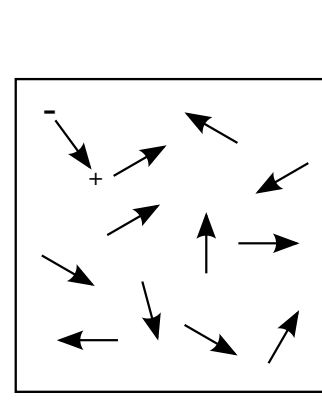

(a)

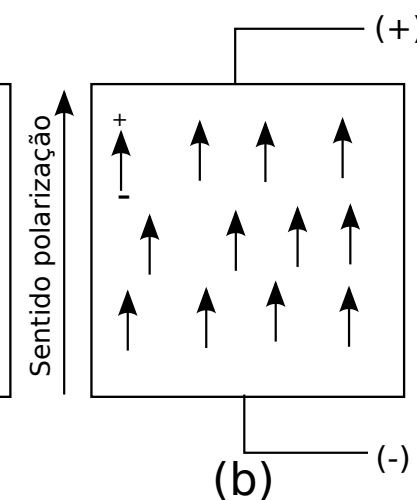

(b)

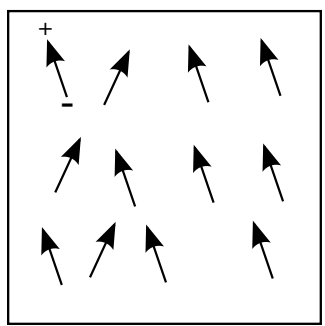

(c)

Fonte: Adaptação de Moheimani e Fleming (2006).

Com a aplicação de um campo elétrico nos materiais piezelétricos, os dipolos sofrerão rotação e serão orientados no sentido do campo empregado. A orientação dos dipolos provoca uma extensão do material, produzindo assim um deslocamento mecânico. Por outro lado, a aplicação de um esforço mecânico também produz giro dos dipolos elétricos da estrutura piezelétrica, que gera uma diferença de potencial e aparente movimento de cargas, que pode ser medida através de eletrodos nas superfícies do material (LEO, 2007). A carga produzida dividida pela área dos eletrodos é o deslocamento elétrico e pode ser medido em $C / m^{2}$.

Os piezelétricos possuem grande vantagem em relação a outros materiais na geração de energia por coleta, devido ao fato de possuírem grande densidade energética e facilidade para aplicação (ERTURK; INMAN, 2011). Podem ser utilizados como estruturas inteligentes, capazes de controlar vibrações e suprimir ruídos, além de serem leves e ocuparem pouco espaço. No caso de controle passivo, os piezelétricos são associados a circuitos elétricos shunt compostos de resistores e indutores. Quando existe apenas a resistência, o circuito se comporta similarmente a materiais viscoelásticos, enquanto que ao se adicionar a indutância o comportamento será semelhante a um absorvedor dinâmico de vibrações amortecido (LOPES JR; STEFFEN JR; SAVI, 2016). Quando deformados por vibrações mecânicas, os materiais piezelétricos geram energia elétrica pelo efeito direto, 
processo conhecido como Piezoelectric Energy Harvesting (colheita de energia piezelétrica) ou Piezoelectric Energy Scavenging (coleta de energia piezelétrica).

Para analisar o comportamento dos materiais piezelétricos as equações (1.1) e (1.2) são utilizadas:

$$
\begin{aligned}
& \varepsilon=\mathbf{s}^{\mathbf{E}} \boldsymbol{\sigma}+\mathrm{d}^{\mathrm{t}} \mathbf{E} \\
& \mathrm{D}=\boldsymbol{\epsilon}^{\sigma} \mathbf{E}+\mathrm{d} \boldsymbol{\sigma}
\end{aligned}
$$

em que $\boldsymbol{\varepsilon}$ e $\mathbf{D}$ são vetores de deformação mecânica e deslocamento elétrico $\left[C / \mathrm{m}^{2}\right], \mathbf{E}$ é o vetor de campo elétrico $[V / m]$ e $\boldsymbol{\sigma}$ o vetor de tensão mecânica $\left[N / m^{2}\right], \boldsymbol{\epsilon}^{\sigma}, \mathbf{s}^{E}$ e $\mathbf{d}$ são matrizes de permissividade dielétrica para tensões constantes medidas em $[C / V m]$, rigidez elástica para campo elétrico uniforme $\left[N / m^{2}\right]$ e constante piezelétrica $[\mathrm{m} / \mathrm{V}]$, respectivamente.

De acordo com a aplicação da carga no material piezelétrico, há uma polarização, sendo a relação entre carga induzida por unidade de área e força aplicada diretamente proporcional e reversível (RAMADAN; SAMEOTO; EVOY, 2014). Na figura 3, estão retratados dois exemplos clássicos de materiais polarizados, conforme a aplicação da carga, provocando a polarização na mesma direção ou transversalmente a força aplicada, sendo representados pelos coeficientes $\mathrm{d}_{33}$ e $\mathrm{d}_{31}$, chamados coeficientes piezelétricos longitudinal e transversal, respectivamente, podendo ser utilizados para casos de extensão ou cisalhamento.

Figura 3 - Polarização do material piezelétrico conforme direção da carga aplicada: (a) Polarização no mesmo sentido da carga (b) Polarização transversal à carga.

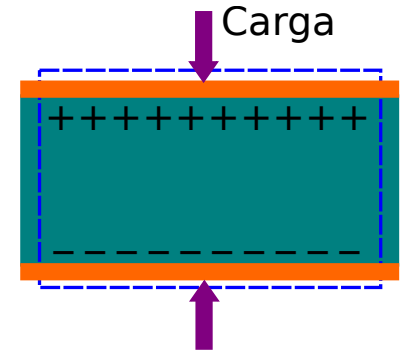

(a)

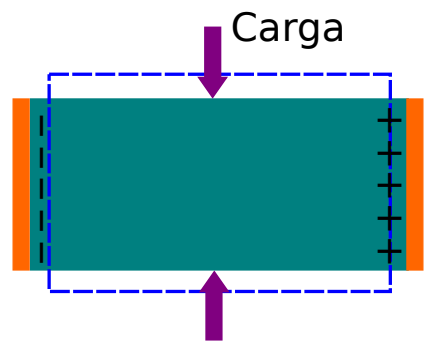

(b)

Fonte: Baseado em Ramadan, Sameoto e Evoy (2014).

Em (SANTOS; TRINDADE, 2011) são apresentados os casos de pastilhas piezelétricas em extensão e cisalhamento para o controle de vibração de uma viga engastada, sendo analisadas as diferenças para cada caso, bem como as condições para aplicação da disposição das pastilhas. Estudos em elementos finitos com uma profunda abordagem do 
equacionamento de compósitos de macro-fibras (MFC) piezelétricas segundo o modelo $\mathrm{d}_{31}$ também podem ser encontrados em algumas pesquisas (TRINDADE; BENJEDDOU, 2016). Para análise da eficiência e disposição geométrica das pastilhas, associada a coleta de energia, também pode ser encontrado um estudo sobre o caso (GODOY; TRINDADE; DEÜ, 2012). Assim, muitos trabalhos têm sido elaborados com a finalidade de se estudar as diferentes aplicações e investigar o comportamento dos materiais piezelétricos.

\subsection{Coleta de energia usando vigas cantilever}

Em vários trabalhos de Energy Harvesting, dispositivos com viga cantilever são modelos clássicos de estudo, sendo que por meio de transdutores piezelétricos é possível converter a energia mecânica em elétrica. Geralmente, o dispositivo é composto de um engaste que recebe excitação, um substrato, que é a viga engastada, transdutores piezelétricos posicionados em alguma parte do substrato, uma massa inercial fixada na extremidade livre da viga e circuito elétrico acoplado aos transdutores, conforme figura 4. Por meio de uma excitação da base, a viga entra em movimento, possibilitando a conversão da energia mecânica em elétrica através do material piezelétrico. Por intermédio do circuito elétrico, uma tensão irregular AC é gerada, e com o uso de pontes retificadoras, capacitores e conversores pode-se obter uma tensão DC. A energia que é gerada pode ser utilizada para alimentação de dispositivos portáteis ou redes de sensores sem fio, para casos de estruturas projetadas para coleta de energia (ERTURK; INMAN, 2011).

Figura 4 - Modelo esquemático de dispositivos para estudo de coleta de energia.

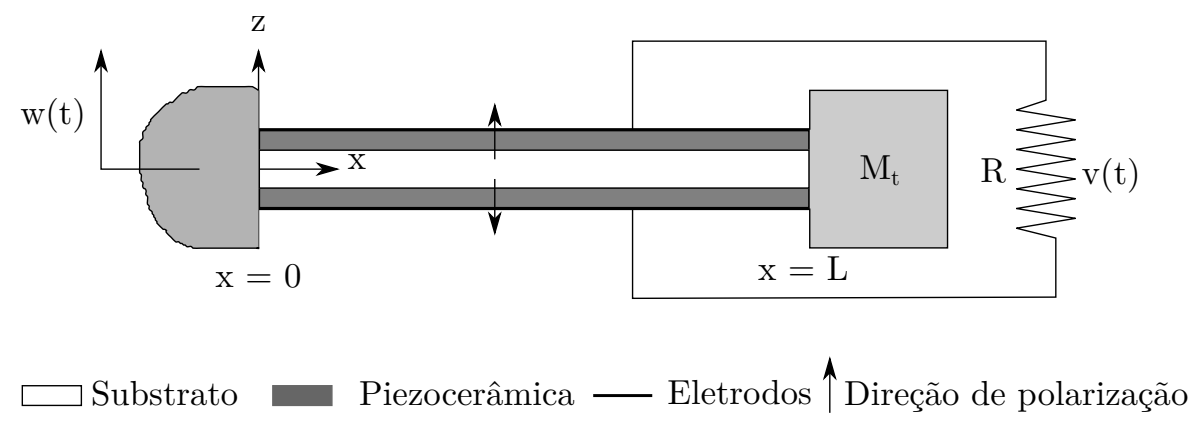

Fonte: Adaptação de Erturk e Inman (2011).

A base da viga é excitada por uma entrada w(t); possui uma massa na extremidade $\mathrm{M}_{\mathrm{t}}$; uma resistência elétrica $\mathrm{R}$, que permite um diferencial de tensão $\mathrm{v}(\mathrm{t})$ entre os seus terminais; tem comprimento L e duas camadas de material piezelétrico polarizados no sentido da espessura. 
Para aumentar a eficiência energética gerada com uma excitação na base de uma viga, é importante a sintonização da frequência de ressonância do modelo estudado com a frequência de operação, pois isso implicará uma maior amplitude de vibração e, consequentemente, maior energia extraída. Isso pode ser feito com a variação da rigidez ou da massa do modelo. Assim, modelos de vigas associados com materiais piezelétricos podem ser utilizados para sintonização de frequências, já que ao transdutor está associada uma rigidez eletromecânica, que pode ser mudada com um acoplamento elétrico de um circuito tipo shunt.

Alguns métodos com sintonização de frequências, conhecidos como passivos, consideram carga ou deflexão pré-estabelecidas na viga engastada, ajuste de comprimento ou mudança do centro de massa com o intuito de mudar a rigidez e assim se conseguir trabalhar em uma banda de frequência. Por outro lado, métodos de sintonização ativa consideram uma fonte externa como um atuador que mude a frequência e alcance uma melhor coleta de energia. Uma característica negativa deste último método é a necessidade de energia para intervir no atuador, o que pode não ser interessante do ponto de vista de Energy Harvesting, já que a energia gerada acaba sendo utilizada para alimentação do atuador. Assim, métodos passivos para sintonização de frequência em vigas engastadas são estudados em muitos trabalhos (ELVIN; ERTURK, 2013; BRAND et al., 2015).

Figura 5 - Sistemas de vigas excitadas para alcance da frequência natural.

(a) Modelo de sintonização para microssistemas. (b) Modelo para múltiplos modos de vibração.
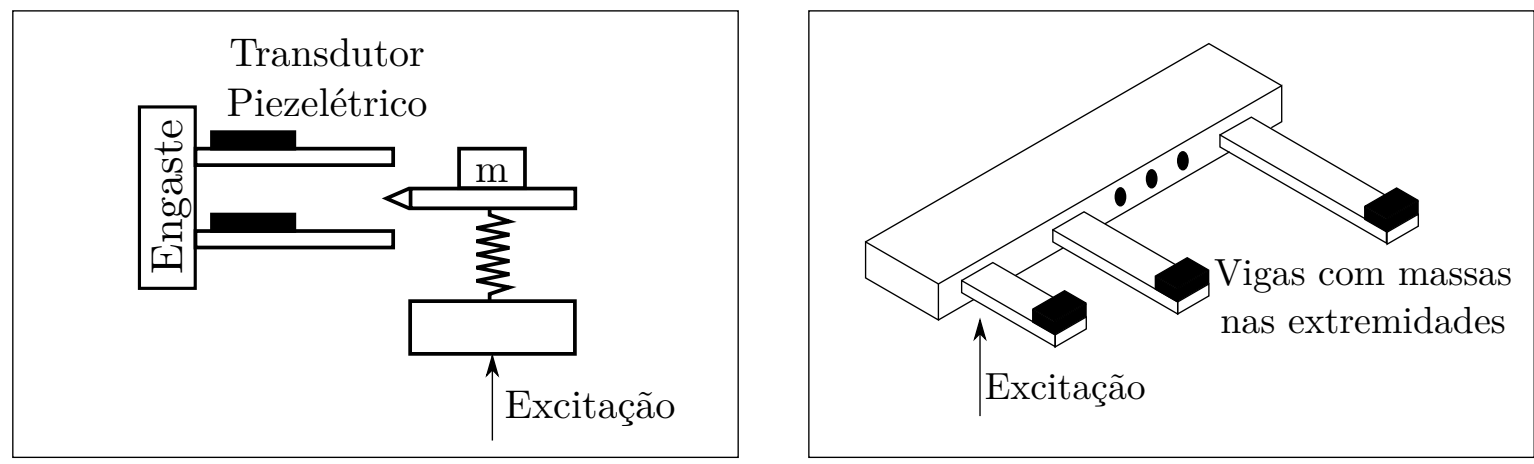

Fonte: Adaptação de Brand et al. (2015).

A fim de sintonizar a frequência de vibração para microssistemas, que possuem em geral altos valores de frequências naturais comparados com sistemas de maior escala, uma estrutura conversora foi desenvolvida para aumento da energia coletada sem necessidade de atuador elétrico, apenas com uma excitação de base em um conjunto massa-mola, como pode ser visto na figura $5 \mathrm{a}$, que representa duas vigas engastadas com transdutores piezelétricos, sendo excitadas por outro mecanismo (BRAND et al., 2015). Pelo fato da primeira unidade ou sistema com massa oscilante receber uma excitação na base, o dente mecânico atinge as vigas cantilevers, que começam a oscilar, e o sistema atinge a frequên- 
cia natural de vibração. Portanto, a energia contida na baixa frequência de vibração da primeira unidade é transferida para as vigas, constituindo um modelo de excitação para estruturas de microssistemas, levando em conta, além do mais, que dispositivos com baixa frequência natural podem conter elevada energia associada para coleta.

Alguns exemplos de estudos com viga engastada para coleta de energia, são casos de análises com múltiplos graus de liberdade, nos quais vigas de variados comprimentos e com massas de prova nas extremidades são engastadas em uma mesma base que pode ser excitada como na figura 5b, caracterizando diferentes frequências de vibração. Quando o valor da excitação aproxima-se de alguma frequência natural de uma das vigas engastada, um dos modos de vibração do sistema pode ser excitado. Embora com algumas desvantagens, como aumento de volume ou peso, que diminui a densidade energética, e necessidades de circuitos elétricos mais complexos, são exemplos largamente estudados de sistemas com vigas cantilevers para coleta de energia; além disso, facilitam uma abordagem espectral para determinadas bandas de frequência. No caso de Energy Harvesting, um maior aproveitamento energético geralmente é conseguido analisando o primeiro e segundo modo de vibração (ELVIN; ERTURK, 2013).

Em (FRANCO; VAROTO, 2012), um estudo de coleta de energia é elaborado em uma viga com excitação de base, massa inercial, pastilhas piezelétricas em ambos os lados e conectadas por resistor. Funções de resposta em frequência são empregadas para saída de tensão e energia elétrica com a finalidade de se verificar o desempenho do sistema frente a otimização de parâmetros geométricos e de projeto. Nesse caso, é estabelecida uma faixa para a frequência natural do dispositivo a ser otimizado, bem como condições de contorno para os parâmetros, e uma análise via Programação Quadrática Sequencial (SQP) é realizada. Também se emprega Simulação de Monte Carlo (MCS) considerando a aleatoriedade dos parâmetros, o que permite verificar a robustez, conforme o aumento da frequência natural. Por último, uma análise estocástica por programação foi conduzida para verificar o desempenho da coleta de energia, apresentando os valores dos parâmetros para o caso ótimo, levando em conta as incertezas.

Para o estudo de uma viga cantilever com movimento devido à determinada massa inercial, no caso de Energy Harvesting, uma análise mais simples pode ser feita tomando o modo fundamental de vibração e, assim, obter-se o modelo com um grau de liberdade, levando em conta um sistema massa, mola e amortecimento. Desconsiderando a viscosidade do ar e o acoplamento eletromecânico dado pelo transdutor, o modelo pode ser aproximado conforme a representação da figura 6a, em que existe a atuação de uma excitação na base. Os parâmetros atribuídos para a massa total do sistema, amortecimento e rigidez são representados por $\mathrm{m}_{\mathrm{eq}}$, $\mathrm{c}_{\mathrm{eq}}$ e $\mathrm{k}_{\mathrm{eq}}$, respectivamente. Com a entrada $\mathrm{y}(\mathrm{t})$ na base, uma saída $\mathrm{x}(\mathrm{t})$ é esperada na massa $\mathrm{m}_{\mathrm{eq}}$. Por outro lado, ao supor a existência do transdutor piezelétrico surge a força elétrica restauradora que é representada por $f_{e}$ na 
figura $6 \mathrm{~b}$ e $\mathrm{R}_{\mathrm{L}}$ é a resistência a corrente elétrica gerada "i".

Figura 6 - Modelos para vigas cantilevers com um grau de liberdade.

(a) Modelo desconsiderando transdutor.

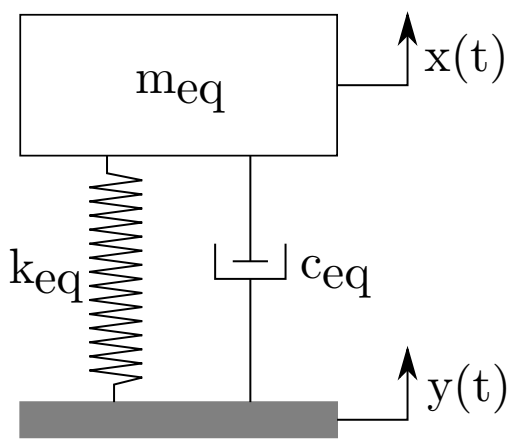

(b) Modelo considerando transdutor.

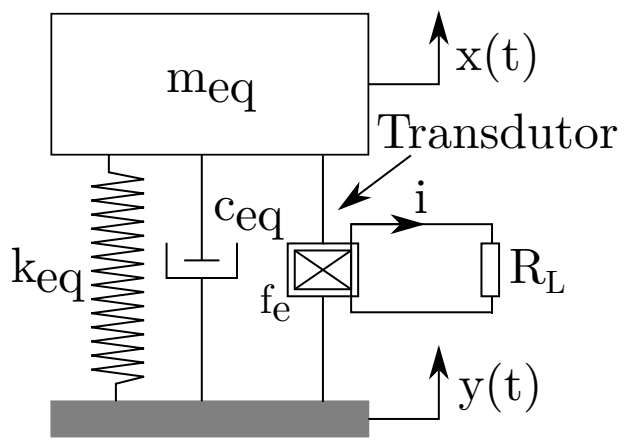

Fonte: Adaptação de Brand et al. (2015).

Os modelos representados nas figuras $6 \mathrm{a}$ e $6 \mathrm{~b}$ podem ser descritos matematicamente para um estudo mais abrangente, considerando um grau de liberdade. Para a coleta de energia, os modelos podem ser simples para análise, no entanto devem ser sofisticados para não haver grandes divergências dos casos práticos e, ainda, descreverem as condições dinâmicas da estrutura.

Pelo fato da coleta de energia necessitar de aprimorados projetos, uma vez que a parcela disponível de energia para ser convertida, geralmente, é pequena, torna-se conveniente optar por técnicas de otimização para determinados parâmetros do sistema. No entanto, assumir comportamento determinístico pode significar uma simplificação da realidade, sendo que diante da complexidade imposta na conversão energética, é interessante levar-se em consideração as incertezas inerentes ao sistema, o que conduz à busca de projetos robustos. O conceito de robustez está associado à insensibilidade às variações ou mudanças em parâmetros, geometria, efeitos externos, dentre outros fatores. No presente trabalho são estudados os conceitos de otimização e projeto robusto.

\subsection{Otimização e projeto robusto}

Técnicas de otimização são importantes pelo fato de melhorarem o desempenho e reduzirem o custo do sistema estudado em alguns casos. Na engenharia, muitas aplicações consideram parâmetros e modelos determinísticos para estudo, sendo que muitas condições de variabilidade ficam agregadas em fatores de segurança e valores médios, como mudanças climáticas, carga variável, geometria e propriedades dos materiais.

A finalidade de um procedimento de otimização é encontrar um mínimo ou máximo para uma dada função estudada. Para isso, uma minimização ou maximização da 
função é feita considerando certas condições de restrição impostas, que podem ser representadas por inequações ou igualdades. Este tipo de otimização também é conhecida como otimização restrita e os parâmetros estudados podem ficar restritos a certas condições de contorno. Por outro lado, existem otimizações sem restrições, conhecidas também como otimizações irrestritas. Um problema de otimização determinístico, baseado em cálculo, pode ser escrito da seguinte maneira:

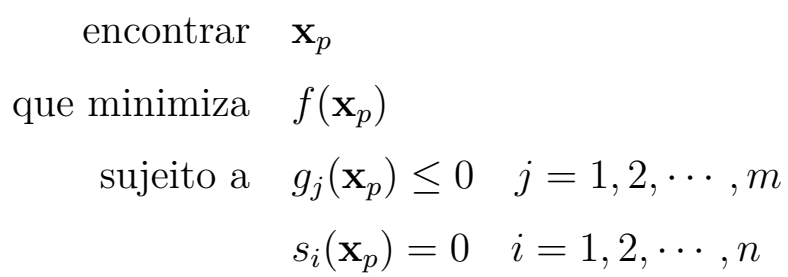

em que $\mathbf{x}_{p}$ representa o vetor de variáveis de projeto a serem encontradas ao se minimizar uma função $f\left(\mathbf{x}_{p}\right)$, sob as condições de restrições de desigualdade $g_{j}\left(\mathbf{x}_{p}\right)$ e de igualdade dadas por $s_{i}\left(\mathbf{x}_{p}\right)$.

Graficamente a otimização pode ser exemplificada e visualizada, conforme figura 7, na qual existem um gráfico para as superfícies das restrições, à esquerda, e outro para a função objetivo, à direita. Como pode ser visualizado, cada superfície de restrição $\left(g_{1}\right.$ até $\left.g_{5}\right)$ contribui para gerar uma área apropriada de trabalho e, com isso, o vetor de projeto ficará limitado a essa área. Na otimização, a intenção é encontrar o menor valor da função objetivo, respeitando a área de trabalho, que é limitada pelas restrições. Cada valor da função, para determinados pontos escolhidos, gera um valor de curva de nível, sendo que no gráfico à direita da figura 7 existe uma representação de $C_{1}$ até $C_{7}$. Como pode ser notado, o menor valor da função objetivo é dado por $f=C_{1}$, sendo que o valor ótimo é encontrado em $f=C_{2}$, pelo fato de respeitar a restrição $g_{4}$.

Problemas de otimização podem ser divididos de acordo com a natureza das funções estudadas em quadrática, geométrica, linear e não-linear (RAO, 2009). No primeiro caso, as funções, de fato, são quadráticas, enquanto para o caso geométrico são baseadas em polinômios. Para o caso de otimizações não-lineares, que constituem grande quantidade de problemas, um método de extrema importância é conhecido como Programação Quadrática Sequencial (SQP - Sequential Quadratic Programming).

A Programação Quadrática Sequencial é um potencial método, em que uma função não-linear é transformada em quadrática, que pode ser facilmente resolvida. Através da utilização de um método para problemas irrestritos, conhecido como Método de Newton, e condições específicas para as restrições, é possível encontrar um problema quadrático e, então, prosseguir com a otimização, fundamentando no exposto anteriormente (RAO, 2009). Em softwares comerciais de programação, como Matlab, é possível utilizar o algoritmo SQP para resolução de problemas determinísticos. 
Figura 7 - Curvas de níveis para restrições e função objetivo.

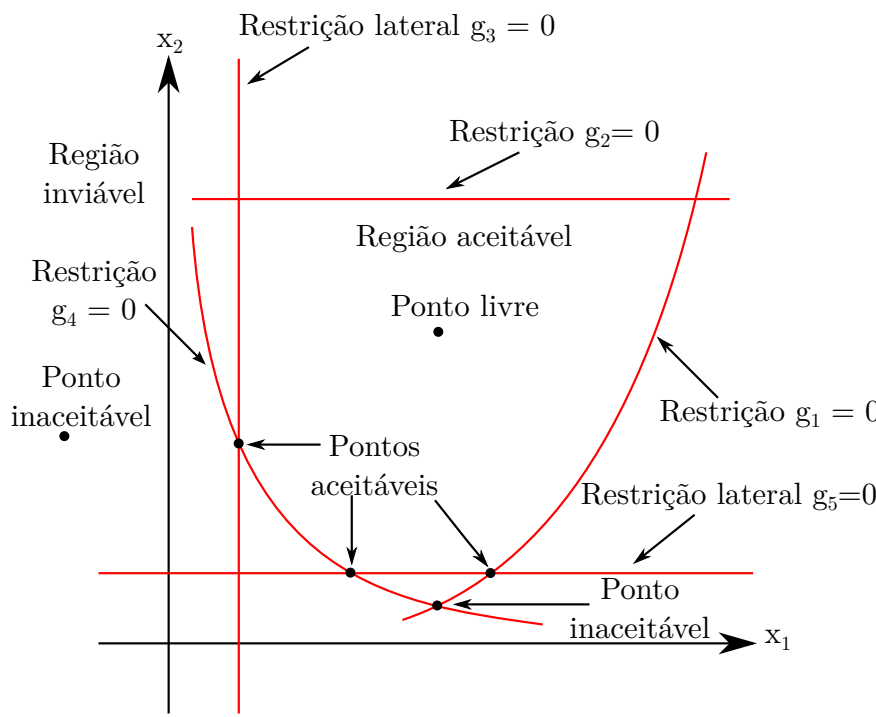

a) Gráfico de superfícies das restrições

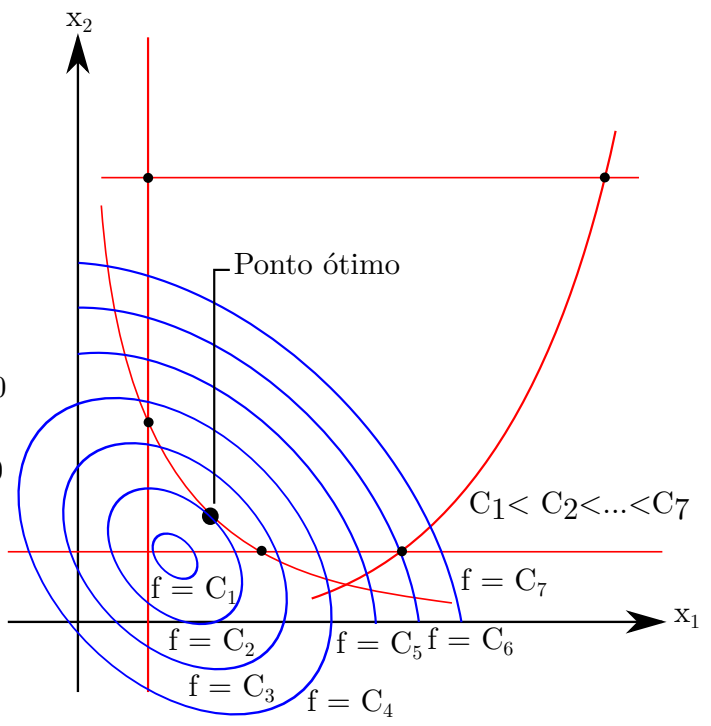

b) Gráfico da função objetivo

Fonte: Adaptação de Rao (2009).

Por outro lado, problemas de otimização podem constituir uma simplificação para alguns casos, pois observações e medidas feitas estão sujeitas a variação e aleatoriedade. Neste caso, um procedimento adequado, levando em contas as incertezas inerentes ao projeto, consiste em se trabalhar com otimização de projetos robustos, que são menos sensíveis a variabilidades externas ou mesmo inerentes ao próprio sistema.

Quando incertezas são consideradas em projetos, a otimização pode ser baseada em confiabilidade, projetos robustos e problemas inversos (SCHUËLLER; JENSEN, 2008). O primeiro caso é quando as incertezas são quantificadas considerando a probabilidade de falha e valores esperados, enquanto que para os problemas inversos o modelo é modificado para reduzir a disparidade do padrão testado e o previsto (ZANG; FRISWELL; MOTTERSHEAD, 2005).

Projetos de otimização baseados em aleatoriedade requerem identificação e definição dos dados de entrada, como variáveis projetadas e parâmetros de incertezas, formulação de eventos associados a falha, definição das restrições do problema projetado e de uma função objetivo a ser minimizada/maximizada. Estes problemas são de caráter probabilístico e podem ser analisados via simulações computacionais. Dependendo da escolha, a simulação pode envolver esforço e custo de processamento, por isso em (SCHUËLLER; JENSEN, 2008) métodos para redução de custo são propostos.

Para o caso de projetos robustos, é demostrado em (SCHUËLLER; JENSEN, 2008) que o seguinte problema matemático é característico, considerando uma função $f\left(\mathbf{x}_{p}\right)$ a 
ser minimizada/maximizada, que são menos sensíveis com respeito a variabilidade:

$$
\begin{array}{cl}
\text { minimizar } & f\left(\mathbf{x}_{p}\right) \\
\text { sujeito a } & g_{i}\left(\mathbf{x}_{p}, \boldsymbol{\theta}\right) \leq 0, \quad \mathbf{i}=\mathbf{1}, \cdots, \mathbf{I} \\
& s_{j}\left(\mathbf{x}_{p}, \boldsymbol{\theta}\right)=0, \quad \mathbf{j}=\mathbf{1}, \cdots, \mathbf{J} \\
& h_{l}\left(\mathbf{x}_{p}\right) \leq 0, \quad \mathbf{l}=\mathbf{1}, \cdots, \mathbf{L}
\end{array}
$$

em que $\mathbf{x}_{p}$ e $\boldsymbol{\theta}$ são os vetores que correspondem as variáveis de projeto e incertezas, respectivamente. Os parâmetros das funções $g_{i}$ e $s_{j}$ são restrições do problema e representam condições de falha do sistema, enquanto $h_{l}$ representa restrições determinísticas.

Um esclarecimento do conceito de projeto robusto pode ser verificado através da figura 8, na qual a curva de Gauss representa a variabilidade, o círculo maior em escuro o alvo a ser atingido e os menores são as tentativas em se atingi-lo. Como pode ser observado, projetos mais robustos têm uma menor variabilidade, embora nem sempre possam alcançar o alvo do problema ou o ponto ótimo de uma otimização determinística, por isso é importante elaborar uma análise e estudo que garanta o estabelecimento do objetivo final. Para o caso estudado, o item "d" da figura mostra o que se deseja alcançar, enquanto o item "b" retrata a meta sendo atingida, no entanto com alta variabilidade.

Figura 8 - Diagramas de variabilidade e alvo a ser alcançado.

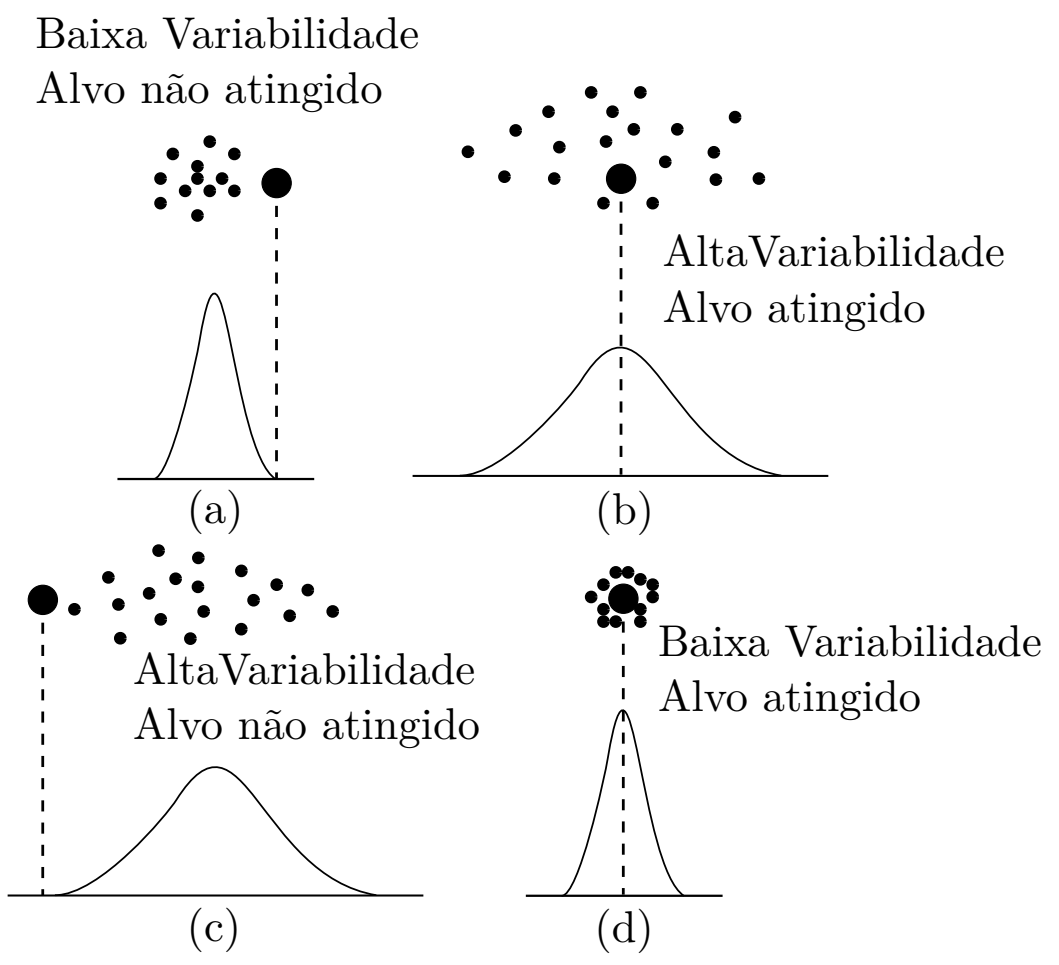

Fonte: Adaptação de Zang, Friswell e Mottershead (2005). 
Na década de 1960, com o intuito de aumentar a produtividade em empresas com produtos de boa qualidade, Genichi Taguchi desenvolveu uma metodologia baseada na sensibilidade e na concepção de robustez de projetos, diante das variações de efeitos que podem ocorrer no ambiente ou mesmo de incertezas que são inerentes ao próprio sistema (ZANG; FRISWELL; MOTTERSHEAD, 2005). Para isso são considerados parâmetros de controle, que são característicos do sistema que se deseja controlar, e fatores de ruído, que levam em consideração algo indesejado no projeto e geram prejuízo no sistema.

A metodologia proposta por Taguchi utiliza o conceito de sensibilidade, definida por uma função, para determinar o nível de variabilidade de um problema estudado. Para isso, pressupõe a existência de fatores de ruídos que afetam a robustez do projeto estudado, sendo que para garantir o mínimo de variabilidade na resposta final, utiliza dos parâmetros de projeto do sistema, de tal forma que a escolha adequada desses parâmetros gere uma baixa variabilidade final. Na figura 9, está um esboço da maneira como a metodologia é conduzida. Os ruídos podem ser imperfeições no projeto, condições externas ou tolerância, que irão afetar o resultado, alcançando ou não o alvo desejado. Um conjunto de matrizes chamadas ortogonais comportam os ruídos e parâmetros de controle e, assim, possibilitam encontrar a resposta ou saída do problema.

Figura 9 - Metodologia de robustez baseada no conceito de sensibilidade.

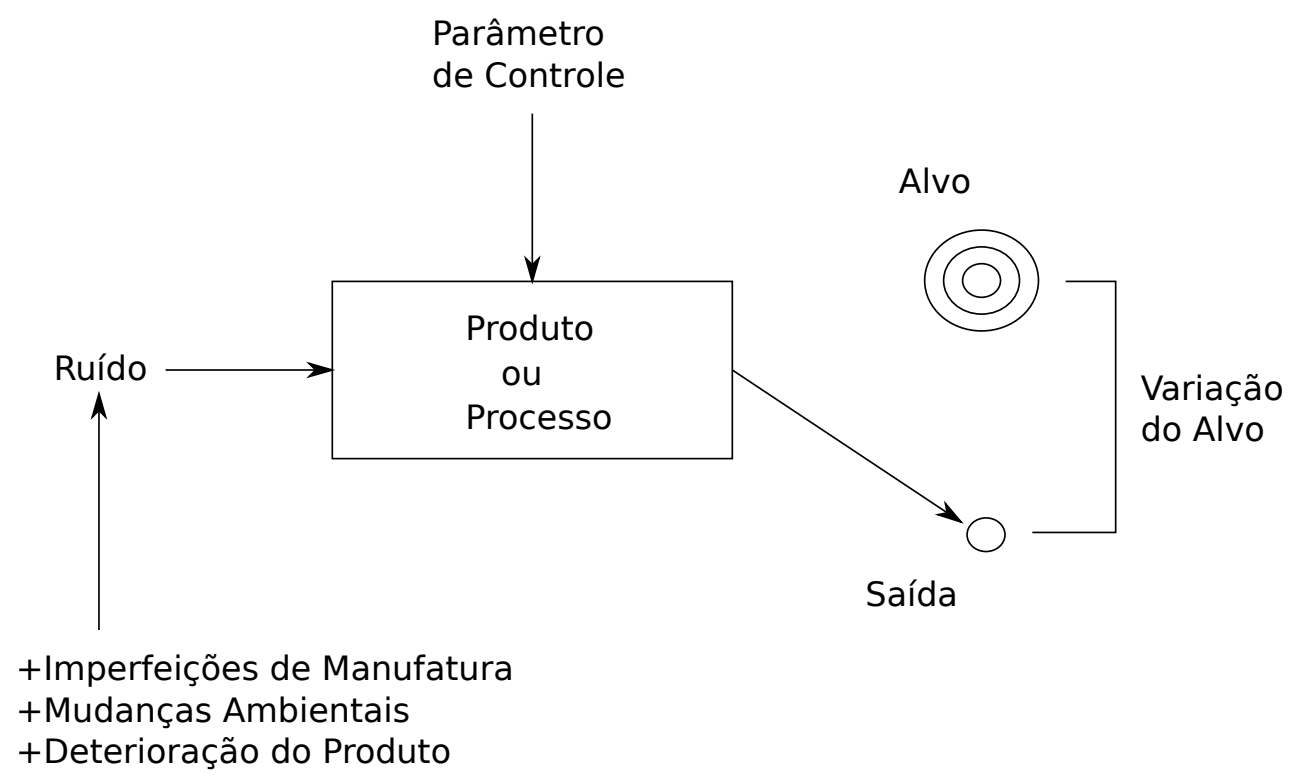

Fonte: Adaptação de Tsui (1992).

Ainda é interessante ressaltar que na otimização de um projeto robusto o alvo a ser atingido deve respeitar certas condições de restrições, à semelhança da otimização determinística. Assim, o projeto estará dentro de uma área ou região de trabalho permitida, considerando as restrições impostas. 


\subsection{Justificativas}

Atualmente, trabalhos estão sendo desenvolvidos na área de otimização e alguns mais especificamente levando em consideração incertezas, o que gera um sistema mais robusto e insensível a variações. Diante dos poucos trabalhos existentes na área de dinâmica e vibrações, considerando incertezas no sistema estudado, o estudo de métodos para análise de robustez se torna importante e a busca por ferramentas eficientes incentiva um estudo mais aprofundado.

O método de otimização robusta através de matrizes ortogonais tem muitas aplicações em industrias que trabalham com controle de qualidade na produção de produtos e pode gerar um produto com satisfatório custo benefício. Além disso, é possível se obter algumas respostas através de softwares comerciais como Minitab ou mesmo Excel de forma não dispendiosa. Para análises mais complexas, nas quais existe a comunicação entre programas diferentes, pela chamada de funções objetivos ou mesmo necessidade prévia de otimizações, a utilização do programa Matlab é uma alternativa interessante. A metodologia via matrizes ortogonais também está inserida em softwares comerciais, como ANSYS, inclusive trabalhos tem sido realizados utilizando-se do método e o software citado (TIKANI et al., 2017). Por isso, as ferramentas desenvolvidas para estudo de dispositivos robustos, com relação a coleta de energia, serão úteis no que diz respeito a custo computacional, levando em consideração que algumas análises estocásticas podem consumir muito tempo de processamento (ZANG; FRISWELL; MOTTERSHEAD, 2005). Além disso, o trabalho é importante para o estudo de novos métodos sobre projeto robusto, partindo do estudado.

Em relação aos dispositivos comercializados para coleta de energia, uma abordagem considerando as incertezas inerentes ao próprio dispositivo, pode mostrar escolhas adequadas de projeto ou justificar uma dada escolha destes para trabalho.

Além do exposto acima, toda implementação computacional, análises de otimização e robustez, tem por base o fato de dispositivos de coleta de energia terem baixa energia disponível para conversão. Assim, determinadas abordagens, como a presente, são fundamentais para um melhor aproveitamento da energia.

\subsection{Objetivo}

O objetivo do presente trabalho consiste em estudar o comportamento de dispositivos coletores de energia mecânica, proveniente da vibração. Pelo fato da energia disponível para conversão elétrica ser pequena, o estudo é focado em otimização e robustez dos dispositivos. Dessa maneira, o engaste, representado na figura 10, é considerado com algum desajuste e, por isso, passa a ser fonte de incertezas. Para isso, a modelagem é 
representada por elementos mecânicos do tipo molas, sendo uma de torção, que restringe a rotação, e outra linear para restrição do deslocamento vertical. Ainda, o movimento horizontal é desprezado ou considerado restrito.

O dispositivo modelo, representado na figura 10, é composto de um substrato (viga) de alumínio, camada piezelétrica associada a uma resistência elétrica, massa sísmica e molas de torção e linear para simulação do engaste. Através de uma excitação, é produzida uma vibração do dispositivo e a massa sísmica serve para sintonizar a frequência do dispositivo com a de operação, visto que a entrada é do tipo harmônica, com frequência definida. Na sintonização entre as frequências (operação e do dispositivo), é obtido um valor máximo de energia, uma vez que o dispositivo estará trabalhando no ponto de ressonância. Por isso, a definição das condições de contorno para o sistema, ou seja, as zonas apropriadas para trabalho da viga e dos componentes é fundamental.

Figura 10 - Dispositivo modelo para estudo da coleta de energia.

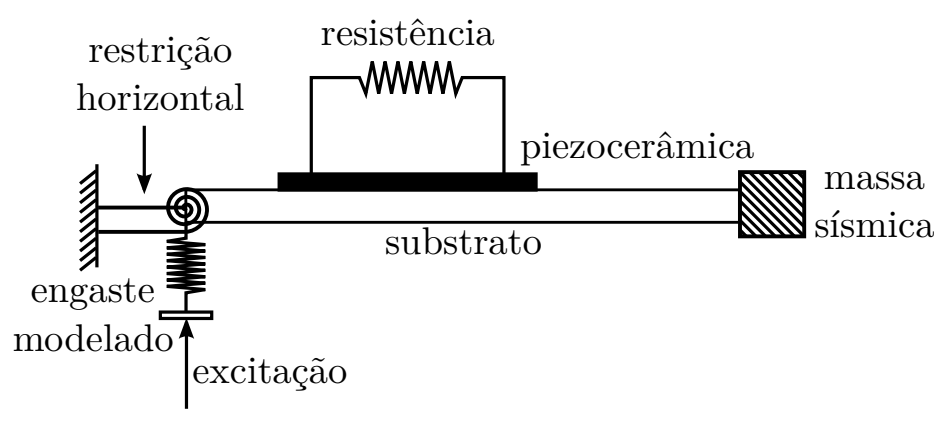

Na obtenção dos valores ótimos de energia, o engaste é considerado sem variabilidade, ou seja o projeto é otimizado deterministicamente para encontrar um dispositivo adequado. A intenção é maximizar a função geração de potência do modelo, sendo que nesse processo deve ocorrer a sintonização entre as frequências, uma vez que a máxima amplitude do dispositivo ocorre na frequência natural, que deve ser a mesma de operação. Portanto, em um primeiro momento, o projeto do dispositivo desconsidera fontes de incerteza ou tolerâncias de projeto. Definido o primeiro dispositivo, outros de diferente dimensionamento são projetado para comparação, tendo em vista que incertezas serão acrescentadas para análise entre os mesmos.

Na otimização determinística do dispositivo o objetivo é implementar o algoritmo de Programação Quadrática Sequencial (SQP) respeitando certas condições de contorno para projeto do dispositivo. Por outro lado, a análise de robustez é conduzida através do método de matrizes ortogonais, onde são consideradas as incertezas de projeto. Neste caso, uma divisão entre parâmetros de projeto e fatores de ruído é adequadamente realizada. A comparação essencial dos resultados é em relação a geração de energia ou potência elétrica do dispositivo, tanto em termos de valor médio de saída como sensibilidade ou robustez final. 
Na análise de robustez, a resistência elétrica é estudada considerando valores próximos ao ótimo determinístico, que gera maior potência para cada dispositivo, e com tolerâncias para representar a incerteza do circuito elétrico. No amortecimento estrutural e engaste, representado por molas, também são inseridos ou valores de incertezas para verificar o impacto nos dispositivos e na resposta de saída de potência.

O estudo estará concentrado no primeiro modo de vibração da viga. Para isso, um modelo em elementos finitos baseado na teoria de Bernoulli-Euler e Timoshenko será utilizado. As função de resposta em frequência (FRF) é estudada para saída de potência. 


\section{Modelo de Viga em Elementos Finitos}

Diante do objetivo apresentado na introdução, o capítulo atual visa estudar um dispositivo para coleta de energia com viga engastada. Na figura 11, está uma representação do modelo estudado, composto de um substrato metálico com espessura $h_{v}$ e comprimento $l_{v}$; camada piezelétrica com espessura $h_{p}$, comprimento $l_{p}$ a uma distância $d_{p}$ do engaste e unida ao substrato através de camada adesiva Epoxy (em vermelho na figura 11), com espessura $h_{c}$; resistência elétrica $R_{c}$; massa sísmica $m_{b}$; e as molas no engaste $k_{w}$ e $k_{\theta}$. Por meio de uma entrada de deslocamento imposto $w_{0}(t)$, uma excitação no dispositivo é produzida.

Figura 11 - Modelo do dispositivo para coleta de energia.

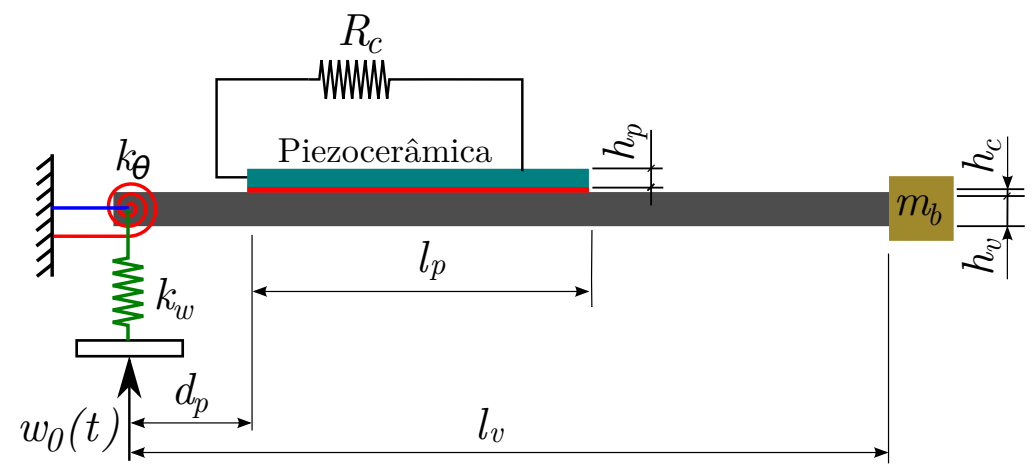

Na extremidade da viga está uma massa sísmica $m_{b}$, que serve para sintonização de frequências, uma vez que a entrada $w_{0}(t)$ é do tipo harmônica, contendo a frequência de operação do sistema. O engaste de um dispositivo real pode estar assentado sobre uma base vibratória, de massa desconhecida, e, dessa maneira, a entrada de deslocamento é utilizada neste trabalho. Assim, considerando uma frequência de operação $\Omega$, uma equação para $w_{0}(t)$ pode ser representada por:

$$
w_{0}(t)=\tilde{w}_{0} e^{j \Omega t}
$$

em que $\tilde{w}_{0}$ é o valor absoluto da entrada de deslocamento imposto.

A entrada $w_{0}$ pode ser utilizada para encontrar valores de velocidade ou aceleração no engaste. Dessa forma, reescrevendo a equação (2.1) para a forma de aceleração, conforme equação (2.2), é possível se fazer o estudo tendo como referência os valores de aceleração conhecidos.

$$
\ddot{w}_{0}(t)=-\tilde{w}_{0} \Omega^{2} e^{j \Omega t}
$$


em que $\tilde{w}_{0} \Omega^{2}$ representa a amplitude da aceleração. Por isso, para um valor conhecido de aceleração é possível encontrar a amplitude do deslocamento imposto, dividindo-o por $\Omega^{2}$.

Neste capítulo, o objetivo é encontrar um modelo matemático que descreva o movimento do dispositivo e, com isso, desenvolver uma FRF para saída de potência, medida por meio da resistência elétrica, com entrada de deslocamento ou, por consequência, aceleração no engaste. Assim, a metodologia utiliza parte do modelo de viga em elementos finitos desenvolvida em trabalho de dissertação de mestrado (SANTOS, 2008). O modelo desenvolvido está baseado na teoria clássica de Bernoulli-Euler e Timoshenko para vigas sanduíches com três camadas. Para a camada central é considerada a teoria de Timoshenko, enquanto que para as camadas exteriores a de Bernoulli-Euler. Além disso, leva-se em conta que o material piezelétrico é ortotrópico, coberto totalmente por eletrodos e as camadas perfeitamente coladas. Ainda são consideradas para o modelo deformações planas e interligação com circuito elétrico. No entanto, para o dispositivo estudado apenas duas camadas são consideradas, para a viga e piezocerâmica com camada adesiva e, como existem massa sísmica na extremidade da viga e molas no engaste, uma adaptação do modelo desenvolvido é necessária.

\subsection{Modelo cinemático e constitutivo para vigas com camadas piezelétricas}

Na figura 12, há uma representação para o caso de deslocamento axiais $\left(u_{1}, u_{2}\right.$ e $\left.u_{3}\right)$, transversal $(w)$ e rotação das seções externas e interna, representada pelos ângulos $w^{\prime}$ e $\beta_{2}$, respectivamente, no eixo das coordenadas x-z. Os índices 1 e 3 representam as camadas superior e inferior, respectivamente, enquanto que a camada central é representada pelo índice 2. Para o desenvolvimento do modelo para coleta de energia, o objetivo é representar o equacionamento para as camadas externas e implementar para o modelo particular.

As deformações de membrana, flexão e cisalhamento, representadas por, $\varepsilon_{k}^{m}, \varepsilon_{k}^{f}$ e $\varepsilon_{k}^{c}$, respectivamente, para as camadas superior $(k=1)$ e inferior $(k=3)$, são tal que:

$$
\varepsilon_{k}^{m}=u_{k}^{\prime} ; \quad \varepsilon_{k}^{f}=w^{\prime \prime} ; \quad \varepsilon_{k}^{m}=0 ;
$$

Como apresentado no capítulo 1 deste trabalho, a equação constitutiva para materiais piezelétricos, considerando a energia elástica, elétrica e de acoplamento eletromecânico para campo elétrico constante, pode ser escrita por:

$$
\left\{\begin{array}{l}
\boldsymbol{\sigma} \\
\boldsymbol{E}
\end{array}\right\}=\left[\begin{array}{cc}
\boldsymbol{c}^{D} & -\boldsymbol{h}^{t} \\
-\boldsymbol{h} & \boldsymbol{\beta}^{\varepsilon}
\end{array}\right]\left\{\begin{array}{l}
\boldsymbol{\varepsilon} \\
\boldsymbol{D}
\end{array}\right\}
$$


Figura 12 - Deslocamentos para uma viga sanduíche considerando as hipóteses de Timoshenko para camada central e Bernoulli-Euler para camadas externas.

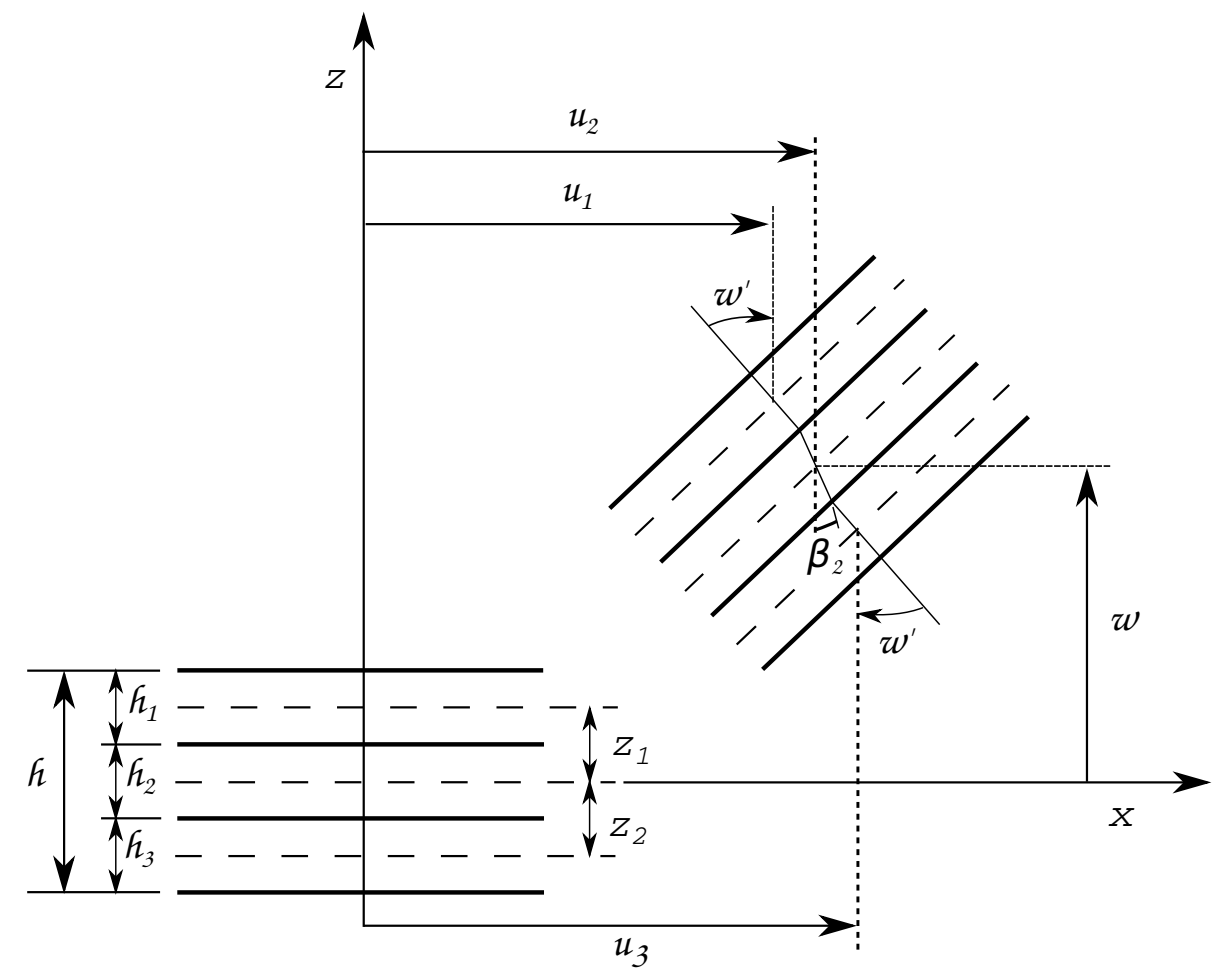

Fonte: Baseado em Santos (2008).

em que $\boldsymbol{c}^{D}$ é a matriz de constante elástica para deslocamento elétrico constante, $\boldsymbol{\beta}^{\varepsilon}$ a matriz de permissividade dielétrica para deformações constantes e $\boldsymbol{h}$ a matriz piezelétrica.

Em (SANTOS, 2008) fica demonstrado que, para uma viga com camadas piezelétricas inferior e superior, com hipóteses de tensões superficiais e deslocamentos elétricos unidimensionais, a equação (2.4) pode ser reescrita como:

$$
\left\{\begin{array}{l}
\boldsymbol{\sigma}_{1 k} \\
\boldsymbol{E}_{3 k}
\end{array}\right\}=\left[\begin{array}{cc}
\bar{c}_{11}^{D k} & -\bar{h}_{31}^{k} \\
-\bar{h}_{31}^{k} & \bar{\beta}_{33}^{\varepsilon k}
\end{array}\right]\left\{\begin{array}{c}
\boldsymbol{\varepsilon}_{1 k} \\
\boldsymbol{D}_{3 k}
\end{array}\right\}
$$

em que o subíndice $k$ refere-se a camada inferior $(k=1)$ ou superior $(k=3)$.

Os índices com "barras" são pelo fato das hipóteses de tensões superficiais assu- 
midas anteriormente e, assim, a representação das constantes fica modicadas como:

$$
\begin{aligned}
& \bar{c}_{11}^{D k}=c_{11}^{D k}-c_{13}^{D k} \frac{c_{13}^{D k}}{c_{33}^{D k}} \\
& \bar{h}_{31}^{k}=h_{31}^{k}-h_{33}^{k} \frac{c_{13}^{D k}}{c_{33}^{D k}} \\
& \bar{\beta}_{33}^{\varepsilon k}=\beta_{33}^{\varepsilon k}-\frac{h_{33}^{k}{ }^{2}}{c_{33}^{D k}}
\end{aligned}
$$

\subsection{Formulação Variacional}

Em (SANTOS, 2008), a formulação das equações de movimento é fundamentada no Princípio do Trabalho Virtual, levando em conta a estrutura piezelétrica com características eletromecânicas. A equação do trabalho virtual é descrita como:

$$
\delta W^{c}+\delta W^{i n}+\delta W^{e x}=0
$$

em que $\delta W^{c}, \delta W^{i n}$ e $\delta W^{e x}$ são os trabalhos virtuais realizados pelas forças de inércia, internas e externas, respectivamente. Assim, equações são elaboradas para encontrar cada uma dessas parcelas, com a intenção de se chegar a uma expressão final.

Para as forças de inércia, uma expressão é encontrada para a i-ésima camada da viga sanduíche e representada da seguinte maneira:

$$
\delta W_{i}^{c}=-\int_{0}^{L}\left[\rho_{i} A_{i}\left(\delta u_{i} \ddot{u}_{i}+\delta w \ddot{w}\right)+\rho_{i} I_{i} \delta \beta_{i} \ddot{\beta}_{i}\right] d x
$$

em que $\rho_{i}$ é a densidade do material, $A_{i}$ e $I_{i}$ são a área e o segundo momento de área da seção transversal, respectivamente. O parâmetro $u_{i}$ corresponde ao deslocamento axial no plano médio e $\beta_{i}$ a rotação, todos em relação a i-ésima camada, enquanto que $w$ é a deflexão ou deslocamento transversal.

No caso, para o cálculo do trabalho virtual realizado pelas forças internas são levadas em consideração as contribuições mecânicas, eletromecânicas e dielétricas. Para cada contribuição, também é considerada a parcela referente as camadas da estrutura piezelétrica. Além disso, todo procedimento, para encontrar as contribuições eletromecânicas para a camada piezelétrica, é baseado na expressão da energia livre de Helmholtz, dada por:

$$
H(\varepsilon, \boldsymbol{D})=\frac{1}{2} \varepsilon^{t} \boldsymbol{c}^{D} \boldsymbol{\varepsilon}-\boldsymbol{\varepsilon}^{t} \boldsymbol{h} \boldsymbol{D}+\frac{1}{2} \boldsymbol{D}^{t} \boldsymbol{\beta}^{\varepsilon} \boldsymbol{D}
$$

Os parâmetros referentes a esta última equação são os mesmos descritos para a equação constitutiva de materiais piezelétricos. O trabalho das forças internas é o negativo 
da energia potencial, assim, considerando $\delta H_{m}, \delta H_{m e}$ e $\delta H_{e}$ como energias referentes as contribuições mecânica, eletromecânica e dielétrica, o trabalho das forças internas $\delta W^{\text {in }}$ será o negativo da soma dessas parcelas, ou seja, $\delta W^{i n}=-\left(\delta H_{m}+\delta H_{m e}+\delta H_{e}\right)$.

A contribuição mecânica para as camadas externas $(k=1,3)$ é representada por:

$$
\delta H_{m k}=\int_{0}^{L}\left(\delta \varepsilon_{k}^{m} \bar{c}_{11}^{D k} A_{k} \varepsilon_{k}^{m}+\varepsilon_{k}^{f} \bar{c}_{11}^{D k} I_{k} \varepsilon_{k}^{f}\right) d x
$$

A contribuição eletromecânica, também, é expressa em termos das camadas externas. Assim:

$$
\delta H_{m e k}=-\int_{0}^{L}\left(\delta \varepsilon_{k}^{m} \bar{h}_{31}^{k} A_{k} D_{3 k}+\delta D_{3 k} \bar{h}_{31}^{k} A_{k} \varepsilon_{k}^{m}\right) d x ; k=1,3
$$

Para a contribuição dielétrica, a expressão será:

$$
\delta H_{e k}=\int_{0}^{L}\left(\delta D_{3 k} \bar{\beta}_{33}^{\varepsilon k} A_{k} D_{3 k}\right) d x ; k=1,3
$$

Finalmente o trabalho virtual para as forças mecânicas externas, que se supõe serem aplicadas em cada uma das linhas neutras, pode ser representado por:

$$
\delta W^{e x}=\int_{0}^{L}\left(\delta u_{i} f_{x i} A_{i}+\delta w f_{y i} A_{i}\right) d x
$$

\subsection{Formulação em elementos finitos}

Com a formulação variacional, o modelo em elementos finitos é descrito considerando os deslocamentos axiais, $u_{1}$ e $u_{3}$, deflexão $w$, rotação $w^{\prime}$, e os deslocamentos elétricos $D_{31}, D_{32}$ e $D_{33}$. Para isso, são usadas as equações de Lagrange. Além do mais, as equações cúbicas Hermitianas são utilizadas para descrever as deflexões do elemento.

Um modelo em elementos finitos com dois nós, quatro graus de liberdade mecânico e três elétricos, por nó, é caracterizado e ilustrado na figura 13.

Figura 13 - Elemento e graus de liberdades considerados (SANTOS, 2008).

$$
\left(\begin{array}{ll}
\left(u_{1}^{1}, u^{1}, w^{1}, w^{\prime 1}\right) & \left(u_{1}^{2}, u^{2}, w^{2}, w^{\prime 2}\right) \\
\left(\mathcal{D}^{1}{ }_{31}, \mathcal{D}^{1}{ }_{32}, \mathcal{D}^{1}{ }_{33}\right) & \left(\mathcal{D}^{2}{ }_{31}, \mathcal{D}^{2}{ }_{32}, \mathcal{D}^{2}{ }_{33}\right)
\end{array}\right.
$$


Os graus de liberdade mecânicos são agrupados vetorialmente e representados pela seguinte igualdade:

$$
\boldsymbol{u}_{n}=\left[\begin{array}{llllllll}
u_{1}^{1} & u_{3}^{1} & w^{1} & w^{\prime 1} & u_{1}^{2} & u_{3}^{2} & w^{2} & w^{\prime 2}
\end{array}\right]^{t}
$$

Cada um dos deslocamentos axial e transversal, bem como a rotação da i-ésima camada, são descritos em função dos graus de liberdade representados pelo vetor $\boldsymbol{u}_{n}$, de tal maneira que $u_{i}=\boldsymbol{N}_{x i} \boldsymbol{u}_{n}, w=\boldsymbol{N}_{z} \boldsymbol{u}_{n}$ e $\beta_{i}=\boldsymbol{N}_{r i} \boldsymbol{u}_{n}$, em que $\boldsymbol{N}_{x i}, \boldsymbol{N}_{z}$ e $\boldsymbol{N}_{r i}$ são vetores que contém funções de forma em relação ao comprimento do modelo.

Para os deslocamentos elétricos o mesmo raciocínio é feito, sendo que os graus de liberdade são agrupados no seguinte vetor:

$$
\boldsymbol{D}_{n}=\left[\begin{array}{llllll}
D_{31}^{1} & D_{32}^{1} & D_{33}^{1} & D_{31}^{2} & D_{32}^{2} & D_{33}^{2}
\end{array}\right]^{t}
$$

As expressões generalizadas para deformações de membrana, flexão e cisalhamento, $\varepsilon_{i}^{m}, \varepsilon_{i}^{f}$ e $\varepsilon_{i}^{c}$ da mesma forma são relacionadas aos graus de liberdade representados pelo vetor $u_{n}$, de maneira que $\varepsilon_{i}^{m}=\boldsymbol{B}_{m i} \boldsymbol{u}_{n}, \varepsilon_{i}^{f}=\boldsymbol{B}_{f i} \boldsymbol{u}_{n}$ e $\varepsilon_{2}^{c}=\boldsymbol{B}_{c 2} \boldsymbol{u}_{n}$, em que $\boldsymbol{B}_{m i}, \boldsymbol{B}_{f i}$ e $\boldsymbol{B}_{c 2}$ também são operadores que possuem funções de forma.

\subsection{Discretização das expressões de trabalho virtual}

Através das expressões representativas da formulação variacional e do descritivo em elementos finitos, foram discretizadas as expressões do trabalho virtual para cada camada do modelo. Assim, para as forças de inércia a seguinte expressão resulta:

$$
\begin{aligned}
\delta W_{i}^{c} & =-\int_{0}^{L}\left[\rho_{i} A_{i}\left(\delta u_{i} \ddot{u}_{i}+\delta w \ddot{w}\right)+\rho_{i} I_{i} \delta \beta_{i} \ddot{\beta}_{i}\right] d x \\
& =-\boldsymbol{\delta} \boldsymbol{u}_{n}^{t}\left(\int_{0}^{L}\left[\rho_{i} A_{i}\left(\boldsymbol{N}_{x i}^{t} \boldsymbol{N}_{x i}+\boldsymbol{N}_{z i}^{t} \boldsymbol{N}_{z i}\right)+\rho_{i} I_{i} \boldsymbol{N}_{r i}^{t} \boldsymbol{N}_{r i}\right] d x\right) \ddot{\boldsymbol{u}}_{n} \\
& =-\boldsymbol{\delta} \boldsymbol{u}_{n}^{t} \boldsymbol{M}_{i} \ddot{\boldsymbol{u}}_{n}
\end{aligned}
$$

em que $\boldsymbol{M}_{i}$ é a matriz de massa da i-ésima camada.

Em relação ao trabalho virtual das forças internas, as equações para forças mecânicas, eletromecânicas e dielétricas são desenvolvidas em relação as camadas externas com as condições impostos para o elemento finito. Assim, para as forças mecânicas, sendo $\boldsymbol{K}_{m i}$ a rigidez mecânica da i-ésima camada e partindo da equação (2.10), tem-se:

$$
\delta H_{m k}=\boldsymbol{\delta} \boldsymbol{u}_{n}^{t}\left(\int_{0}^{L}\left(\boldsymbol{B}_{m k}^{t} \bar{c}_{11}^{D k} A_{k} \boldsymbol{B}_{m k}+\boldsymbol{B}_{f i}^{t} \bar{c}_{11}^{D k} I_{k} \boldsymbol{B}_{f i}\right) d x\right) \boldsymbol{\delta} \boldsymbol{u}_{n}=\boldsymbol{\delta} \boldsymbol{u}_{n}^{t} \boldsymbol{K}_{m k} \boldsymbol{u}_{n} ; k=1,3
$$


No caso, a contribuição das forças eletromecânicas, de acordo com a equação (2.11), considerando $\boldsymbol{K}_{m e i}$ como a rigidez eletromecânica da i-ésima camada, é representada como:

$$
\begin{aligned}
\delta H_{m e k} & =-\boldsymbol{\delta} \boldsymbol{u}_{n}^{t}\left(\int_{0}^{L}\left(\boldsymbol{B}_{m k}^{t} \bar{h}_{31}^{k} A_{k} \boldsymbol{N}_{D k}\right) d x\right) \boldsymbol{D}_{n}-\boldsymbol{\delta} \boldsymbol{D}_{n}^{t}\left(\int_{0}^{L}\left(\boldsymbol{N}_{D k}^{t} \bar{h}_{31}^{k} A_{k} \boldsymbol{B}_{m k}\right) d x\right) \boldsymbol{u}_{n} \\
& =-\boldsymbol{\delta} \boldsymbol{u}_{n}^{t} \boldsymbol{K}_{m e k} \boldsymbol{D}_{n}-\boldsymbol{\delta} \boldsymbol{D}_{n}^{t} \boldsymbol{K}_{m e k}^{t} \boldsymbol{u}_{n} ; k=1,3
\end{aligned}
$$

Em relação ao trabalho virtual das forças dielétricas da equação (2.12), tomando $\boldsymbol{K}_{e i}$ como a constante de rigidez dielétrica da i-ésima camada, a equação resultante fica:

$$
\delta H_{e k}=\boldsymbol{\delta} \boldsymbol{D}_{n}^{t}\left(\int_{0}^{L}\left(\boldsymbol{N}_{D k}^{t} \bar{\beta}_{33}^{\varepsilon k} A_{k} \boldsymbol{N}_{D k}\right) d x\right) \boldsymbol{D}_{n}=\boldsymbol{\delta} \boldsymbol{D}_{n}^{t} \boldsymbol{K}_{e k} \boldsymbol{D}_{n} ; k=1,3
$$

Por fim, a equação (2.20) expressa o resultado da contribuição para o trabalho virtual das forças externas, referente a equação (2.13), onde $\boldsymbol{F}_{i}$ é a força resultante na i-ésima camada.

$$
\delta W_{i}^{e x}=\boldsymbol{\delta} \boldsymbol{u}_{n}^{t} \int_{0}^{L}\left(\boldsymbol{N}_{x i}^{t} f_{x i} A_{i}+\boldsymbol{N}_{z}^{t} f_{y i} A_{i}\right) d x=\boldsymbol{\delta} \boldsymbol{u}_{n}^{t} \boldsymbol{F}_{i}
$$

A equação (2.7) do trabalho virtual é rearranjada de tal maneira que:

$$
\delta W_{i}^{c}-\left(\delta H_{m i}+\delta H_{m e i}+\delta H_{e i}\right)+\delta W_{i}^{e x}=0
$$

Dando origem à:

$$
\boldsymbol{\delta} \boldsymbol{u}_{n}^{t}\left(\boldsymbol{M}_{i} \ddot{\boldsymbol{u}}_{n}+\boldsymbol{K}_{m i} \boldsymbol{u}_{n}-\boldsymbol{K}_{m e i} \boldsymbol{D}_{n}-\boldsymbol{F}_{i}\right)+\boldsymbol{\delta} \boldsymbol{D}_{n}^{t}\left(-\boldsymbol{K}_{m e i}^{t} \boldsymbol{u}_{n}+\boldsymbol{K}_{e i} \boldsymbol{D}_{n}\right)=0
$$

Se as pastilhas piezelétricas estiverem perfeitamente recobertas por eletrodos e tiverem espessura uniforme, o deslocamento elétrico será o mesmo para cada nó, o que permite reescrever a equação acima para o caso geral. Além disso, para um mesmo valor de carga elétrica entre material piezelétrico e circuito elétrico, as equações do movimento podem ser escritas em função da carga elétrica do circuito $\boldsymbol{q}_{c}$. É possível então encontrar a equação matricial (2.23) para o caso geral, modificando para isso os valores de rigidez, para levar em conta a área dos eletrodos, como também é demostrado em (GODOY, 2012), e neste caso são simbolizadas com "barras".

$$
\left[\begin{array}{cc}
\boldsymbol{M} & 0 \\
0 & 0
\end{array}\right]\left\{\begin{array}{c}
\ddot{\boldsymbol{u}} \\
\ddot{\boldsymbol{q}}_{c}
\end{array}\right\}+\left[\begin{array}{cc}
\boldsymbol{K}_{m} & -\overline{\boldsymbol{K}}_{m e} \\
-\overline{\boldsymbol{K}}_{m e}^{t} & \overline{\boldsymbol{K}}_{e}
\end{array}\right]\left\{\begin{array}{c}
\boldsymbol{u} \\
\boldsymbol{q}_{c}
\end{array}\right\}=\left\{\begin{array}{c}
\boldsymbol{F} \\
0
\end{array}\right\}
$$


Para um caso específico de circuito com resistências elétricas, a equação anterior pode ser expandida utilizando o princípio do trabalho virtual (SANTOS, 2008; GODOY, 2012). Assim, considerando um vetor $\boldsymbol{R}_{c}$, com valores de resistências, o equacionamento fica expresso por:

$$
\left[\begin{array}{cc}
\boldsymbol{M} & 0 \\
0 & 0
\end{array}\right]\left\{\begin{array}{c}
\ddot{\boldsymbol{u}} \\
\ddot{\boldsymbol{q}}_{c}
\end{array}\right\}+\left[\begin{array}{cc}
0 & 0 \\
0 & \boldsymbol{R}_{c}
\end{array}\right]\left\{\begin{array}{c}
\dot{\boldsymbol{u}} \\
\dot{\boldsymbol{q}}_{c}
\end{array}\right\}+\left[\begin{array}{cc}
\boldsymbol{K}_{m} & -\overline{\boldsymbol{K}}_{m e} \\
-\overline{\boldsymbol{K}}_{m e}^{t} & \overline{\boldsymbol{K}}_{e}
\end{array}\right]\left\{\begin{array}{c}
\boldsymbol{u} \\
\boldsymbol{q}_{c}
\end{array}\right\}=\left\{\begin{array}{c}
\boldsymbol{F} \\
0
\end{array}\right\}
$$

Como pode ser observado, a inclusão de um valor de resistência elétrica no circuito afeta o amortecimento da estrutura. De fato, a resistência funciona como um amortecedor viscoelástico de vibrações.

\subsection{Modelagem do Dispositivo}

A entrada de deslocamento imposto juntamente com a mola linear provoca a atuação de uma força mecânica no primeiro grau de liberdade do dispositivo. Além do mais, pelo fato do acréscimo do elemento mola linear e torcional no primeiro grau de liberdade, uma alteração na matriz de rigidez mecânica ocorre. Sendo assim, para verificar o ocorrido, a equação (2.25) abaixo é utilizada:

$$
\left[\delta w_{0} \quad \boldsymbol{\delta} \boldsymbol{u}_{r}^{t}\right]\left\{\left[\begin{array}{ll}
M_{p p} & \boldsymbol{M}_{p r} \\
\boldsymbol{M}_{p r}^{t} & \boldsymbol{M}_{r r}
\end{array}\right]\left[\begin{array}{c}
\ddot{w}_{0} \\
\ddot{\boldsymbol{u}}_{r}
\end{array}\right]+\left[\begin{array}{cc}
D_{p p} & \boldsymbol{D}_{p r} \\
\boldsymbol{D}_{p r}^{t} & \boldsymbol{D}_{r r}
\end{array}\right]\left[\begin{array}{c}
\dot{w}_{0} \\
\dot{\boldsymbol{u}}_{r}
\end{array}\right]+\left[\begin{array}{cc}
K_{p p} & \boldsymbol{K}_{p r} \\
\boldsymbol{K}_{p r}^{t} & \boldsymbol{K}_{r r}
\end{array}\right]\left[\begin{array}{c}
w_{0} \\
\boldsymbol{u}_{r}
\end{array}\right]-\left[\begin{array}{c}
0 \\
0
\end{array}\right]\right\}=0
$$

em que o índice $p$ é referente ao grau de liberdade prescrito do movimento e o índice $r$ dos graus restantes. As matrizes de massa são representadas por $\boldsymbol{M}$, as de amortecimento por $\boldsymbol{D}$ e as de rigidez por $\boldsymbol{K}$. O vetor $\boldsymbol{u}_{r}$ é referente aos graus de liberdade mecânico do modelo em elementos finitos sem a adição das molas.

Como se conhece o valor do deslocamento prescrito, o valor da primeira linha da equação (2.25) é nulo, em função de $\delta w_{0}=0$. Assim, a equação resultante é:

$$
\delta \boldsymbol{u}_{r}^{t}\left(\boldsymbol{M}_{p r}^{t} \ddot{w}_{0}+\boldsymbol{M}_{r r}^{t} \ddot{\boldsymbol{u}}_{r}+\boldsymbol{D}_{p r}^{t} \dot{w}_{0}+\boldsymbol{D}_{r r} \dot{\boldsymbol{u}}_{r}+\boldsymbol{K}_{p r}^{t} w_{0}+\boldsymbol{K}_{r r} \ddot{\boldsymbol{u}}_{r}\right)=0
$$

A equação anterior também pode ser reescrita da seguinte forma:

$$
\boldsymbol{M}_{r r} \ddot{\boldsymbol{u}}_{r}+\boldsymbol{D}_{r r} \dot{\boldsymbol{u}}_{r}+\boldsymbol{K}_{r r} \boldsymbol{u}_{r}=-\boldsymbol{M}_{p r}^{t} \ddot{w}_{0}-\boldsymbol{D}_{p r}^{t} \dot{w}_{0}-\boldsymbol{K}_{p r}^{t} w_{0}
$$

Ainda, por haver apenas elementos de rigidez elástica unidos ao primeiro grau de liberdade, a matriz $\boldsymbol{M}_{p r}^{t}$ é nula. O valor do amortecimento para o engaste, representado 
na matriz $\boldsymbol{D}_{p r}^{t}$ é desprezado no caso da modelagem, embora uma variável $\zeta$ seja utilizada como valor global para todo o sistema e, nesse caso, toda análise de robustez contempla incertezas embutidas nesse valor. Dessa forma, a equação anterior pode ser reduzida basicamente a:

$$
\boldsymbol{M}_{r r} \ddot{\boldsymbol{u}}_{r}+\boldsymbol{D}_{r r} \dot{\boldsymbol{u}}_{r}+\boldsymbol{K}_{r r} \boldsymbol{u}_{r}=-\boldsymbol{K}_{p r}^{t} w_{0}
$$

No caso, chamando o último termo do lado direito da equação de $\boldsymbol{F}_{p}$ é possível escrever a seguinte expressão:

$$
\boldsymbol{F}_{p}=-\boldsymbol{K}_{p r}^{t} w_{0}=-\boldsymbol{K}_{p r}^{t} \tilde{w}_{0} e^{j \Omega t}
$$

A equação (2.28) representa o modelo do dispositivo considerando os graus de liberdade mecânicos com acréscimo de elementos de rigidez, sendo que um deslocamento prescrito $w_{0}$ é imposto. Para alocar o deslocamento na posição correta, que no presente estudo está inserido no engastamento, é preciso investigar a matriz de rigidez após considerar as molas de constantes $k_{w}$ e $k_{\theta}$. A matriz que representa o elemento de rigidez da mola linear pode ser expressa como:

$$
\boldsymbol{k}_{w}=\left[\begin{array}{cc}
k_{w} & -k_{w} \\
-k_{w} & k_{w}
\end{array}\right]
$$

A matriz de rigidez mecânica $\boldsymbol{K}_{m}$ que pode ser vista através da equação (2.24) é alterada após o acréscimo das molas no engaste, sendo que a matriz de rigidez torcional é semelhante a equação (2.30), com constantes $k_{\theta}$. Seja a matriz $\boldsymbol{K}_{m}$ dada pela seguinte equação:

$$
\boldsymbol{K}_{m}=\left[\begin{array}{ccccc}
k_{m}^{11} & k_{m}^{12} & k_{m}^{13} & \cdots & k_{m}^{1 N} \\
k_{m}^{21} & k_{m}^{22} & k_{m}^{23} & \cdots & k_{m}^{2 N} \\
\vdots & \vdots & \vdots & \ddots & \vdots \\
k_{m}^{N 1} & k_{m}^{N 2} & k_{m}^{N 3} & \cdots & k_{m}^{N N}
\end{array}\right]
$$

em que $k_{m}$ é o valor de cada elemento e $N$ é o tamanho da matriz.

Através do conceito de matriz de alocação, um sistema de coordenada elementar pode ser definido a partir de um sistema generalizado. De outra forma, para uma estrutura definida em um sistema de coordenadas e através de uma matriz de alocação, um dos elementos da estrutura pode ser representado em um sistema particular. Assim, para um sistema de coordenadas generalizado $\boldsymbol{U}$, que pode ser composto de vários graus de 
liberdade, e uma dada matriz de alocação $\boldsymbol{L}_{e}$, um elemento pode ser representado em seu sistema particular $\hat{\boldsymbol{u}}_{e}$, através da seguinte expressão:

$$
\hat{\boldsymbol{u}}_{e}=\boldsymbol{L}_{e} \boldsymbol{U}
$$

O número de colunas da matriz de alocação $\boldsymbol{L}_{e}$ é igual ao número de graus de liberdade da estrutura considerada, enquanto que o número de linhas é o mesmo do elemento estudado (CRAIG, 1981). A matriz de alocação é formada por elementos binários, sendo a posição dos valores unitários correspondentes as colunas dos respectivo graus de liberdades afetados pelo elemento particular no sistema global. Além do mais, a matriz de alocação permite alocar elementos de rigidez elástica nas devidas posições em uma matriz de rigidez global. Primeiramente, o elemento de rigidez elástica (mola) é escrito em uma matriz de tamanho semelhante a matriz de rigidez global, com os elementos nas devidas posições referentes ao graus de liberdades afetados e os outros elementos nulos. Por fim, a matriz encontrada para o elemento de rigidez elástica é somada juntamente com a matriz global e os elementos ficam alocados corretamente nas devidas posições. Assim, definindo uma matriz elementar de rigidez elástica dada por $\hat{\boldsymbol{k}}_{e}$, uma matriz com a mesma dimensão da matriz de um sistema global pode ser escrita como:

$$
\boldsymbol{K}_{e}=\boldsymbol{L}_{e}^{T} \hat{\boldsymbol{k}}_{e} \boldsymbol{L}_{e}^{T}
$$

Para o problema particular onde uma mola linear e outra de torção estão representadas no engaste, ocorre um aumento do número de graus de liberdade do sistema. Considerando o elemento mola torcional não engastado, a princípio, dois graus de liberdade são acrescentados ao sistema mecânico, um referente a mola torcional e o outro a linear. Assim, a matriz de alocação terá $N+2$ colunas, onde $N$ é o número de graus de liberdade mecânicos sem as molas. Então, para a mola linear uma matriz de alocação pode ser escrita como:

$$
\boldsymbol{L}_{w}=\left[\begin{array}{cccccccc}
1 & 0 & 0 & 0 & 0 & 0 & \cdots & 0 \\
0 & 0 & 0 & 0 & 1 & 0 & \cdots & 0
\end{array}\right]
$$

Nesse caso, o primeiro grau de liberdade é referente a entrada da mola linear e o segunda da mola de torção. Antes do acréscimos das molas, o grau de liberdade referente a $w^{1}$, era o terceiro, porém com dois graus a mais, ele passa a ser o quinto, conforme matriz de alocação anterior para a mola linear. Por outro lado, a mola de torção irá afetar apenas o segundo grau de liberdade, referente a entrada, que a princípio é considerada sem restrição, e o sexto, referente a rotação $w^{\prime 1}$. Assim, a matriz de alocação para a mola 
de torção é do tipo:

$$
\boldsymbol{L}_{\theta}=\left[\begin{array}{llllllll}
0 & 1 & 0 & 0 & 0 & 0 & \cdots & 0 \\
0 & 0 & 0 & 0 & 0 & 1 & \cdots & 0
\end{array}\right]
$$

Para o elemento viga com as molas lineares, uma matriz de alocação com dimensão $N \times(N+2)$ pode ser encontrada, sendo que a primeira e segunda colunas possuem elementos nulos, pois dizem respeito aos graus de liberdades da molas de torção e linear, assim é possível escrever:

$$
\boldsymbol{L}_{k m}=\left[\begin{array}{ccccccc}
0 & 0 & 1 & 0 & 0 & \cdots & 0 \\
0 & 0 & 0 & 1 & 0 & \cdots & 0 \\
0 & 0 & 0 & 0 & 1 & \cdots & 0 \\
\vdots & \vdots & \vdots & \vdots & \vdots & \ddots & \vdots \\
0 & 0 & 0 & 0 & 0 & \cdots & 1
\end{array}\right]
$$

Uma matriz de rigidez pode ser encontrada tal que:

$$
\boldsymbol{K}_{G}=\boldsymbol{K}_{m}+\boldsymbol{K}_{w}+\boldsymbol{K}_{\theta}
$$

sendo os termos são escritos como:

$$
\begin{gathered}
\boldsymbol{K}_{w}=\boldsymbol{L}_{w}^{t} \boldsymbol{k}_{w} \boldsymbol{L}_{w} \\
\boldsymbol{K}_{\theta}=\boldsymbol{L}_{\theta}^{t} \boldsymbol{k}_{\theta} \boldsymbol{L}_{\theta} \\
\boldsymbol{K}_{M}=\boldsymbol{L}_{k m}^{t} \boldsymbol{K}_{m} \boldsymbol{L}_{k m}
\end{gathered}
$$

Por isso, a matriz $\boldsymbol{K}_{G}$ pode ser escrita como:

$$
\boldsymbol{K}_{G}=\left[\begin{array}{ccccccccc}
k_{w} & 0 & 0 & 0 & -k_{w} & 0 & 0 & \cdots & 0 \\
0 & k_{\theta} & 0 & 0 & 0 & -k_{\theta} & 0 & \cdots & 0 \\
0 & 0 & k_{m}^{11} & k_{m}^{12} & k_{m}^{13} & k_{m}^{14} & k_{m}^{15} & \cdots & k_{m}^{1 N} \\
0 & 0 & k_{m}^{21} & k_{m}^{22} & k_{m}^{23} & k_{m}^{24} & k_{m}^{25} & \cdots & k_{m}^{2 N} \\
-k_{w} & 0 & k_{m}^{31} & k_{m}^{32} & k_{m}^{33}+k_{w} & k_{m}^{34} & k_{m}^{35} & \cdots & k_{m}^{3 N} \\
0 & -k_{\theta} & k_{m}^{41} & k_{m}^{42} & k_{m}^{43} & k_{m}^{44}+k_{\theta} & k_{m}^{45} & \cdots & k_{m}^{4 N} \\
0 & 0 & k_{m}^{51} & k_{m}^{52} & k_{m}^{53} & k_{m}^{54} & k_{m}^{55} & \cdots & k_{m}^{5 N} \\
\vdots & \vdots & \vdots & \vdots & \vdots & \vdots & \vdots & \ddots & \vdots \\
0 & 0 & k_{m}^{N 1} & k_{m}^{N 2} & k_{m}^{N 3} & k_{m}^{N 4} & k_{m}^{N 5} & \cdots & k_{m}^{N N}
\end{array}\right]
$$


A matriz $\boldsymbol{K}_{G}$ encontrada anteriormente é referente ao dispositivo com as molas de torção e linear, sendo a mola de torção não engastada. No entanto, a mola de torção deve ser engastada no modelo, por isso a segunda linha e segunda coluna da matriz anterior devem ser excluídas, o que fornece a seguinte matriz:

$$
\hat{\boldsymbol{K}}_{G}=\left[\begin{array}{c|ccccccc}
k_{w} & 0 & 0 & -k_{w} & 0 & 0 & \cdots & 0 \\
\hline 0 & k_{m}^{11} & k_{m}^{12} & k_{m}^{13} & k_{m}^{14} & k_{m}^{15} & \cdots & k_{m}^{1 N} \\
0 & k_{m}^{21} & k_{m}^{22} & k_{m}^{23} & k_{m}^{24} & k_{m}^{25} & \cdots & k_{m}^{2 N} \\
-k_{w} & k_{m}^{31} & k_{m}^{32} & k_{m}^{33}+k_{w} & k_{m}^{34} & k_{m}^{35} & \cdots & k_{m}^{3 N} \\
0 & k_{m}^{41} & k_{m}^{42} & k_{m}^{43} & k_{m}^{44}+k_{\theta} & k_{m}^{45} & \cdots & k_{m}^{4 N} \\
0 & k_{m}^{51} & k_{m}^{52} & k_{m}^{53} & k_{m}^{54} & k_{m}^{55} & \cdots & k_{m}^{5 N} \\
\vdots & \vdots & \vdots & \vdots & \vdots & \vdots & \ddots & \vdots \\
0 & k_{m}^{N 1} & k_{m}^{N 2} & k_{m}^{N 3} & k_{m}^{N 4} & k_{m}^{N 5} & \cdots & k_{m}^{N N}
\end{array}\right]
$$

A matriz anterior pode ser escrita na forma representada pela equação (2.25), ou seja:

$$
\hat{\boldsymbol{K}}_{G}=\left[\begin{array}{c|c}
K_{p p} & \boldsymbol{K}_{p r} \\
\hline \boldsymbol{K}_{p r}^{t} & \boldsymbol{K}_{r r}
\end{array}\right]
$$

A inserção de molas linear e de torção no engaste do dispositivo irá afetar os elementos da diagonal principal da matriz $\boldsymbol{K}_{m}$, referentes ao grau de liberdade de deflexão e rotação do modelo, como visto na equação (2.42). Por isso, a matriz $\boldsymbol{K}_{r r}$ é a matriz $\boldsymbol{K}_{m}$ levando em consideração o efeito de $k_{w}$ e $k_{\theta}$ nos devidos elementos referentes aos graus de liberdade. Além disso, das equações (2.29), (2.42) e (2.43), segue que uma força de atuação no grau de liberdade referente a deflexão do mesmo modelo irá ocorrer de magnitude:

$$
f_{p}=k_{w} w_{0}=k_{w} \tilde{w}_{0} e^{j \Omega t}
$$

Com o mesmo raciocínio de formação da matriz $\boldsymbol{K}_{r r}$, a partir das molas de engastamento, a matriz $\boldsymbol{M}_{r r}$ pode ser encontrada, bastando acrescentar a massa sísmica no último grau de liberdade referente a deflexão. Assim, a matriz de massa do sistema é dada por:

$$
\boldsymbol{M}=\left[\begin{array}{cccc}
m^{11} & m^{12} & \cdots & m^{1 N} \\
m^{21} & m^{22} & \cdots & m^{2 N} \\
\vdots & \vdots & \ddots & \vdots \\
m^{(N-1) 1} & \cdots & m^{(N-1)(N-1)} & m^{(N-1) N} \\
m^{N 1} & m^{N 2} & \cdots & m^{N N}
\end{array}\right]
$$


em que $m$ é o valor de cada elemento e $N$ é o tamanho da matriz. Após a inserção da massa sísmica $m_{b}$ a matriz $\boldsymbol{M}_{r r}$ é encontrada modificando o elemento $m^{(N-1)(N-1)}$, que é o penúltimo grau de liberdade, ou seja o último grau de liberdade referente a deflexão. Dessa forma, a matriz $\boldsymbol{M}_{r r}$ é dada por:

$$
\boldsymbol{M}_{r r}=\left[\begin{array}{cccc}
m^{11} & m^{12} & \cdots & m^{1 N} \\
m^{21} & m^{22} & \cdots & m^{2 N} \\
\vdots & \vdots & \ddots & \vdots \\
m^{(N-1) 1} & \cdots & m^{(N-1)(N-1)}+m_{b} & m^{(N-1) N} \\
m^{N 1} & m^{N 2} & \cdots & m^{N N}
\end{array}\right]
$$

Com a modificação das matrizes de massa, rigidez mecânica, e atuação do deslocamento vertical no engaste do dispositivo, a equação 2.24 é modificada e escrita como:

$$
\left[\begin{array}{cc}
\boldsymbol{M}_{r r} & 0 \\
0 & 0
\end{array}\right]\left\{\begin{array}{c}
\ddot{\boldsymbol{u}} \\
\ddot{\boldsymbol{q}}_{c}
\end{array}\right\}+\left[\begin{array}{cc}
0 & 0 \\
0 & \boldsymbol{R}_{c}
\end{array}\right]\left\{\begin{array}{c}
\dot{\boldsymbol{u}} \\
\dot{\boldsymbol{q}}_{c}
\end{array}\right\}+\left[\begin{array}{cc}
\boldsymbol{K}_{r r} & -\overline{\boldsymbol{K}}_{m e} \\
-\overline{\boldsymbol{K}}_{m e}^{t} & \overline{\boldsymbol{K}}_{e}
\end{array}\right]\left\{\begin{array}{c}
\boldsymbol{u} \\
\boldsymbol{q}_{c}
\end{array}\right\}=\left\{\begin{array}{c}
\boldsymbol{F}_{p} \\
0
\end{array}\right\}
$$

Assim, para análise, tem que ser incrementado os valores das molas de engaste e da massa sísmica nas matrizes de rigidez mecânica e massa do sistema, nas devidas posições, referentes aos graus de liberdade. Além disso, uma força, conforme a equação (2.44), no primeiro grau de liberdade referente a deflexão do modelo, deve ser considerada.

\subsection{Resposta em Frequência}

Para a análise de um modelo dinâmico, o estudo da função de resposta em frequência pode trazer informações importantes e assegurar o alcance dos objetivos predefinidos. Dessa maneira, o presente caso estudado, de uma viga cantilever engastada, pode ser avaliado partindo da equação (2.47) com a intenção de obter uma função de resposta em frequência (FRF).

Em (GODOY, 2012) é desenvolvida uma análise modal para o caso de uma excitação puramente mecânica, sendo o desenvolvimento atual baseado no trabalho citado, com diferenciação na entrada de deslocamento e matrizes de massa e rigidez mecânica modificadas. A força da mola linear pode ser escrita como $\boldsymbol{F}_{p}=\boldsymbol{b} f_{p}(t)$ onde $\boldsymbol{b}$ é um vetor coluna que define a posição da força e $f_{p}(t)=\tilde{f}_{p} e^{j \omega t}$. Ainda, o deslocamento pode ser expresso na forma modal segundo a equação abaixo:

$$
\boldsymbol{u}(t)=\boldsymbol{\phi} \boldsymbol{\alpha}(t)
$$


em que $\phi$ é uma base modal não-amortecida sem dependência do tempo, utilizada para normalização da massa, enquanto $\boldsymbol{\alpha}$ é o deslocamento modal. Tanto $\boldsymbol{\alpha}$ como $q_{c}$ podem ser expressos na forma harmônica, tal que $\boldsymbol{\alpha}=\tilde{\boldsymbol{\alpha}} e^{j \omega t}$ e $q_{c}=\tilde{q}_{c} e^{j \omega t}$.

Ao se considerar o caso de conexão com uma resistência $R_{c}$, a base modal não amortecida $\phi$ e as expressões anteriores, é possível reescrever a equação (2.47), tal que:

$$
\begin{gathered}
\left(-\boldsymbol{\phi}^{t} \boldsymbol{M}_{r r} \boldsymbol{\phi} \omega^{2}+\boldsymbol{\phi}^{t} \overline{\boldsymbol{K}}_{r r} \boldsymbol{\phi}\right) \tilde{\boldsymbol{\alpha}}-\boldsymbol{\phi}^{t} \overline{\boldsymbol{K}}_{m e} \tilde{q}_{c}=\boldsymbol{\phi}^{t} \boldsymbol{b} \tilde{f}_{p} \\
\left(j \omega R_{c}+\bar{K}_{e}\right) \tilde{q}_{c}-\overline{\boldsymbol{K}}_{m e}^{t} \boldsymbol{\phi} \tilde{\boldsymbol{\alpha}}=0
\end{gathered}
$$

As seguintes manipulações para os termos que estão sendo normalizados são realizadas: $\boldsymbol{I}=\boldsymbol{\phi}^{t} \boldsymbol{M}_{r r} \boldsymbol{\phi} ; \boldsymbol{\Omega}^{2}=\boldsymbol{\phi}^{t} \boldsymbol{K}_{r r} \boldsymbol{\phi} ; \boldsymbol{K}_{p}=\boldsymbol{\phi}^{t} \boldsymbol{K}_{m e} ; \boldsymbol{b}_{\phi}=\boldsymbol{\phi}^{t} \boldsymbol{b}$. Adicionando-se o termo de amortecimento, representado por uma matriz $\boldsymbol{\Lambda}$, as equações acima são reestruturadas e escritas como:

$$
\begin{gathered}
\left(-\boldsymbol{I} \omega^{2}+j 2 \omega \boldsymbol{\Lambda} \boldsymbol{\Omega}+\boldsymbol{\Omega}^{2}\right) \tilde{\boldsymbol{\alpha}}-\boldsymbol{K}_{p} \tilde{q}_{c}=\boldsymbol{b}_{\phi} \tilde{f}_{p} \\
\left(j \omega R_{c}+\bar{K}_{e}\right) \tilde{q}_{c}-\boldsymbol{K}_{p}^{t} \tilde{\boldsymbol{\alpha}}=0
\end{gathered}
$$

Através da aplicação do deslocamento no engaste do dispositivo, uma saída de velocidade ou corrente elétrica pode ser medida por meio de um sensor apropriado. A velocidade é representada por $v=\boldsymbol{c}_{v} \dot{\boldsymbol{u}}$, onde $\boldsymbol{c}_{v}$ é o vetor que identifica a posição da velocidade no modelo. Substituindo o valor de $\boldsymbol{u}=\phi \tilde{\boldsymbol{\alpha}} e^{j \omega t}$ em $v=\boldsymbol{c}_{v} \dot{\boldsymbol{u}}$, resulta em $v=\tilde{v} e^{j \omega t}$, onde $\tilde{v}=j \omega \boldsymbol{c}_{\phi} \tilde{\boldsymbol{\alpha}}$, sendo $\boldsymbol{c}_{\phi}=\boldsymbol{c}_{v} \boldsymbol{\phi}$. Por outro lado, o valor de corrente elétrica é dado por $I=\tilde{I} e^{j \omega t}$, onde $\tilde{I}=j \omega \tilde{q}_{c}$. Assim, é possível verificar o valor da resposta em frequência para saídas de velocidade ou corrente elétrica com a entrada de deslocamento, representadas como $G_{v w}(\omega)$ e $G_{I w}(\omega)$, pois $\tilde{v}=G_{v w}(\omega) \tilde{w}_{0}$ e $\tilde{I}=G_{I w}(\omega) \tilde{w}_{0}$.

Por meio do cálculo de $q_{c}$ na equação (2.52) e substituição na equação (2.51), é encontrada a relação entre $\tilde{\alpha}$ e $\tilde{f}_{p}$, que permite calcular o valor de $G_{v w}(\omega)$, pois $\tilde{f}_{p}=k_{w} w_{0}$, tal que:

$$
G_{v w}(\omega)=j \omega k_{w}\left(j \omega R_{c}+\bar{K}_{e}\right) \boldsymbol{c}_{\phi}[\boldsymbol{D}]^{-1} \boldsymbol{b}_{\phi}
$$

Em que $[\boldsymbol{D}]=\left[\left(j \omega R_{c}+\bar{K}_{e}\right)\left(-\boldsymbol{I} \omega^{2}+j 2 \omega \boldsymbol{\Lambda} \boldsymbol{\Omega}+\boldsymbol{\Omega}^{2}\right)-\boldsymbol{K}_{p} \boldsymbol{K}_{p}^{t}\right]$. 
Pelo mesmo raciocínio chega-se ao cálculo de $G_{I w}(\omega)$, substituindo o valor encontrado de $\tilde{\boldsymbol{\alpha}}$ na equação $(2.52)$ e obtendo a relação entre $\tilde{I}$ e $\tilde{w}_{0}$. Assim o valor de $G_{I w}(\omega)$ é expresso como:

$$
G_{I w}(\omega)=j \omega k_{w} \boldsymbol{K}_{p}^{t}\left[\boldsymbol{D}^{-1}\right] \boldsymbol{b}_{\phi}
$$

O produto da última FRF pelo valor da resistência elétrica fornece a FRF para saída de tensão, considerando a entrada de deslocamento, tal que:

$$
G_{V w}(\omega)=R_{c} G_{I w}(\omega)
$$

Para a saída de potência, a FRF pode ser encontrada considerando $\tilde{P}=R_{c} \tilde{I}^{2}$. Então a FRF de saída de potência por deslocamento ao quadrado é representada como:

$$
G_{P w}(\omega)=R_{c} G_{I w}(\omega)^{2}
$$

Considerando que o produto da amplitude de deslocamento pelo quadrado da frequência conduz à amplitude de aceleração na base, é possível encontrar a FRF para saída de potência por aceleração quadrada e escrevê-la como:

$$
G_{P a}(\omega)=\frac{G_{P w}(\omega)}{\omega^{4}}
$$

A equação (2.57) é utilizada para quantificar a energia coletada através do dispositivo, sendo interessante maximizar a coleta e, portanto, projetar o dispositivo em função desse critério. Para condições em que a frequência de ressonância do dispositivo esteja sintonizada com a de operação imposta no engaste, espera-se um pico de potência encontrado e maior coleta de energia. Assim, o equacionamento para o dispositivo apresentado na figura 13 pode ser representado através da equação (2.47) para o movimento e as últimas equações descrevem a saída de potência em função do deslocamento ou aceleração. 



\section{Projeto Robusto e Matrizes Ortogonais}

\subsection{Função Perda de Qualidade}

Na engenharia, ao se detalhar um projeto e fazer especificações é comum tratar parâmetros, propriedades ou características de equipamentos, peças ou dispositivos com determinado valor mais ou menos um desvio considerado. Assim, para um valor alvo $m$ e um desvio ou tolerância $\Delta_{0}$, uma especificação adequada poderia ser: $m \pm \Delta_{0}$. Considerando, ainda, uma variável de resposta $y$, pode-se escrever: $|y-m| \leq \Delta_{0}$. Desta maneira, a função perda de qualidade é escrita respeitando a especificação descrita. Uma função degrau poderia representar esse caso, sabendo que se o produto atender o requisito não há custo adicional de reparo ou perda de qualidade, enquanto que para valores de $y$ que desviem do alvo além do permitido, um custo adicional $A_{0}$ deve ser considerado. Considerando uma função degrau, a função perda de qualidade $L_{1}(y)$ é descrita como:

$$
L_{1}(y)=\left\{\begin{array}{lc}
0, & \text { se }|y-m| \leq \Delta_{0} \\
A_{0}, & \text { caso contrário }
\end{array}\right.
$$

Para muitos casos, a função perda de qualidade quadrática representa adequadamente a especificação considerada, assim pode-se escrever $L_{2}(y)$ por:

$$
L_{2}(y)=k(y-m)^{2}
$$

em que $k$ é uma constante que relaciona o custo de reparo por desvio do alvo especificado, chamada também de coeficiente de perda de qualidade. O valor de $k$ pode ser escrito em função de $A_{0}$ e $\Delta_{0}$, tal que:

$$
k=\frac{A_{0}}{\Delta_{0}^{2}}
$$

Os gráficos representados na figura 14 são referentes a função degrau (à esquerda) e quadrática (à direita), ambos para a função perda de qualidade. A região possível de trabalho está compreendida entre os pontos $m-\Delta$ e $m+\Delta$, para os quais o custo de reparo é $A_{o}$.

Em alguns casos, é interessante que o valor alvo esteja o mais próximo possível de zero, quando, por exemplo, determinada característica é indesejada, como certas deformações mecânicas, ruídos sonoros, em alguns casos, e vazamentos de ondas eletromagnéti- 
Figura 14 - Funções perda de qualidade.
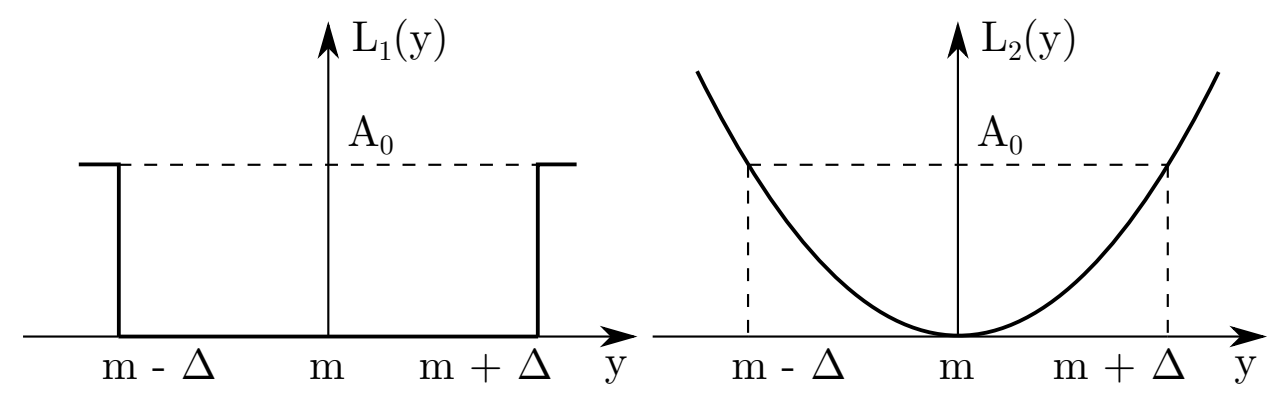

Fonte: Adaptação de Phadke (1995).

cas. Neste caso, a função perda de qualidade é conhecida como do tipo Smaller-the-better ("quanto menor melhor") e pode ser expressa por:

$$
L(y)=k y^{2}
$$

Por outro lado, quando se deseja valores elevados para o alvo, como em casos de geração de energia e resistência de materiais, a função perda de qualidade é do tipo Larger-the-better ("quanto maior melhor"). A expressão para esse tipo de problema é da seguinte maneira:

$$
L(y)=k \frac{1}{y^{2}}
$$

No caso, quando o alvo tem determinado valor nominal a ser alcançado diferente de zero, o problema se reduz a equação (3.2), sendo conhecido com Nominal-the-best ("o nominal é melhor").

Considerando, ainda, o caso Nominal-the-best, é possível escrever uma expressão para a perda de qualidade média $Q$. Sejam $y_{1}, y_{2}, \cdots, y_{n}$ "n" medidas representativas da qualidade características " $y$ " e " $m$ " o alvo. A perda de qualidade média pode ser escrita como (PHADKE, 1995):

$$
\begin{aligned}
Q & =\frac{1}{n}\left[L\left(y_{1}\right)+L\left(y_{2}\right)+\cdots+L\left(y_{n}\right)\right] \\
& =\frac{k}{n}\left[\left(y_{1}-m\right)^{2}+\left(y_{2}-m\right)^{2}+\cdots+\left(y_{n}-m\right)^{2}\right] \\
& =k\left[(\mu-m)^{2}+\frac{n-1}{n} \sigma^{2}\right]
\end{aligned}
$$

sendo $\mu$ e $\sigma^{2}$, respectivamente, média e variância das " $n$ " medidas realizadas e dadas por:

$$
\mu=\frac{1}{n} \sum_{i=1}^{n} y_{i} \quad e \quad \sigma^{2}=\frac{1}{n-1} \sum_{i=1}^{n}\left(y_{i}-\mu\right)^{2}
$$


Para um grande valor de "n", a equação (3.6) se torna da seguinte forma:

$$
Q=k\left[(\mu-m)^{2}+\sigma^{2}\right]
$$

Ao se escolher um valor desejado para o alvo $m$ igual a $\mu_{0}$, é possível reescrever a equação (3.7) multiplicando a média $\mu$ e o desvio padrão $\sigma$ por um fator $\mu_{0} / \mu$. A equação (3.8) representa a perda de qualidade ajustada para um valor desejado $\mu_{0}$.

$$
\begin{aligned}
Q_{a} & =k\left[\left(\mu \frac{\mu_{0}}{\mu}-\mu_{0}\right)^{2}+\left(\frac{\mu_{0}}{\mu} \sigma\right)^{2}\right] \\
& =k \mu_{0}^{2} \frac{\sigma^{2}}{\mu^{2}}
\end{aligned}
$$

Como $k \mu_{0}^{2}$ representa uma constante, a relação $\sigma^{2} / \mu^{2}$ é utilizada para cálculo de sensibilidade, conforme a seguinte equação (3.9). Em geral, deseja-se baixo valores de perda de qualidade, o que significa produtos menos sensíveis a variações ou mais robustos. Por isso, diminuir o valor da equação (3.8) é semelhante a aumentar o valor da equação (3.9), que representa o grau de sensibilidade na análise.

$$
\eta=-10 \log \left(\frac{\sigma^{2}}{\mu^{2}}\right)=10 \log \left(\frac{\mu^{2}}{\sigma^{2}}\right)
$$

Se a função perda de qualidade estudada for do tipo Smaller-the better (STB) ou Larger-the-better (LTB), as equações (3.10) e (3.11) representarão o grau de sensibilidade pra cada um dos casos, respectivamente (PARK et al., 2006; ESEN; TURGUT, 2015; CHEN; HUANG; LIN, 2015).

$$
\begin{aligned}
& \eta=-10 \log _{10}\left(\frac{1}{n} \sum_{i=1}^{n} y_{i}^{2}\right) \\
& \eta=-10 \log _{10}\left(\frac{1}{n} \sum_{i=1}^{n} \frac{1}{y_{i}^{2}}\right)
\end{aligned}
$$

Em todos os casos anteriores, o fator $\eta$ representa uma sensibilidade de algum tipo das funções perda de qualidade, calculada em decibéis. O aumento da sensibilidade implica em diminuir a perda de qualidade, seja para problemas do tipo NTB, STB ou LTB, o que é desejado.

\subsection{Parâmetros de Análises na Função Perda de Qualidade}

Em muitas situações, é comum a existência de fatores que causam variabilidade na resposta de um sistema, o que pode ser representado pela variância $\sigma^{2}$ na equação (3.7). 
Isso pode estar relacionado a medidas imprecisas, imperfeições ou mesmo tolerâncias associadas a materiais, mudanças no meio ambiente, dadas por umidade, temperatura ou pressão, montagens com desajustes, dentre outras causas. Neste caso, é comum nomear um fator de ruído para representar essas condições de incertezas, o que gera um efeito de variabilidade.

$\mathrm{Na}$ análise de um problema, geralmente existem fatores de sinais, parâmetros de controle e fatores de ruídos. Os fatores de sinais estão relacionados a resposta desejada, de tal forma que um fator de sinal pode ser manipulado por um agente externo, um operador, por exemplo, provocando determinada resposta. Os fatores de sinais podem ser manipulados de acordo com uma pretensão final, como o aumento da rotação (fator de sinal) das hélices de um ventilador para produção de uma resposta no aumento de vazão de ar (PHADKE, 1995). Parâmetros de controle estão ligados a características do projeto que se pode mudar sem causar grandes prejuízos, geralmente evitando um retrabalho, uma manufatura ou algo parecido. Pode-se, por exemplo, escolher um novo tipo de material, dispositivo ou dimensionamento, o que implica em uma melhor robustez ou resposta do sistema. Assim os parâmetros de controle são essenciais para garantir a robustez e uma escolha adequada é essencial na análise. Por fim, os fatores de ruídos são aqueles que geram variabilidade, prejuízo, deslocamento da resposta em relação ao alvo, sendo portanto algo indesejado (DEHNAD, 2012).

No entanto, os fatores de ruído muitas vezes não podem ser evitados, sendo inerentes ao sistema estudado; eles existem e causam a variabilidade. Por exemplo, tolerâncias estão associadas a fabricação de materiais e acabam sendo embutidas em fatores de ruído, sendo que diminuir a tolerância causa um aumento no custo e, portanto, não é interessante. No caso, a troca de um material por outro ou dimensionamento do projeto pode ser uma alternativa para a garantia da robustez e, nesse caso, é o que implica na mudança de um parâmetro de controle por outro. Na figura 15, está a exemplificação em diagrama de blocos do sinal de entrada ou fator do sinal, parâmetros de controle e fatores de ruídos com a saída de resposta.

A função estudada y está relacionada à resposta ou saída do sistema, que depende dos fatores de entrada, podendo ser representados pelo vetor de parâmetros de controle $\mathbf{x}$ e pelos fatores de ruído $\mathbf{z}$. O alvo desejado é representado por $m$ e a resposta por $y$, que é função dos parâmetros de controle e fatores de ruído, também exibida através da seguinte equação (3.12):

$$
y=f(\mathbf{z}, \mathbf{x})
$$

É importante no estudo da equação (3.12), a distinção entre os parâmetros de controle e fatores de ruído, para adequada análise e evitar equívocos ou má interpretações. 
Figura 15 - Diagrama de blocos para o sistema ou produtos.

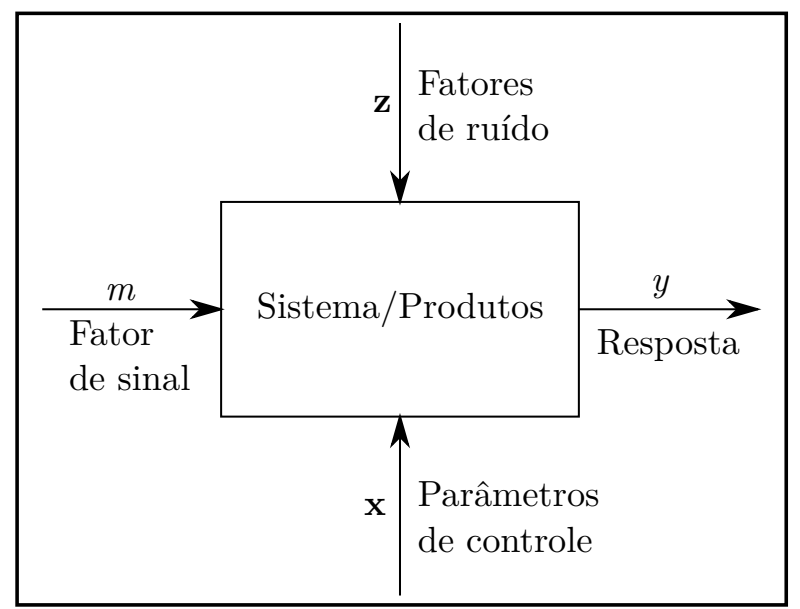

Fonte: Adaptação de Park et al. (2006).

\subsection{Matrizes Ortogonais}

A função perda de qualidade quadrática associada aos parâmetros de controle e ruídos permite estudar a resposta de um sistema e verificar a robustez ou diminuir a sensibilidade frente às mudanças externas ou à variabilidade inerente ao próprio projeto. Uma maneira de quantificar a média, a variabilidade e utilizar a função perda de qualidade é através das chamadas matrizes ortogonais, que são matrizes com níveis de fatores igualmente distribuídos em cada coluna. Matrizes ortogonais foram utilizadas por Genichi Taguchi no final dos anos 1940, buscando uma forma de reduzir custo e otimizar problemas (DOLTSINIS; KANG, 2004)

As matrizes ortogonais são escolhidas em função dos graus de liberdade dos parâmetros ou fatores estudados. Assim, para um problema em que exista " $N$ " graus de liberdade, deve-se escolher uma matriz que tenha pelo menos " $N$ " linhas, conhecidas como número de experimentos da matriz ortogonal. A representação de uma matriz ortogonal com " $N$ " experimentos é dada por $L_{N}$.

Os níveis em uma matriz ortogonal, que podem ser para parâmetros de controle ou fatores de ruído, estão relacionados a determinados cenários para os parâmetros ou fatores. Um conjunto de dados podem se referir ao primeiro nível em uma matriz, enquanto outro conjunto ao segundo nível e assim por diante. Dessa maneira, para cada conjunto de medidas diferentes realizadas em um determinado fator existirá uma matriz apropriada que comporta esse conjunto de medidas. Por exemplo, para três diferentes materiais estudados ou, também, considerados os níveis, deverá existir uma matriz ortogonal com três níveis. Além do mais, é necessário verificar o número de graus de liberdade para todos os fatores estudados, garantindo uma matriz de tamanho adequado.

Os graus de liberdade estão relacionados aos números de experimentos ou medi- 
das, geralmente sendo menor que o número de experimentos em uma unidade (PHADKE, 1995). A somatória dos graus de liberdade de todos os fatores mais o grau de liberdade da média geral (que é igual a um) implica no grau de liberdade do problema estudado. Então, basta encontrar uma matriz $L$ adequada, considerando o número final dos graus de liberdade. As colunas de uma matriz ortogonal representam o número de parâmetros estudados. Assim, considerando parâmetros A, B, C e D, deverá existir quatro colunas para compor esses fatores. Para um caso de " $s$ " níveis, " $m$ " fatores e " $N$ " graus de liberdade, a representação completa de uma matriz ortogonal apropriada pode ser $L_{N}\left(s^{m}\right)$. Pode-se escolher matrizes maiores com relação ao número de linhas, caso não haja problema com custo computacional ou até mesmo se houver casos em que os níveis dos parâmetros sejam diferentes. Dessa forma, se existirem níveis do tipo " $t$ " para " $n$ " fatores, além dos mencionados anteriormente, considerando " $N$ " graus de liberdade, pode-se escolher uma matriz com a forma $L_{N}\left(s^{m} \times t^{n}\right)$ (KACKER; LAGERGREN; FILLIBEN, 1991). Na figura 16, está representada uma matriz ortogonal do tipo $L_{32}\left(2^{1} \times 4^{9}\right)$, com 10 colunas, representadas com o índice "c", sendo a primeira com dois experimentos e o restante com quatro.

As matrizes são escolhidas para os parâmetros de controle e fatores de ruído, sendo que a associação entre elas pode gerar respostas, que possibilitam o cálculo da média e variância do sistema. Como exemplo, para um caso de quatro parâmetros de controle (A, B, C e D) divididos em três níveis, o número de graus de liberdade será $2 \times 4$ mais o grau de liberdade da média, resultando em matrizes de pelo menos 9 experimentos. A matriz que comporta os parâmetros de controle é do tipo $L_{9}\left(3^{4}\right)$. Se raciocínio semelhante for utilizado para outro caso com três fatores de ruído (I, II e III) divididos em dois níveis, uma matriz do tipo $L_{4}\left(2^{3}\right)$ é suficiente. Associando as matrizes dos parâmetros de controle e fatores de ruído, é possível encontrar valores de média e variância, conforme representado na tabela 1 (SEKI; ISHII; ESTERMAN, 1997). Para cada linha da matriz de controle, representada por $L_{9}\left(3^{4}\right)$, e para cada coluna da matriz de ruído $L_{4}\left(2^{3}\right)$, há uma resposta que servirá para o calculo estatístico de média e variância. Com os valores de média e variância, é possível encontrar a observação ou sensibilidade $\eta$ em cada linha de experimentos da matriz de parâmetros de controle.

A associação anterior com matrizes pode ser útil para casos do tipo Nominalthe-best (NTB), onde os valores de variância devido aos ruídos são considerados. Para estudos do tipo LTB ou STB, apenas matrizes de controle podem ser suficientes, não necessitando de associação, já que o interesse pode ser apenas no valor da observação ou sensibilidade. Cada linha da matriz de controle irá gerar um valor de observação $\eta$, que deve ser maximizado, neste caso, garantindo um valor minimizado ou maximizado de resposta com maior robustez. Para uma análise mais refinada e detalhada, a associação de matrizes é uma abordagem interessante e empregada em problemas do tipo NTB, pois permite verificar a média e variância simultaneamente. 
Figura 16 - Matriz ortogonal do tipo $L_{32}\left(2^{1} \times 4^{9}\right)$.

\begin{tabular}{|c|c|c|c|c|c|c|c|c|c|c|}
\hline $\begin{array}{l}\text { Número do } \\
\text { Experimento }\end{array}$ & c1 & $\mathrm{c} 2$ & c3 & $c 4$ & c5 & $c 6$ & c7 & c8 & c9 & c10 \\
\hline 1 & 1 & 1 & 1 & 1 & 1 & 1 & 1 & 1 & 1 & 1 \\
\hline 2 & 1 & 1 & 2 & 2 & 2 & 2 & 2 & 2 & 2 & 2 \\
\hline 3 & 1 & 1 & 3 & 3 & 3 & 3 & 3 & 3 & 3 & 3 \\
\hline 4 & 1 & 1 & 4 & 4 & 4 & 4 & 4 & 4 & 4 & 4 \\
\hline 5 & 1 & 2 & 1 & 1 & 2 & 2 & 3 & 3 & 4 & 4 \\
\hline 6 & 1 & 2 & 2 & 2 & 1 & 1 & 4 & 4 & 3 & 3 \\
\hline 7 & 1 & 2 & 3 & 3 & 4 & 4 & 1 & 1 & 2 & 2 \\
\hline 8 & 1 & 2 & 4 & 4 & 3 & 3 & 2 & 2 & 1 & 1 \\
\hline 9 & 1 & 3 & 1 & 2 & 3 & 4 & 1 & 2 & 3 & 4 \\
\hline 10 & 1 & 3 & 2 & 1 & 4 & 3 & 2 & 1 & 4 & 3 \\
\hline 11 & 1 & 3 & 3 & 4 & 1 & 2 & 3 & 4 & 1 & 2 \\
\hline 12 & 1 & 3 & 4 & 3 & 2 & 1 & 4 & 3 & 2 & 1 \\
\hline 13 & 1 & 4 & 1 & 2 & 4 & 3 & 3 & 4 & 2 & 1 \\
\hline 14 & 1 & 4 & 2 & 1 & 3 & 4 & 4 & 3 & 1 & 2 \\
\hline 15 & 1 & 4 & 3 & 4 & 2 & 1 & 1 & 2 & 4 & 3 \\
\hline 16 & 1 & 4 & 4 & 3 & 1 & 2 & 2 & 1 & 3 & 4 \\
\hline 17 & 2 & 1 & 1 & 4 & 1 & 4 & 2 & 3 & 2 & 3 \\
\hline 18 & 2 & 1 & 2 & 3 & 2 & 3 & 1 & 4 & 1 & 4 \\
\hline 19 & 2 & 1 & 3 & 2 & 3 & 2 & 4 & 1 & 4 & 1 \\
\hline 20 & 2 & 1 & 4 & 1 & 4 & 1 & 3 & 2 & 3 & 2 \\
\hline 21 & 2 & 2 & 1 & 4 & 2 & 3 & 4 & 1 & 3 & 2 \\
\hline 22 & 2 & 2 & 2 & 3 & 1 & 4 & 3 & 2 & 4 & 1 \\
\hline 23 & 2 & 2 & 3 & 2 & 4 & 1 & 2 & 3 & 1 & 4 \\
\hline 24 & 2 & 2 & 4 & 1 & 3 & 2 & 1 & 4 & 2 & 3 \\
\hline 25 & 2 & 3 & 1 & 3 & 3 & 1 & 2 & 4 & 4 & 2 \\
\hline 26 & 2 & 3 & 2 & 4 & 4 & 2 & 1 & 3 & 3 & 1 \\
\hline 27 & 2 & 3 & 3 & 1 & 1 & 3 & 4 & 2 & 2 & 4 \\
\hline 28 & 2 & 3 & 4 & 2 & 2 & 4 & 3 & 1 & 1 & 3 \\
\hline 29 & 2 & 4 & 1 & 3 & 4 & 2 & 4 & 2 & 1 & 3 \\
\hline 30 & 2 & 4 & 2 & 4 & 3 & 1 & 3 & 1 & 2 & 4 \\
\hline 31 & 2 & 4 & 3 & 1 & 2 & 4 & 2 & 4 & 3 & 1 \\
\hline 32 & 2 & 4 & 4 & 2 & 1 & 3 & 1 & 3 & 4 & 2 \\
\hline
\end{tabular}

Em (PHADKE, 1995), é demonstrado que a ortogonalidade de uma matriz está relacionada ao produto escalar entre os pesos que podem ser atribuídos a cada uma de suas linhas em relação à determinada coluna. Para isso, é definida a forma linear $L_{i}$ para cada coluna de uma matriz ortogonal. Considerando valores de resposta observados $\eta_{1}, \eta_{2}, \cdots \eta_{9}$, que estão relacionados com a função perda de qualidade, para uma matriz 
Tabela 1 - Matrizes de parâmetros de controle e fatores de ruído com média e variância

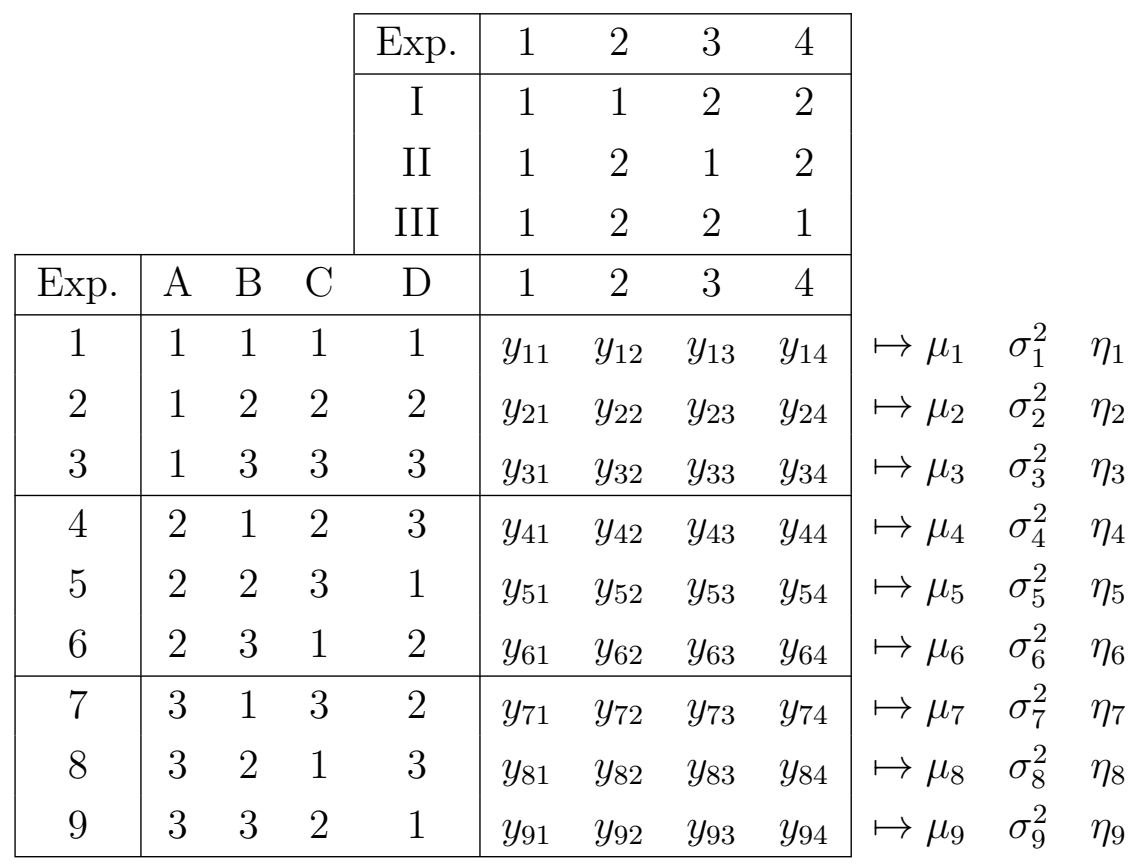

com nove experimentos, uma forma linear pode ser escrita da seguinte maneira:

$$
L_{i}=w_{i 1} \eta_{1}+w_{i 2} \eta_{2}+\cdots+w_{i 9} \eta_{9}
$$

em que $w_{i 1}, w_{i 1}, \cdots w_{i 9}$ são os pesos atribuídos a cada uma das respectivas observações $\eta_{1}, \eta_{2}, \cdots \eta_{9}$ em relação a coluna $i$.

Caso a soma dos pesos de uma forma linear seja igual a zero, define-se a forma linear como sendo um contraste, ou seja, se

$$
w_{i 1}+w_{i 12}+\cdots+w_{i 9}=0
$$

Então se dois contrastes tiverem o produto escalar dos seus pesos igual a zero, diz-se serem ortogonais. Assim, o produto escalar dos pesos entre um primeiro contraste e um segundo pode ser representado por:

$$
w_{11} w_{21}+w_{12} w_{21}+\cdots+w_{19} w_{29}
$$

Se este produto escalar for zero, os contrastes são ortogonais. Dessa forma, é possível verificar a ortogonalidade para uma matriz do tipo $L_{9}\left(3^{4}\right)$. No caso, como cada coluna possui três níveis, existirá uma soma tal que $w_{i 1}+w_{i 2}+w_{i 3}=0$, em que $i$ é uma das colunas, podendo, assim, encontrar um contraste. Considerando a primeira e segunda coluna, 
o produto escalar entre os respectivos pesos dos contrastes poderá ser escrito como:

$$
\begin{aligned}
& w_{11} w_{21}+w_{11} w_{22}+w_{11} w_{23}++w_{12} w_{21}+w_{12} w_{22}+w_{12} w_{23}+ \\
& +w_{13} w_{21}+w_{13} w_{22}+w_{13} w_{23} \\
& =\left(w_{11}+w_{12}+w_{13}\right)\left(w_{21}+w_{22}+w_{23}\right) \\
& =0
\end{aligned}
$$

É possível encontrar o produto escalar igual a zero para cada uma das outras colunas e chegar a ortogonalidade da matriz. Além do mais, ao retirar uma determinada coluna da matriz, a ortogonalidade é preservada. De maneira prática, basta que as matrizes estejam balanceadas, ou seja, para dois pares de coluna, o número de conjuntos de dois elementos distintos deve ser o mesmo. Assim, na matriz $L_{9}\left(3^{4}\right)$, para a primeira e segunda coluna o par $(1,1)$ aparece uma única vez na terceira e quarta coluna, o mesmo valendo para os pares $(1,2),(1,3)$, e assim por diante.

Como a soma dos pesos é igual a zero, ao se escolher dois valores para os pesos, o valor do terceiro fica determinado imediatamente. Isso está relacionado com o número de graus de liberdade, que geralmente é igual ao número de níveis menos um.

\subsection{Análises Estatísticas}

Através da utilização de matrizes ortogonais é possível encontrar valores de média, variância e sensibilidade, o que permite um estudo de análise da variância (ANOVA) (HWANG; LEE; PARK, 2001). Para esse estudo, é necessário encontrar o efeito que cada fator causa na resposta final do sistema, sua contribuição e uma análise de sua significância, que depende da soma dos quadrados dos fatores e do erro associado. Dessa forma, uma introdução, nesse sentido, é descrita nessa sub-seção.

Pelo fato de cada matriz ortogonal possuir níveis que estão relacionados aos parâmetros de controle, é possível encontrar o efeito que estes últimos produzem. Ao se analisar um conjunto de parâmetros, estes estarão divididos em níveis que se associam as matrizes de controle. Dessa forma, é possível encontrar, especificamente, o efeito para cada parâmetro levando em consideração seu nível. Assim, retornando à tabela 1 para 
determinar o efeito dos parâmetros A,B, C e D, nos níveis 1,2 e 3, é possível escrever:

$$
\begin{array}{lll}
m_{A 1}=\frac{\eta_{1}+\eta_{2}+\eta_{3}}{3} ; & m_{A 2}=\frac{\eta_{4}+\eta_{5}+\eta_{6}}{3} ; & m_{A 3}=\frac{\eta_{7}+\eta_{8}+\eta_{9}}{3} ; \\
m_{B 1}=\frac{\eta_{1}+\eta_{4}+\eta_{7}}{3} ; & m_{B 2}=\frac{\eta_{2}+\eta_{5}+\eta_{8}}{3} ; & m_{B 3}=\frac{\eta_{3}+\eta_{6}+\eta_{9}}{3} ; \\
m_{C 1}=\frac{\eta_{1}+\eta_{6}+\eta_{8}}{3} ; & m_{C 2}=\frac{\eta_{2}+\eta_{4}+\eta_{9}}{3} ; & m_{C 3}=\frac{\eta_{3}+\eta_{5}+\eta_{7}}{3} ; \\
m_{D 1}=\frac{\eta_{1}+\eta_{5}+\eta_{9}}{3} ; & m_{D 2}=\frac{\eta_{2}+\eta_{6}+\eta_{7}}{3} ; & m_{D 3}=\frac{\eta_{3}+\eta_{4}+\eta_{8}}{3}
\end{array}
$$

em que o índice $m$ é referente ao efeito de cada parâmetro em determinado nível, ou seja, $m_{A 1}$ é referente ao efeito do fator A no nível 1, $m_{A 2}$ é referente ao efeito do fator A no nível 2 e assim por diante. O cálculo do efeito é realizado através de uma média aritmética das sensibilidades referente à cada nível para determinada coluna. Por outro lado, é possível encontrar o efeito dos parâmetros em relação a média, conduzindo raciocínio semelhante.

Cada parâmetro contribui na resposta final com uma determinada parcela ou porcentagem, que pode ser encontrada por meio de uma análise estatística. Por meio do cálculo da soma dos quadrados para cada parâmetro fica estabelecido um critério inicial, a fim de se encontrar a parcela de contribuição do parâmetro no resultado final. Dos efeitos anteriores a soma dos quadrados para cada parâmetro fica determinada por:

$$
\begin{aligned}
& S S_{A}=3\left(m_{A 1}-\bar{m}\right)+3\left(m_{A 2}-\bar{m}\right)+3\left(m_{A 3}-\bar{m}\right) \\
& S S_{B}=3\left(m_{B 1}-\bar{m}\right)+3\left(m_{B 2}-\bar{m}\right)+3\left(m_{B 3}-\bar{m}\right) \\
& S S_{C}=3\left(m_{C 1}-\bar{m}\right)+3\left(m_{C 2}-\bar{m}\right)+3\left(m_{C 3}-\bar{m}\right) \\
& S S_{D}=3\left(m_{D 1}-\bar{m}\right)+3\left(m_{D 2}-\bar{m}\right)+3\left(m_{D 3}-\bar{m}\right)
\end{aligned}
$$

em que $S S_{A}, S S_{B}, S S_{C}$ e $S S_{D}$, correspondem as somas dos quadrados para os parâmetros $A, B, C$ e $D$, respectivamente, enquanto que $\bar{m}$ é a média geral ou aritmética entre as nove sensibilidades.

Com as somas dos quadrados anteriores, os quadrados médios ou variância são encontrados dividindo as somas pelos graus de liberdade para cada parâmetro, que igual ao número de níveis menos um. Ou seja, os quadrados médios podem ser dados por:

$$
\begin{aligned}
& S_{A}=\frac{S S_{A}}{3-1} ; S_{B}=\frac{S S_{B}}{3-1} \\
& S_{C}=\frac{S S_{C}}{3-1} ; S_{D}=\frac{S S_{D}}{3-1}
\end{aligned}
$$

em que $S_{A}, S_{B}, S_{C}$ e $S_{D}$, correspondem aos quadrados médios para os parâmetros $A, B$, $C$ e $D$, respectivamente. 
Com os valores da soma dos quadrados, pode-se encontrar a soma total dos quadrados pela seguinte equação:

$$
S S T=S S_{A}+S S_{B}+S S_{C}+S S_{D}+S S E
$$

em que $S S E$ é a soma dos quadrados devido ao erro e $S S T$ é a soma dos quadrados para todos os fatores incluindo o erro. Em alguns casos pode ser que as matrizes ortogonais não tenham todas as colunas utilizadas, o que não implica em perda de ortogonalidade. Isso gera um determinado erro ou resíduo, que afetará a soma dos quadrados total SST.

Conhecendo-se o valor de $S S E$, fica determinada a porcentagem de contribuição de cada parâmetro na resposta de um determinado problema por:

$$
\begin{aligned}
& p S S_{A}=\frac{S S_{A}}{S S T} \times 100 \% ; p S S_{B}=\frac{S S_{B}}{S S T} \times 100 \% ; \\
& p S S_{C}=\frac{S S_{C}}{S S T} \times 100 \% ; p S S_{D}=\frac{S S_{D}}{S S T} \times 100 \% ;
\end{aligned}
$$

em que $p S S_{A}, p S S_{B}, p S S_{C}$ e $p S S_{D}$, correspondem a porcentagem de contribuição do parâmetros $A, B, C$ e $D$, respectivamente, na resposta.

Em (PHADKE, 1995), para calcular o valor de SST, é introduzida uma comparação entre análise em série de Fourier e cálculo de soma de quadrados como metodologia alternativa, pois em alguns casos não se conhece o valor do erro previamente. É definida uma equação de soma geral de quadrados $\left(S S T_{G}\right)$ através da seguinte equação:

$$
S S T_{G}=\sum_{j=1}^{n} \eta_{i}^{2}
$$

em que $n$ é número de linhas ou experimentos em uma matriz ortogonal e $\eta_{i}$ é o valor da sensibilidade em determinada linha.

A média geral dos valores de sensibilidade pode ser encontrado através de uma media aritmética entre todos os valores gerados na matriz ortogonal. Como exemplo, para a matriz com nove experimentos um valor médio de sensibilidade poderia ser dado por:

$$
\bar{m}=\frac{\eta_{1}+\eta_{2}+\cdots+\eta_{9}}{9}
$$

Para a média geral $\bar{m}$ fica determinada uma soma de quadrados definida por $S S_{\bar{m}}$ e calculada através da seguinte expressão:

$$
S S_{\bar{m}}=n \bar{m}^{2}
$$


onde $n$ é o número de linhas da matriz ortogonal.

Dessa forma, o cálculo de $S S T$ pode ser realizado subtraindo $S S_{\bar{m}}$ de $S S T_{G}$, tal que:

$$
S S T=S S T_{G}-S S_{\bar{m}}=\sum_{j=1}^{n} \eta_{i}^{2}-n \bar{m}^{2}
$$

Assim, por não conhecer o valor da soma do resíduo ( $S S E)$, previamente, é possível encontrar a soma total dos quadrados através da equação anterior e, então, o valor da contribuição de cada parâmetro no resultado final. Por outro lado, a soma dos quadrados devido ao erro pode ser encontrada fazendo a diferença entre a soma dos quadrados total $(S S T)$ e a soma dos quadrados devido aos vários fatores. Além do mais, tomando a diferença entre os graus de liberdade para a soma total dos quadrados (que é o número de linhas de uma matriz ortogonal menos um) e a soma dos graus de liberdade para os vários fatores tem-se os graus de liberdade do erro $d o f_{e}$. Isto é importante para o cálculo da variância devido ao erro $\sigma_{e}^{2}$, que é encontrada dividindo $S S E$ por $d o f_{e}$, ou seja:

$$
\sigma_{e}^{2}=\frac{S S E}{d o f_{e}}
$$

Cada parâmetro tem um efeito que pode ser verificado através da equação (3.17), para uma matriz com nove experimentos. Caso o efeito de um parâmetro tenha valores muito diferentes em cada nível, irá contribuir significativamente na resposta final, tanto para casos de análise de média como para sensibilidade. O teste estatístico de hipótese $\mathrm{F}$ pode ser aplicado nesse caso, onde a hipótese $H_{0}$ é que a média dos fatores nos níveis são iguais. Um valor calculado $F_{0}$ é definido por:

$$
F_{0}=\frac{S_{X}^{2}}{\sigma_{e}^{2}}
$$

onde $S_{X}^{2}$ é variância devida a um determinado parâmetro $X$.

Se $F_{0}$ for maior ou igual a um determinado valor de referência $F_{c}$, então a hipótese é rejeitada e os parâmetros afetam a resposta, ou seja, têm significância. Em geral quanto maior o valor de $F_{0}$ maior será a probabilidade da resposta ser alterada, sendo o valor de $F_{c}$ retirado de tabelas estatísticas (BARBETTA; REIS; BORNIA, 2004).

Uma exemplificação do procedimento estatístico de análise da variância (ANOVA) se encontra na tabela 2, onde GL são os graus de liberdade, SQ a soma dos quadrados, QM os quadrados médios e F o teste de hipótese. Para um determinado parâmetro a soma dos quadrados é representada por $S S_{X}$ na tabela. 
Tabela 2 - modelo para ANOVA

\begin{tabular}{|l|l|l|l|l|}
\hline Causas de variação & GL & SQ & QM & F \\
\hline Parâmetros & $\mathrm{k}-1$ & $S S_{X}$ & $S_{X}^{2}$ & $F_{0}$ \\
\hline Erro ou Resíduos & $\mathrm{n}-\mathrm{k}$ & $S S E$ & $\sigma_{e}^{2}$ & \\
\hline Total & $\mathrm{n}-1$ & $S S T$ & & \\
\hline
\end{tabular}

\subsection{Interações entre Parâmetros de Controle}

Os parâmetros de controle conduzem a determinados efeitos, tanto para média como observações de sensibilidade, conforme equação (3.17), para nove experimentos. A partir dos valores encontrados de efeito, é possível plotar gráficos para uma análise mais simplificada. Um típico gráfico de efeito é apresentado na figura 17, em que existem três parâmetros estudados (A,B e C) divididos em dois níveis. A resposta geralmente é explícita em função da sensibilidade ou média, embora também possa ser em relação a função perda de qualidade.

Figura 17 - Gráfico de efeito.

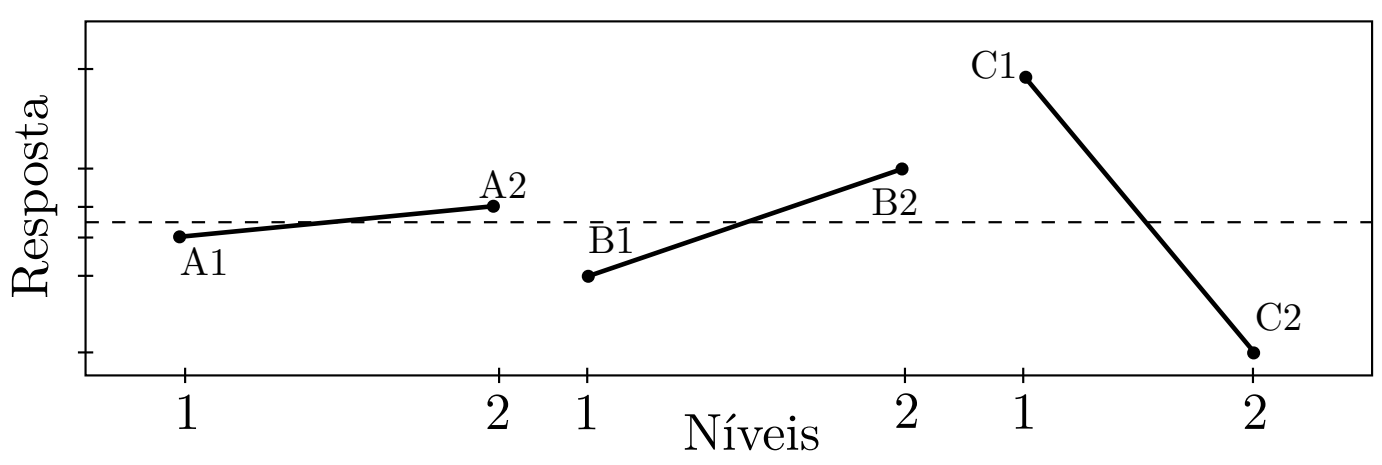

Fonte: Baseado em Phadke (1995).

Ao plotar um gráfico de efeito, é importante analisar a interação entre os parâmetros. Gráficos de efeitos para estudos de interações podem ser plotados de maneira semelhante, no entanto, é analisado o efeito que a interação entre dois parâmetros produzem na resposta. Os gráficos de interações entre fatores podem ser de três tipos diferentes: quando as linhas dos parâmetros são paralelas umas a outras, diz-se que os fatores não interagem entre si, são aditivos ou monotônicos, por outro lado quando as linhas não são paralelas, mas não se cruzam tem-se uma interação sinergética, e quando as linhas se cruzam os parâmetros têm uma alta iteração e são anti-sinergéticos (PHADKE, 1995). Os gráficos com as diferentes iterações entre dois parâmetros A e B para dois níveis podem ser exemplificados através de uma representação na figura 18.

O nível de interação entre os parâmetros é medido pelo não paralelismo dos gráficos. Assim, matematicamente, a diferença entre a soma das respostas dada pela equação 
Figura 18 - Gráfico de efeito com tipos de iterações.

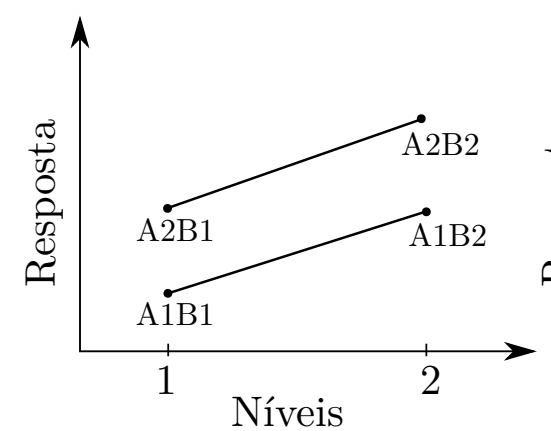

(a) Sem interação

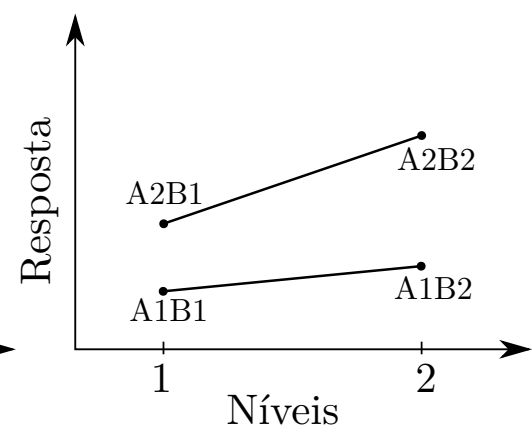

(b) Interação Sinergética

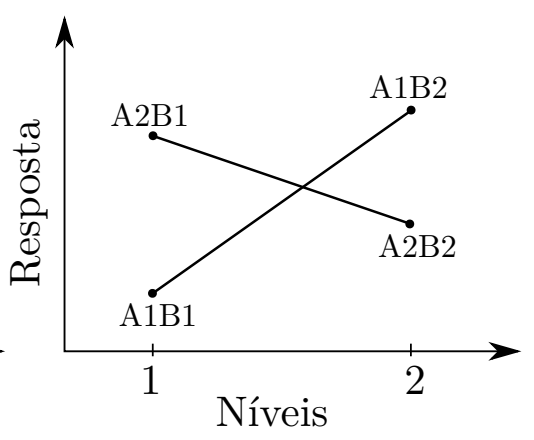

(c) Interação Anti Sinergética

Fonte: Baseado em Phadke (1995).

(3.28) mostra a aditividade ou interação entre os parâmetros, para os gráficos dados na figura 18.

$$
\begin{aligned}
A \times B & =\left(y_{A_{2} B_{2}}-y_{A_{2} B_{1}}\right)-\left(y_{A_{1} B_{2}}-y_{A_{1} B_{1}}\right) \\
& =\left(y_{A_{2} B_{2}}+y_{A_{1} B_{1}}\right)-\left(y_{A_{2} B_{1}}+y_{A_{1} B_{2}}\right)
\end{aligned}
$$

em que a variável y representa o valor da resposta para determinada interação e níveis de fatores.

Nos gráficos da figura 18, em uma das retas, um dos parâmetros é mantido, enquanto o outro é alterado. Para essa análise, são utilizadas duas colunas específicas em uma matriz ortogonal. Ao se escolher, por exemplo, uma matriz do tipo $L_{8}\left(2^{7}\right)$, conforme tabela 3, a primeira e segunda colunas podem ser escolhidas para análise de interação, enquanto a terceira deve ficar inutilizável para esse caso, pois algumas colunas dessa matriz se confundem com outras na análise interativa. Se os parâmetros A e B são atribuídos a primeira e segunda coluna, respectivamente, e um parâmetro hipotético $\mathrm{C}$ à terceira coluna, então é possível verificar a relação entre as colunas. O efeito C2 que aparece do terceiro até o quarto experimento é confundido com as interações A1B2 e A2B1, enquanto o efeito C1 é confundido com as interações A1B1 (experimento 1 e 2) e A2B2 (experimentos 7 e 8) (PHADKE, 1995). Dessa forma, quando se confundem os efeitos de uma coluna em relação a outras duas, ela não deve ser utilizada para análise de interações.

Para verificação de interações entre colunas, pode-se recorrer a gráficos que foram elaborados com essa finalidade. Os gráficos são um conjunto de ábacos estruturados para as matri2zes ortogonais e representam as colunas que podem ser preenchidas com o nível dos parâmetros e quais delas devem ser evitadas, devido ao efeito da interação. Na figura 19, está a representação de um gráfico de interações para a matriz $L_{8}\left(2^{7}\right)$ da tabela 3 . Cada ponto representa uma coluna que não contém interação na matriz e a linha que liga 
Tabela 3 - Matriz Ortogonal $L_{8}\left(2^{7}\right)$

\begin{tabular}{|c|ccccccc|}
\hline Exp. & c1 & c2 & $c 3$ & $c 4$ & c5 & c6 & c7 \\
\hline 1 & 1 & 1 & 1 & 1 & 1 & 1 & 1 \\
2 & 1 & 1 & 1 & 2 & 2 & 2 & 2 \\
3 & 1 & 2 & 2 & 1 & 1 & 2 & 2 \\
4 & 1 & 2 & 2 & 2 & 2 & 1 & 1 \\
\hline 5 & 2 & 1 & 2 & 1 & 2 & 1 & 2 \\
6 & 2 & 1 & 2 & 2 & 1 & 2 & 1 \\
7 & 2 & 2 & 1 & 1 & 2 & 2 & 1 \\
8 & 2 & 2 & 1 & 2 & 1 & 1 & 2 \\
\hline
\end{tabular}

Figura 19 - Gráficos lineares de interação.
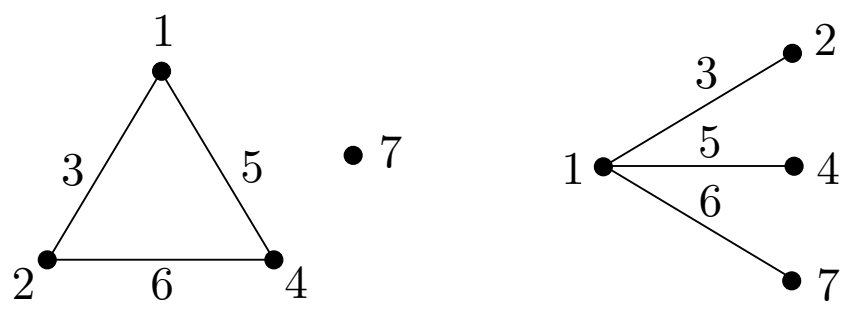

Fonte: Baseado em Phadke (1995).

os pontos representa a coluna que contem a interação e deve ser evitada. Existem duas alternativas possíveis de gráficos lineares para o estudo de interação através da matriz $L_{8}\left(2^{7}\right)$, representados à esquerda e à direita da figura 19.

Quando a interação é alta, o procedimento é rever os parâmetros estudados, pois pode ocorrer da escolha não ser adequada. Assim, é possível que se escolha analisar massa e densidade, o que provocará uma iteração e, dependendo da análise, seria conveniente estudar apenas um desses parâmetros. Situações em que parâmetros de controle e fatores de ruído são escolhidos erroneamente pode também conduzir a interação. Em (ANDERSON; WHITCOMB, 2016), uma abordagem de situações em que há interações é apresentada, levando a um estudo mais apurado do caso e análise de casos estatísticos. No entanto, para o estudo de casos de sensibilidade partindo de matrizes ortogonais, a interação entre fatores pode não conduzir a uma resposta satisfatória, sendo que os parâmetros devem ser reavaliados ou até mesmo a função objetivo alterada (NAIR et al., 1992). Por isso, nos casos em que não há cruzamento entre os gráficos de efeito, o estudo é mais adequado.

A função sensibilidade logarítmica é utilizada juntamente com as matrizes ortogonais pela monotonicidade apresentada, o que evita uma interpretação equivocada dos efeitos dos parâmetros, justamente por evitar a interação gráfica. A menos que a função objetivo e o limite dos parâmetros sejam má escolhidos, a interação não deve ocorrer utilizando as funções de sensibilidade. 


\subsection{Modificação de Matrizes Ortogonais}

As matrizes ortogonais podem ser modificadas para algumas situações importantes. Estes casos são apresentados quando o número de parâmetros ou fatores possuem menos níveis do que a matriz selecionada, quando o número de parâmetros é maior que as colunas disponíveis na matriz, quando se deseja estudar mais níveis de parâmetros em relação a outro e quando as matrizes têm número limitados ou iguais de níveis, além de algumas colunas serem utilizadas para estudo de interação.

Na situação em que o número de parâmetros é menor que o número de níveis da matriz, é possível repetir um dos parâmetros para se fazer a análise. Dessa maneira, caso um parâmetro A tenha dois níveis A1 e A2, um terceiro nível pode ser adquirido por fazer $\mathrm{A} 3=\mathrm{A} 2$ ou A3 = A1. Se for feito A3=A1, então o efeito calculado de A1 na análise será duas vezes mais preciso do que para A2.

Para o caso em que o número de parâmetros é maior que o número de colunas, pode-se recorrer a uma combinação dos parâmetros para a análise. Assim, se um parâmetro tem dois níveis e a matriz é para três níveis, é possível combinar os parâmetros para se chegar a um terceiro nível. Por exemplo, caso os parâmetros A e B tenham dois níveis, pode-se encontrar a seguinte combinação A1B1, A1B2, A1B2 e A2B2. Se forem escolhidas três das combinações, então se formará os níveis necessários para a análise. No caso, a relação entre A1B1 e A1B2 será analisada como o efeito que se adquire ao mudar do nível B1 para B2.

Quando se tem alguns parâmetros com mais níveis que outros, também é possível redimensionar a matriz ortogonal para o estudo de determinados parâmetros. Assim, uma matriz com dois níveis, por exemplo, pode ter uma das colunas agrupada com outra, a fim de se formar uma coluna com quatro níveis. Uma coluna de três níveis pode ser agrupada com outra de três níveis para formar uma de nove ou agrupada com uma de dois níveis para formar uma de seis. Outras matrizes com quatro e cinco níveis são disponíveis para estudo, em questão de interação, formação de novos níveis ou, mesmo, conter vários fatores ou parâmetros na análise.

Na figura 20, está uma exemplificação do procedimento para formação de uma coluna de quatro níveis, partindo de duas colunas de dois níveis. Assim, será possível estudar alguns fatores com dois níveis e um específico com quatro níveis.

Na formação de uma coluna com mais níveis, a matriz tem o número de colunas menor que a condição inicial, pois duas colunas são mescladas para formar uma nova. Além do mais, é necessário escolher criteriosamente quais colunas serão combinadas, pois existem casos de interação entre colunas. Assim, por exemplo, na tabela 20, há uma matriz ortogonal $L_{8}\left(2^{7}\right)$ à esquerda, que terá a primeira coluna (c1) e a segunda (c2) mesclada para formar uma coluna de quatro níveis na matriz a direita. No entanto, a nova coluna 
Figura 20 - Formação de quatro níveis através de pares de dois níveis.

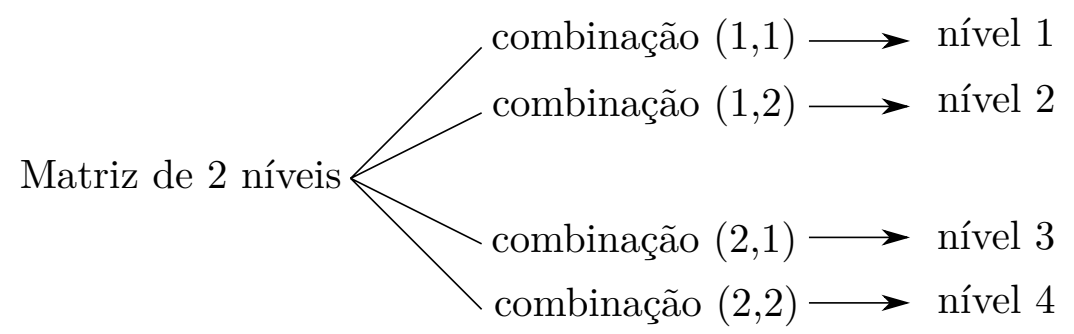

formada substitui a terceira coluna (c3) da matriz original, pois a interação c1xc2 se confunde com c3 e, assim, esta última coluna não deve ser utilizada para união com outra coluna, mas deve ser desprezada e, em seguida, receber a coluna de quatro níveis formada, como visto na tabela 4 à direita.

Tabela 4 - Formação de quatro níveis através de pares de dois níveis

\begin{tabular}{|c|ccccccc|}
\hline Exp. & $\mathrm{c} 1$ & $\mathrm{c} 2$ & $\mathrm{c} 3$ & $\mathrm{c} 4$ & $\mathrm{c5}$ & $\mathrm{c} 6$ & $\mathrm{c7}$ \\
\hline 1 & 1 & 1 & 1 & 1 & 1 & 1 & 1 \\
2 & 1 & 1 & 1 & 2 & 2 & 2 & 2 \\
3 & 1 & 2 & 2 & 1 & 1 & 2 & 2 \\
4 & 1 & 2 & 2 & 2 & 2 & 1 & 1 \\
\hline 5 & 2 & 1 & 2 & 1 & 2 & 1 & 2 \\
6 & 2 & 1 & 2 & 2 & 1 & 2 & 1 \\
7 & 2 & 2 & 1 & 1 & 2 & 2 & 1 \\
8 & 2 & 2 & 1 & 2 & 1 & 1 & 2 \\
\hline
\end{tabular}

\begin{tabular}{|c|ccccc|}
\hline Exp. & c1 x c2 & $c 4$ & $c 5$ & $c 6$ & $c 7$ \\
\hline 1 & 1 & 1 & 1 & 1 & 1 \\
2 & 1 & 2 & 2 & 2 & 2 \\
3 & 2 & 1 & 1 & 2 & 2 \\
4 & 2 & 2 & 2 & 1 & 1 \\
\hline 5 & 3 & 1 & 2 & 1 & 2 \\
6 & 3 & 2 & 1 & 2 & 1 \\
7 & 4 & 1 & 2 & 2 & 1 \\
8 & 4 & 2 & 1 & 1 & 2 \\
\hline
\end{tabular}

\subsection{Análises de Robustez e Matrizes Ortogonais}

Projetos robustos foram estudados pelo engenheiro e consultor Genichi Taguchi no final dos anos 1940, buscando uma forma de reduzir custo e otimizar problemas (DOLTSINIS; KANG, 2004). O método utilizado por Taguchi é baseado em uma análise de sensibilidade segundo as equações para os casos NTB, LTB e STB, apresentadas anteriormente, juntamente com a utilização de matrizes ortogonais. No caso, Taguchi utiliza a nomenclatura sinal e ruído (signal-to-noise, S/N) para analisar a sensibilidade de parâmetros, sendo que o sinal representa o valor desejado, ao contrário do ruído que pode ser temperatura, poeira, deterioração ou outra representação prejudicial que causa perda de qualidade. Para que seja encontrado um produto otimizado e menos sensível a flutuações, os ruídos não devem causar efeitos indesejados na resposta final do problema. Uma análise estatística de variância (ANOVA) é elaborada após encontrar os efeitos de média e sensibilidade, além de verificações de interações entre parâmetros de controle para garantia de uma resposta satisfatória com menor variabilidade. 
Taguchi utiliza as nomenclaturas smaller-the-better (STB), nominal-the-best (NTB) e larger-the-better (LTB) para o estudos dos problemas de robustez, sendo que a definição está relacionada ao valor ideal encontrado do problema. Na tabela 5, estão representados os casos descritos neste parágrafo, com o domínio de estudo para cada situação e as equações que definem cada caso, ou seja, a sensibilidade $\mathrm{S} / \mathrm{N}$ ou $\eta$. Os valores da média e variância são representados por $\mu$ e $\sigma$ na tabela 5 e o valor da variável de resposta para $n$ funções analisadas é expresso por $y_{i}$.

Tabela 5 - Limites para cada fator de ruído

\begin{tabular}{|c|c|c|c|}
\hline Tipo de Problema & Domínio & Valor Ideal & Sensibilidade $-\mathrm{S} / \mathrm{N}$ \\
\hline Smaller-the-better & $0 \leq y \leq \infty$ & 0 & $\eta=-10 \log _{10}\left(\frac{1}{n} \sum_{i=1}^{n} y_{i}^{2}\right)$ \\
\hline Nominal-the-best & $0 \leq y \leq \infty$ & finito e não zero & $\eta=-10 \log _{10} \frac{\sigma^{2}}{\mu^{2}}$ \\
\hline Larger-the-better & $0 \leq y \leq \infty$ & $\infty$ & $\eta=-10 \log _{10}\left(\frac{1}{n} \sum_{i=1}^{n} \frac{1}{y_{i}^{2}}\right)$ \\
\hline Signed-target (ST) & $-\infty \leq y \leq \infty$ & finito, pode ser 0 & $\eta=-10 \log _{10} \sigma^{2}$ \\
\hline
\end{tabular}

Na tabela 5, está apresentado um tipo de problema definido como signed-target ("alvo assinalado"), que é referente a situações onde o alvo pode ser nulo, sendo a sensibilidade verificada para a variância. Embora o problema ST geralmente tenha valor ideal nulo, a referência para o alvo pode ser considerada como zero, permitindo, assim, o estudo de um problema ST ao invés de NTB (PHADKE, 1995).

Quanto à utilização da equação de sensibilidade para o caso NTB, na avaliação de problemas com alvo desejado, a variabilidade poderá diminuir, além disso, a vantagem é uma maior monotonicidade em comparação com a função perda de qualidade quadrática. Esta equação pode tornar um determinado problema com menor variabilidade de forma irrestrita e, então, após isso, é possível ajustar a média em um alvo desejado, através de um parâmetro de controle que tenha pouca influência na resposta em relação à variância. Portanto, o projeto robusto está dividido em duas etapas como proposto em (PARK et al., 2006). Primeiramente, a variabilidade do problema estudado deve ser reduzida, o que não garante um resultado da média no alvo desejado, havendo a necessidade de uma segunda etapa, para ajuste da média no ponto adequado. A figura 21 representa o exposto anteriormente, sendo que a partir do aumento do valor de $\mathrm{S} / \mathrm{N}$ (sensibilidade), uma menor variabilidade é encontrada, satisfazendo a primeira etapa, enquanto que, por escolha de um adequado parâmetro, o alvo tende a ser atingido.

Em (NAIR et al., 1992) é demonstrado como a escolha adequada de parâmetros de controle pode diminuir a variância de um problema quadrático. Dessa forma, a equação (3.29), na qual os vetores $\mathbf{x}$ e $\mathbf{z}$ contém os parâmetros de controle e fatores de ruído, 
Figura 21 - Divisão de etapas desenvolvidas para otimização do projeto robusto.

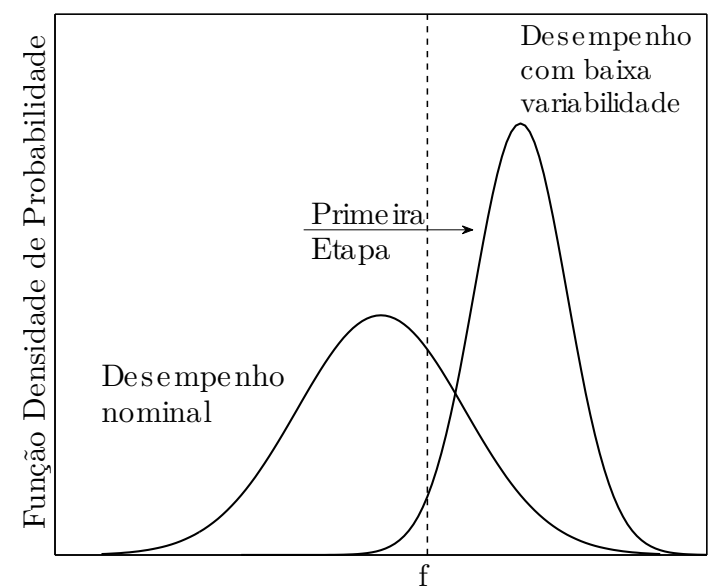

(a) Diminuição da variabilidade

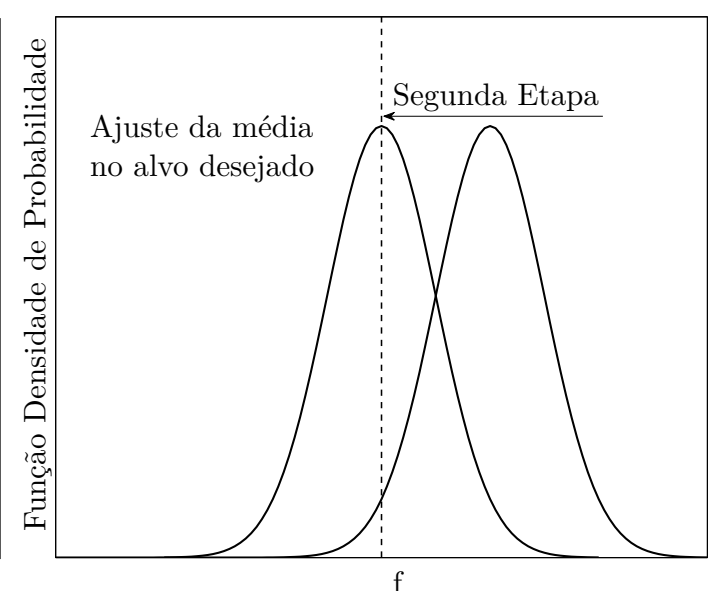

(b) Ajuste da média no alvo desejado

Fonte: Adaptação de Park et al. (2006).

respectivamente, é reescrita algebricamente, conforme equação (3.30), para o estudo de um polinômio de segunda ordem, como exemplo.

$$
\begin{gathered}
\hat{y}=f(\mathbf{x}, \mathbf{y}) \\
\hat{y}=b_{0}+b_{1} x_{1}+b_{2} x_{2}+b_{12} x_{1} x_{2}+b_{11} x_{1}^{2}+b_{22} x^{2}+ \\
c_{1} z_{1}+c_{2} z_{2}+\delta_{11} z_{1} x_{1}+\delta_{12} z_{1} x_{2}
\end{gathered}
$$

em que os índices $b, c$ e $\delta$ são constantes do problema. Então, são tomados dois parâmetros $x_{1}$ e $x_{2}$ e dois fatores de ruído $z_{1}$ e $z_{2}$.

Os ruídos $z_{1}$ e $z_{2}$ não interagem entre si e são independentes, assim utilizando o conceito de covariância e aplicando o operador de variância é possível escrever $\sigma_{z}(y)$ para a equação (3.30), tal que:

$$
\begin{aligned}
\sigma_{z}^{2}(y)= & c_{2}^{2}+\left(c_{1}+\delta_{11} x_{1}+\delta_{22} x_{2}\right)^{2} \\
& =c_{2}^{2}+\left(\partial \hat{y} / \partial z_{1}\right)^{2}
\end{aligned}
$$

É possível notar que ao se escolher valores apropriados $x_{1}$ e $x_{2}$, pode ocorrer uma diminuição da variabilidade, dependendo dos valores das constantes, sem necessidade de excluir a atuação dos ruídos.

Em (PHADKE, 1995) é demonstrado que a metodologia através de matrizes ortogonais pode ser aplicada de maneira irrestrita para um problema de minimização, conforme equação (3.32). Para isso, é definido um vetor de controle $\mathbf{x}=\left[x_{1}, x_{2}, \cdots, x_{n}\right]^{\prime} \mathrm{e}$ 
um de ruído z. Então, por meio da escolha de um valor $x_{1}$ inicial, são encontrados um conjunto de parâmetros de controle que minimizam o valor da variância do problema. Por fim, altera-se o valor de $x_{1}$ escolhido por outro que ajuste a média em $\mu_{0}$, sem interferir no valor mínimo da variância encontrado.

$$
\begin{array}{ll}
\operatorname{minimize} & \sigma^{2}(\mathbf{x}) \\
\text { sujeito a } & \mu(\mathbf{x})=\mu_{0}
\end{array}
$$

Portanto, a metodologia empregada com a utilização de matrizes ortogonais está focada na minimização da variabilidade inicialmente, seguida de um ajuste da média no ponto alvo, quando se trata de problemas em que o alvo é predefinido ou de valor conhecido. Neste caso, a metodologia é conduzida de maneira irrestrita, diferindo de outros métodos, sendo que na literatura está registrada a necessidade de uma otimização determinística inicial para localizar a média em um valor desejado e, então, prosseguir com a otimização robusta utilizando matrizes ortogonais (PARK et al., 2006).

Em (PARK et al., 2006), é enfatizada a questão da limitação do método quando um parâmetro de ajuste não pode ser encontrado, reforçando a necessidade de se realizar uma otimização determinística previamente, supondo o alvo encontrado nesse procedimento. Após encontrar o alvo, alguns parâmetros podem ser escolhido em uma região que não afetem muito o valor da média, mas gerem uma menor variância do problema. 


\section{Metodologia}

\subsection{Introdução}

O procedimento utilizado para obtenção de resultados satisfatórios em termos de coleta de energia baseia-se no objetivo proposto neste trabalho, no equacionamento matemático e em funções de resposta em frequência desenvolvidos no capítulo 2 , bem como na técnica de robustez com matrizes ortogonais apresentada no capítulo 3, pressupondo uma otimização determinística previamente. Na figura 22, está representado um sistema utilizado em Energy Harvesting, em que uma viga com material piezelétrico e massas na extremidade está preso num engaste montado. Para o correto funcionamento do dispositivo é importante que a montagem do engaste seja feita adequadamente, evitando problemas que possam levar a diminuição de rigidez da fixação e assim mudança da frequência natural esperada. O dispositivo é devidamente colocado em uma base excitável, o que produz energia cinética devido a vibração da viga, possibilitando a geração de energia elétrica.

Conforme a necessidade da produção de energia, pode ser feita uma escolha do dispositivo, baseada no custo e eficiência deste. O circuito acoplado ao sensor piezelétrico é puramente resistivo, o que causa um pico de vibração acentuado na ressonância do dispositivo. Assim, é importante definir a frequência natural do dispositivo, a fim de que se tenha sua frequência em sintonização com a do sistema gerador de vibração, condição de maior geração energética. Além do mais, o projeto do dispositivo por meio de uma otimização é essencial, já que existe um máximo global para a função resposta em frequência em termos de potência gerada. Ainda, pelo motivo do pico de vibração com resistência elétrica ser acentuado, o que torna o dispositivo mais sensível a mudanças, uma análise de robustez é necessária e importante neste trabalho.

A viga cantilever é fixada em um engaste, que na prática permite analisar desejados comportamentos mecânicos. No entanto, para a investigação dinâmica da vibração e coleta de energia, a proposta é considerar o engastamento simulado por molas com incertezas, que podem existir no sistema de acoplamento da viga, e restringir o deslocamento horizontal. Dispositivos como o apresentado na figura 22 podem estar dispostos sobre bases excitantes e, por isso, a energia mecânica pode ser convertida em elétrica com a utilização de materiais piezelétricos nos mesmos. A base de fixação dos dispositivos pode conter massa desconhecida, portanto avaliar a entrada de deslocamento ou aceleração imposta é interessante desse ponto de vista.

O software comercial Matlab é utilizado juntamente com o algoritmo de otimiza- 
Figura 22 - Dispositivo prático utilizado em coleta de energia.

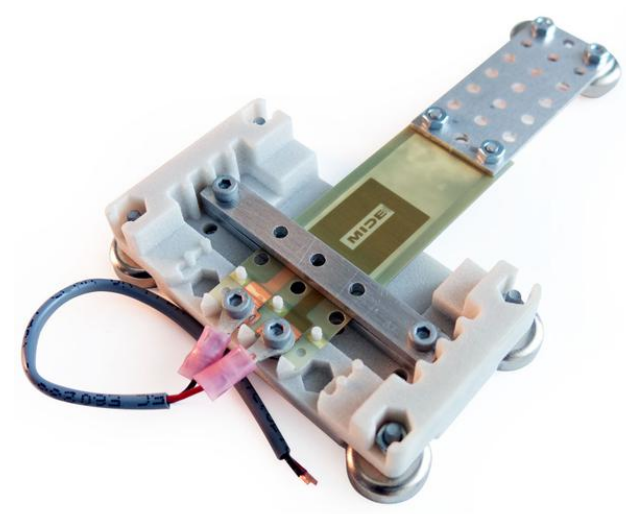

Fonte: Mide Technology (1989).

ção determinística SQP, prontamente existente no software, e a análise de robustez via matrizes ortogonais é programada integralmente. Além disso, a função de resposta em frequência para saída de potência é investigada por meio do dispositivo em elementos finitos, implementado computacionalmente em pacotes do Matlab em trabalho anterior (SANTOS, 2008). Assim, a FRF com as características particulares e dados prescritos para os dispositivos é implementada no software que contém os pacotes em elementos finitos já desenvolvidos.

\subsection{Análise paramétrica}

Para simplificação do procedimento da metodologia, o modelo da figura exposto no capítulo 2 é reapresentado neste capítulo.

Figura 23 - Modelo do dispositivo para coleta de energia.

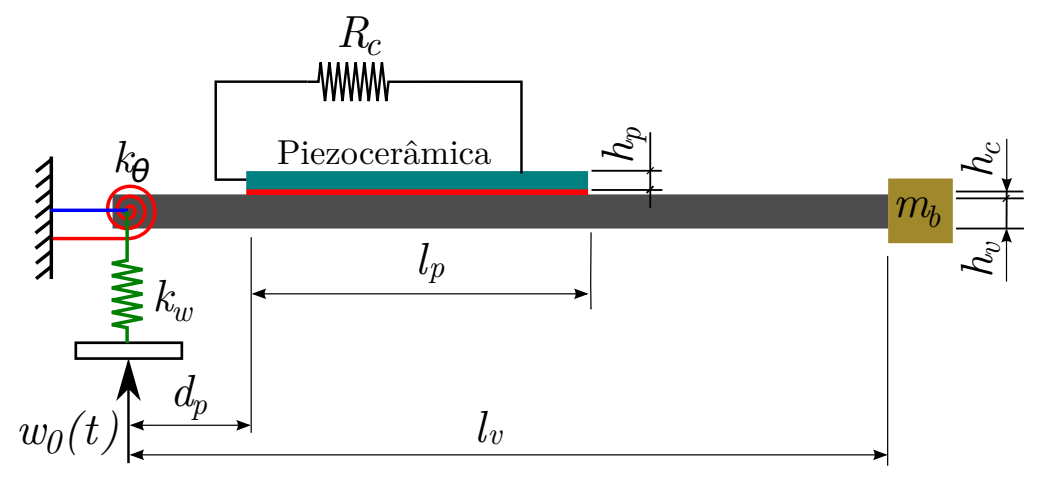

O procedimento para projeto do dispositivo consiste em realizar uma otimização 
determinística previamente, encontrando parâmetros de projeto que proporcionem uma amplitude máxima em termos de potência na frequência de operação da estrutura de fixação do dispositivo. Encontrando-se o dispositivo apropriado, valores de incertezas são embutidos no engaste, no amortecimento e na resistência elétrica. Para aplicar a técnica de otimização determinística e em seguida a análise de robustez, os valores das constantes de molas do engaste são encontrados previamente via uma análise paramétrica. A premissa imposta é de que os valores de molas não gerem variabilidade na resposta e, assim, permitam a condução da otimização satisfatoriamente. Dessa forma, um estudo preliminar para análise paramétrica, que verifica a saída de velocidade na extremidade que contém a massa sísmica $m_{b}$ através da FRF dada pela equação (2.53) do capítulo 2 é realizado em função dos valores das molas $k_{w}$ e $k_{\theta}$. A princípio considera-se a rotação restrita, sendo estudado o valor de rigidez linear para uma dada aceleração na base. Quando o valor de $k_{w}$ deixar de interferir na resposta da FRF, ou seja, a variabilidade for baixa, esse valor é utilizado para otimização determinística. Com o valor encontrado para $k_{w}$, a mola de torção $k_{\theta}$ no engaste é estudada, em uma segunda etapa, e quando o valor da FRF para saída de velocidade também se mostrar uniforme o valor de $k_{\theta}$ que provoque esse efeito é utilizado juntamente com a mola linear para o procedimento de otimização.

\subsection{Otimização do dispositivo}

No projeto do dispositivo, determinar quais são os parâmetros de projeto é importante para conduzir a otimização determinística. O algoritmo de Programação Quadrática Sequencial (SQP) é utilizado para obtenção de valores ótimos para o dispositivo no software comercial Matlab. Por outro lado, a técnica de análise de robustez via matrizes ortogonais é aplicada após otimização determinística, para investigação da influência das incertezas no desempenho final. Nesse caso, uma divisão entre parâmetros de controle e fatores de ruído torna-se necessária.

Os parâmetros de projeto podem ser determinados tendo por base o modelo representado na figura 23. Os seguintes parâmetros são predeterminados: distância da base até a camada piezelétrica $d_{p}$; espessura da viga $h_{v}$, da camada piezelétrica $h_{p}$ e da camada adesiva $h_{c}$. O comprimento do sensor piezelétrico $l_{p}$ é definido em função do comprimento da viga. Assim, um vetor de parâmetros de projeto $\mathbf{x}_{p}$ a ser encontrado pode ser representado como função do comprimento da viga $l_{v}$, da massa inercial $m_{b}$ e do resistor elétrico $R_{c}$, tal que $\mathbf{x}_{p}=\left[l_{v}, m_{b}, R_{c}\right]$. Uma análise de saída de potência é investigada tendo em vista a máxima geração de energia. Dessa maneira, o problema se reduz basicamente em maximizar a função de resposta em frequência para saída de potência representada pela 
equação abaixo :

$$
G_{P a}(\omega)=\left(1 / \omega^{4}\right) G_{P w}(\omega)
$$

Na otimização, os valores de incertezas no engaste e amortecimento não são considerados, sendo possível encontrar o valor de $\mathbf{x}_{p}$ com uma entrada de deslocamento na base do dispositivo. Assim, uma explanação do procedimento de otimização a ser implementado, considerando um vetor com os parâmetros de projeto e o exposto anteriormente, pode ser escrito da seguinte maneira: Encontrar $\mathbf{x}_{p}$ tal que,

$$
\begin{array}{cl}
\operatorname{maximize} & f\left(\mathbf{x}_{p}\right) \\
\text { sujeito a } & l_{v l} \leq l_{v} \leq l_{v u} \\
& m_{b l} \leq m_{b} \leq m_{b u}
\end{array}
$$

em que os subscritos com letra final $l$ e $u$ indicam as condições limites inferior e superior, respectivamente. A função $f\left(\mathbf{x}_{p}\right)$ representa a FRF para saída de potência da equação (4.1), sendo que maximizá-la implica em encontrar valores de pico de ressonância, ou seja, a frequência natural do dispositivo tende a se igualar com a frequência de operação da estrutura de fixação do mesmo.

O algoritmo SQP necessita de valores inicias para encontrar parâmetros ótimos que gerem mínimos/máximos de uma função estudada. No caso da FRF de saída de potência, considerando comprimento e massa sísmica, pode ocorrer de máximos locais serem encontrados, a depender do comprimento da viga. Por isso, em determinado intervalo de comprimento a intenção é encontrar o melhor projeto de viga, ou seja o comprimento que gere mais potência, com sua respectiva massa sísmica. Assim, em cada intervalo de comprimento e massa, representados no problema, uma divisão em determinados números de pontos, igualmente para o comprimento e a massa sísmica, é realizada. Após dividir o intervalo em determinados subintervalos, os pontos gerados de massa e comprimento são combinados entre si, correspondendo aos pontos iniciais utilizados no algoritmo SQP. Todas as combinações são utilizadas, permitindo assim obter um valor máximo de potência no intervalo de comprimento e garantir um dispositivo adequado nesse intervalo. Quanto a resistência elétrica, um valor inicial é utilizado para todas as combinações de massa sísmica e comprimento, sendo o algoritmo de otimização eficiente para encontrar o valor ótimo de resistência para cada comprimento de viga. Os parâmetros com o valor máximo da FRF são encontrados através deste processos e a tendência é que a frequência de ressonância do dispositivo se iguale com a de operação da estrutura de fixação. 


\subsection{Análise de Robustez}

Obtidos os dispositivos, o passo seguinte é fazer uma investigação sobre a robustez do sistema. Para esta análise, é necessário encontrar os parâmetros de controle e fatores de ruído corretamente. Para os dispositivos encontrados, é possível fazer uma divisão em número de experimentos para utilização de matrizes ortogonais e verificação de robustez. Assim, a inserção das incertezas nos fatores de ruído deve ser realizada, permitindo a verificação da variância e sensibilidade para a função estudada de saída de potência. Além do mais, uma verificação de interação entre os parâmetros é importante para garantir a precisão da resposta.

$\mathrm{Na}$ otimização do dispositivo, a frequência natural se assemelha a de operação introduzida pela base do sistema no engaste da viga, como consequência do valor ótimo ou máximo de potência disponível para conversão em energia. Nesse caso, para determinadas faixas de comprimentos de vigas, consegue-se projetos ótimos de dispositivos sintonizados. A otimização considerando a função potência permite encontrar um valor ótimo de resistência elétrica $R_{c}$ para determinado dispositivo, além de estar sintonizado. Sendo assim, para cada comprimento de viga $l_{v}$, uma massa sísmica $m_{b}$ e resistência $R_{c}$ são encontradas, sintonizando o dispositivo. Por isso, basta que a massa sísmica e resistência sejam tomados como parâmetros de controle, pois todos os outros parâmetros de projeto estarão vinculados, em função da sintonização do dispositivo. A massa símica, nesse caso, será representativa de um determinado dispositivo, exceto que a resistência elétrica pode mudar. Dessa maneira, tomando um vetor $\mathbf{x}$ para parâmetros de controle é possível escrevê-lo como:

$$
\mathbf{x}=\left[m_{b}, R_{c}\right]
$$

O desajuste do engaste pode influenciar na mudança da frequência natural dos dispositivos e, por consequência, na energia disponível para coleta. Além do mais, incertezas nos valores de rigidez do engaste e no amortecimento $\zeta$ do dispositivo também afetam o valor de energia disponível. Por isso, tais fatores são considerados como fatores de ruído na análise e possuem tolerância ou incertezas inerentes. Um vetor $\boldsymbol{z}$ para fatores de ruído pode ser escrito da seguinte maneira:

$$
\mathbf{z}=\left[k_{w}, k_{\theta}, \zeta\right]
$$

Na figura 24, está esquematizado um diagrama de blocos com as entradas de ruído e parâmetros de controle. No caso estudado de coleta de energia, a maximização da potência gerada pelo dispositivo ou dissipada na resistência elétrica é uma característica de interesse. Por isso, a função $\mathrm{g}=(\mathbf{x}, \mathbf{z})$ mede a potência que o dispositivo pode gerar em função da entrada de aceleração imposta. 
Figura 24 - Diagrama de bloco para o sistema.

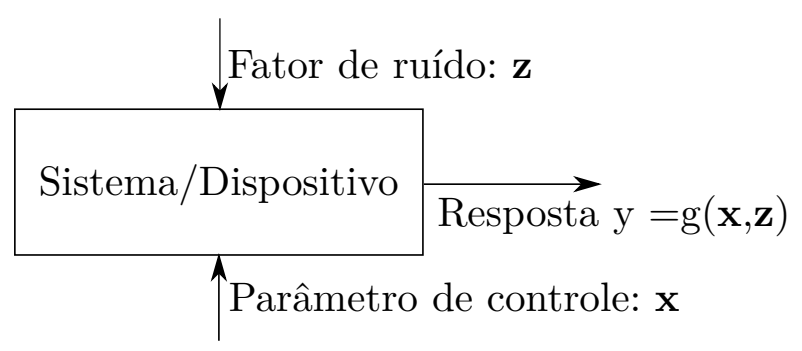

Na utilização da matriz para os fatores de ruído, uma definição do nível de tolerância para a rigidez linear, de torção e fator de amortecimento é importante para formação dos níveis que são inerentes à matriz ortogonal. Por isso, uma limitação de tolerância $(t)$ em três desvios padrão $(\sigma=t / 3)$ é imposta para os fatores de ruído, limitando os dados em intervalo de confiança adequado.

Os fatores são supostos com distribuição normal e uma matriz de dois níveis é escolhida. Assim, escolhendo um valor de tolerância para cada fator obtém-se os valores em cada nível. Se valores absolutos médios $k_{w}, k_{\theta}$ e $\zeta$ são supostos para os fatores de ruído, com as respectivas tolerâncias $t_{1}, t_{2}$ e $t_{3}$, então os níveis podem ser encontrado como mostrado na tabela 6.

Tabela 6 - Formação de níveis para fatores de ruído e resistência com tolerâncias

\begin{tabular}{|c|c|c|c|}
\hline média & tolerância & Nível 1 & Nível 2 \\
\hline$k_{w}$ & $t_{1} \%$ & $k_{w}\left(1-\frac{t_{1} \%}{3}\right)$ & $k_{w}\left(1+\frac{t_{1} \%}{3}\right)$ \\
\hline$k_{\theta}$ & $t_{2} \%$ & $k_{\theta}\left(1-\frac{t_{2} \%}{3}\right)$ & $k_{\theta}\left(1+\frac{t_{2} \%}{3}\right)$ \\
\hline$\zeta$ & $t_{3} \%$ & $\zeta\left(1-\frac{t_{3} \%}{3}\right)$ & $\zeta\left(1+\frac{t_{3} \%}{3}\right)$ \\
\hline$R_{c}$ & $t_{4} \%$ & $R_{c}\left(1-\frac{t_{4} \%}{3}\right)$ & $R_{c}\left(1+\frac{t_{4} \%}{3}\right)$ \\
\hline
\end{tabular}

A resistência é um parâmetro de projeto, no entanto, determinada tolerância é considerada para representar a incerteza inerente ao circuito para coleta de energia. Como apresentado para os ruídos, pode ser definido um limite de tolerância similar, ou seja, três desvios padrão e, então, calcula-se dois níveis, conforme tabela 6 com tolerância $t_{4}$ para o valor de resistência $R_{c}$.

Para se estudar determinada região de atuação de um fator de ruído, uma metodologia consiste em se encontrar o desvio absoluto e valor médio, obtendo, assim, a tolerância. Se o fator de ruído $k_{w}$, por exemplo, estiver em uma região limitada por valores inferior e superior dados pelas equações (4.5) e (4.6), respectivamente, o valor médio 
e desvio podem ser encontrados através das equações 4.7 e 4.8, respectivamente.

$$
k_{w}^{L}=k_{w}-\Delta k_{w}
$$

em que $k_{w}^{L}$ é o limite inferior para $k_{w}$ e $\Delta k_{w}$ o desvio.

$$
k_{w}^{U}=k_{w}+\Delta k_{w}
$$

em que $k_{w}^{L}$ é o limite inferior para $k_{w}$.

$$
\begin{gathered}
k_{w}=\frac{k_{w}^{L}+k_{w}^{U}}{2} \\
\Delta k_{w}=\frac{k_{w}^{U}-k_{w}^{L}}{2}
\end{gathered}
$$

A relação entre o desvio absoluto e o valor médio do fator anterior permite encontrar a tolerância e, assim, os níveis 1 e 2, conforme tabela 6 . O mesmo raciocínio pode ser aplicado para os outros fatores, com vista a se encontrar os valores médios e desvios em relação às condições de contorno superior e inferior, se um estudo de determinadas regiões de atuação dos fatores for empregado. Com os valores de ruído e parâmetros de controle com tolerância, existe uma necessidade de implementá-los em matrizes de ruído. Assim, os níveis 1 e 2 da tabela 6 podem compor uma matriz de ruído e, como, há quatro fatores com dois níveis, cinco graus de liberdade são encontrados, considerando a média. Por isso uma matriz do tipo $L_{8}\left(2^{7}\right)$ pode ser utilizada para conter os parâmetros. Como a matriz $L_{8}\left(2^{7}\right)$ possui mais de quatro colunas, algumas podem ser desconsideradas. Assim, os parâmetros podem ser alocados na matriz conforme representação na tabela 7 , padronizada com 8 experimentos para o calculo de média, variância e sensibilidade.

Tabela 7 - Matriz ortogonal $L_{8}\left(2^{7}\right)$ para fatores de ruído e resistência

\begin{tabular}{|c|ccccccc|}
\hline Exp. & $R_{c}$ & $k_{w}$ & $k_{\theta}$ & $\zeta$ & $\mathrm{c} 5$ & $\mathrm{c} 6$ & $\mathrm{c7}$ \\
\hline 1 & 1 & 1 & 1 & 1 & 1 & 1 & 1 \\
2 & 1 & 1 & 1 & 2 & 2 & 2 & 2 \\
3 & 1 & 2 & 2 & 1 & 1 & 2 & 2 \\
4 & 1 & 2 & 2 & 2 & 2 & 1 & 1 \\
\hline 5 & 2 & 1 & 2 & 1 & 2 & 1 & 2 \\
6 & 2 & 1 & 2 & 2 & 1 & 2 & 1 \\
7 & 2 & 2 & 1 & 1 & 2 & 2 & 1 \\
8 & 2 & 2 & 1 & 2 & 1 & 1 & 2 \\
\hline
\end{tabular}

As colunas na tabela 7 são representadas pelo índice $c$, sendo que os fatores podem ser alocados aleatoriamente em algumas das colunas, pelo fato da matriz ser balanceada. 
No caso, os parâmetros foram alocados nas quatro primeiras colunas, como pode ser visto na tabela 7, em que as colunas nomeadas por c5, c6 e c7 não serão utilizadas.

Os parâmetros de controle $m_{b}$ e $R_{c}$ compõem uma matriz dependendo do número de experimentos computados. No presente projeto, a quantidade de dispositivos estudados pode referenciar o número de experimentos. Sendo assim, uma matriz de controle que contenha uma quantidade de níveis suficiente para alocar os dispositivos analisados deve ser encontrada ou, então, uma matriz com menos níveis deve ser modificada para satisfazer o requerimento dos projetos. Se cinco dispositivos são encontrados pela otimização, por exemplo, uma matriz $L_{50}\left(2^{1} \times 5^{11}\right)$ pode ser utilizada e os parâmetros irão compor uma das colunas que contenha cinco níveis. Na tabela 8 , está a representação da matriz $L_{50}\left(2^{1} \times 5^{11}\right)$ com a primeira coluna com dois níveis e o restante com cinco. Para esse tipo de matriz a primeira e segunda coluna são associadas para formar uma nova coluna com dez níveis; isso possibilita estudar dez tipos diferentes de resistências elétricas. O gráfico linear, referente a matriz $L_{50}\left(2^{1} \times 5^{11}\right)$, dado pela figura 25 expressa a possibilidade de união da primeira com a segunda coluna, enquanto as outras colunas são mantidas inalteradas (representação dada pelos pontos negros sem linhas de interligação). Assim, na tabela 8, também está a associação entre a primeira e segunda coluna (c1 x c2) com os dez níveis formados. Utilizando a nova coluna formada para a resistência elétrica e a coluna c3 da tabela 8 para a massa, pode-se associar a matriz de fatores de ruído com a de parâmetros de controle para obter os valores de média, variância e sensibilidade, conforme representado na tabela 9 .

Figura 25 - Gráfico linear para matriz ortogonal do tipo $L_{50}\left(2^{1} \times 5^{11}\right)$.

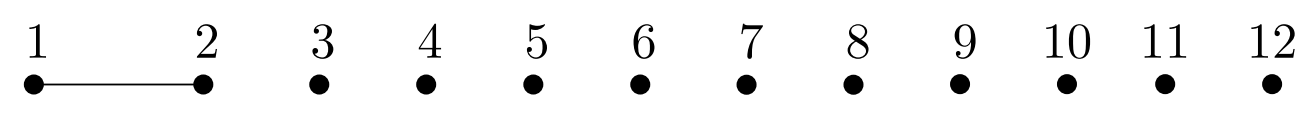

Fonte: Baseado em Phadke (1995).

O valor de sensibilidade $S / N$ encontrado através do procedimento representado na tabela 9 pode se referir tanto a escolha de problemas do tipo NB (nominal-the-best) ou ST (signed-target). Após otimizar cada dispositivo, a maior energia possível é adquirida, sendo que com a alteração da resistência, uma análise de robustez pode ser verificada. Assim, cada dispositivo tem uma variância particular, a depender dos fatores de ruído e resistência elétrica, o que implica em ser suficiente analisar o problema do tipo ST, proporcionando uma análise de sensibilidade referente a variância. Como os dispositivos estão sintonizados, escolhas de resistências próximas ao valor otimizados é interessante para não ocorrer grande perda de potência e, assim, ser possível verificar a robustez.

Após encontrar os valores de média, variância, e sensibilidade uma análise estatística é conduzida. O valor da potência disponível, que tem relação com a média da resposta 
é verificado, sendo interessante altos valores. Quanto a robustez, a análise é feita através de gráficos de efeitos, que contém os valores de sensibilidade $S / N$ para os parâmetros $m_{b}$ e $R_{c}$, sendo interessante altos valores de sensibilidade. Concluída toda análise de robustez e geração de energia, é realizada uma verificação de interação entre os fatores em 3 níveis. Nesse caso, uma matriz ortogonais com três experimentos do tipo $L_{9}\left(3^{4}\right)$ é suficiente para análise.

Com os valores de média e variância encontrados pela utilização das matrizes de controle e ruído, exemplificada na tabela 9, são averiguados quais combinações entre resistência e dispositivos permitem um projeto mais robusto. Além disso, os dispositivos são comparados entre si para verificar a maior geração de potência diante da variabilidade, podendo, dessa forma, escolher um dispositivo adequado para a aplicação em coleta de energia. 
Tabela 8 - Matriz $L_{50}\left(2^{1} \times 5^{11}\right)$ para parâmetros de controle

\begin{tabular}{|c|c|c|c|c|c|c|c|c|c|c|c|c|c|}
\hline Exp. & c1 & c2 & c3 & c4 & $\mathrm{c} 5$ & c6 & c7 & $\mathrm{c} 8$ & c9 & c10 & c11 & c12 & $\mathrm{c} 1 \times \mathrm{c} 2$ \\
\hline 1 & $\overline{c 1}$ & $\overline{c 1}$ & $\overline{c 1}$ & $\overline{c 1}$ & $\overline{c 1}$ & $\overline{c 1}$ & $\overline{c 1}$ & 1 & 1 & 1 & 1 & 1 & 1 \\
\hline 2 & 1 & 1 & 2 & 2 & 2 & 2 & 2 & 2 & 2 & 2 & 2 & 2 & 1 \\
\hline 3 & 1 & 1 & 3 & 3 & 3 & 3 & 3 & 3 & 3 & 3 & 3 & 3 & 1 \\
\hline 4 & 1 & 1 & 4 & 4 & 4 & 4 & 4 & 4 & 4 & 4 & 4 & 4 & 1 \\
\hline 5 & 1 & 1 & 5 & 5 & 5 & 5 & 5 & 5 & 5 & 5 & 5 & 5 & 1 \\
\hline 6 & 1 & 2 & 1 & 2 & 3 & 4 & 5 & 1 & 2 & 3 & 4 & 5 & 2 \\
\hline 7 & 1 & 2 & 2 & 3 & 4 & 5 & 1 & 2 & 3 & 4 & 5 & 1 & 2 \\
\hline 8 & 1 & 2 & 3 & 4 & 5 & 1 & 2 & 3 & 4 & 5 & 1 & 2 & 2 \\
\hline 9 & 1 & 2 & 4 & 5 & 1 & 2 & 3 & 4 & 5 & 1 & 2 & 3 & 2 \\
\hline 10 & 1 & 2 & 5 & 1 & 2 & 3 & 4 & 5 & 1 & 2 & 3 & 4 & 2 \\
\hline 11 & 1 & 3 & 1 & 3 & 5 & 2 & 4 & 4 & 1 & 3 & 5 & 2 & 3 \\
\hline 12 & 1 & 3 & 2 & 4 & 1 & 3 & 5 & 5 & 2 & 4 & 1 & 3 & 3 \\
\hline 13 & 1 & 3 & 3 & 5 & 2 & 4 & 1 & 1 & 3 & 5 & 2 & 4 & 3 \\
\hline 14 & 1 & 3 & 4 & 1 & 3 & 5 & 2 & 2 & 4 & 1 & 3 & 5 & 3 \\
\hline 15 & 1 & 3 & 5 & 2 & 4 & 1 & 3 & 3 & 5 & 2 & 4 & 1 & 3 \\
\hline 16 & 1 & 4 & 1 & 4 & 2 & 5 & 3 & 5 & 3 & 1 & 4 & 2 & 4 \\
\hline 17 & 1 & 4 & 2 & 5 & 3 & 1 & 4 & 1 & 4 & 2 & 5 & 3 & 4 \\
\hline 18 & 1 & 4 & 3 & 1 & 4 & 2 & 5 & 2 & 5 & 3 & 1 & 4 & 4 \\
\hline 19 & 1 & 4 & 4 & 2 & 5 & 3 & 1 & 3 & 1 & 4 & 2 & 5 & 4 \\
\hline 20 & 1 & 4 & 5 & 3 & 1 & 4 & 2 & 4 & 2 & 5 & 3 & 1 & 4 \\
\hline 21 & 1 & 5 & 1 & 5 & 4 & 3 & 2 & 4 & 3 & 2 & 1 & 5 & 5 \\
\hline 22 & 1 & 5 & 2 & 1 & 5 & 4 & 3 & 5 & 4 & 3 & 2 & 1 & 5 \\
\hline 23 & 1 & 5 & 3 & 2 & 1 & 5 & 4 & 1 & 5 & 4 & 3 & 2 & 5 \\
\hline 24 & 1 & 5 & 4 & 3 & 2 & 1 & 5 & 2 & 1 & 5 & 4 & 3 & 5 \\
\hline 25 & 1 & 5 & 5 & 4 & 3 & 2 & 1 & 3 & 2 & 1 & 5 & 4 & 5 \\
\hline 26 & 2 & 1 & 1 & 1 & 4 & 5 & 4 & 3 & 2 & 5 & 2 & 3 & 6 \\
\hline 27 & 2 & 1 & 2 & 2 & 5 & 1 & 5 & 4 & 3 & 1 & 3 & 4 & 6 \\
\hline 28 & 2 & 1 & 3 & 3 & 1 & 2 & 1 & 5 & 4 & 2 & 4 & 5 & 6 \\
\hline 29 & 2 & 1 & 4 & 4 & 2 & 3 & 2 & 1 & 5 & 3 & 5 & 1 & 6 \\
\hline 30 & 2 & 1 & 5 & 5 & 3 & 4 & 3 & 2 & 1 & 4 & 1 & 2 & 6 \\
\hline 31 & 2 & 2 & 1 & 2 & 1 & 3 & 3 & 2 & 4 & 5 & 5 & 4 & 7 \\
\hline 32 & 2 & 2 & 2 & 3 & 2 & 4 & 4 & 3 & 5 & 1 & 1 & 5 & 7 \\
\hline 33 & 2 & 2 & 3 & 4 & 3 & 5 & 5 & 4 & 1 & 2 & 2 & 1 & 7 \\
\hline 34 & 2 & 2 & 4 & 5 & 4 & 1 & 1 & 5 & 2 & 3 & 3 & 2 & 7 \\
\hline 35 & 2 & 2 & 5 & 1 & 5 & 2 & 2 & 1 & 3 & 4 & 4 & 3 & 7 \\
\hline 36 & 2 & 3 & 1 & 3 & 3 & 1 & 2 & 5 & 5 & 4 & 2 & 4 & 8 \\
\hline 37 & 2 & 3 & 2 & 4 & 4 & 2 & 3 & 1 & 1 & 5 & 3 & 5 & 8 \\
\hline 38 & 2 & 3 & 3 & 5 & 5 & 3 & 4 & 2 & 2 & 1 & 4 & 1 & 8 \\
\hline 39 & 2 & 3 & 4 & 1 & 1 & 4 & 5 & 3 & 3 & 2 & 5 & 2 & 8 \\
\hline 40 & 2 & 3 & 5 & 2 & 2 & 5 & 1 & 4 & 4 & 3 & 1 & 3 & 8 \\
\hline 41 & 2 & 4 & 1 & 4 & 5 & 4 & 1 & 2 & 5 & 2 & 3 & 3 & 9 \\
\hline 42 & 2 & 4 & 2 & 5 & 1 & 5 & 2 & 3 & 1 & 3 & 4 & 4 & 9 \\
\hline 43 & 2 & 4 & 3 & 1 & 2 & 1 & 3 & 4 & 2 & 4 & 5 & 5 & 9 \\
\hline 44 & 2 & 4 & 4 & 2 & 3 & 2 & 4 & 5 & 3 & 5 & 1 & 1 & 9 \\
\hline 45 & 2 & 4 & 5 & 3 & 4 & 3 & 5 & 1 & 4 & 1 & 2 & 2 & 9 \\
\hline 46 & 2 & 5 & 1 & 5 & 2 & 2 & 5 & 3 & 4 & 4 & 3 & 1 & 10 \\
\hline 47 & 2 & 5 & 2 & 1 & 3 & 3 & 1 & 4 & 5 & 5 & 4 & 2 & 10 \\
\hline 48 & 2 & 5 & 3 & 2 & 4 & 4 & 2 & 5 & 1 & 1 & 5 & 3 & 10 \\
\hline 49 & 2 & 5 & 4 & 3 & 5 & 5 & 3 & 1 & 2 & 2 & 1 & 4 & 10 \\
\hline 50 & 2 & 5 & 5 & 4 & 1 & 1 & 4 & 2 & 3 & 3 & 2 & 5 & 10 \\
\hline
\end{tabular}


Tabela 9 - Matrizes de controle associada com matriz de ruído

\begin{tabular}{|c|c|c|c|c|c|c|c|c|c|c|c|c|c|}
\hline & Exp. & 1 & 2 & 3 & 4 & 5 & 6 & 7 & 8 & \multirow[b]{7}{*}{$\mapsto \mu_{1}$} & \multirow[b]{7}{*}{$\sigma_{1}^{2}$} & \multirow[b]{7}{*}{$S / N_{1}$} \\
\hline & & $k_{w}$ & 1 & 1 & 1 & 1 & 2 & 2 & 2 & 2 & & & \\
\hline & & $k_{\theta}$ & 1 & 1 & 2 & 2 & 1 & 1 & 2 & 2 & & & \\
\hline & & $\zeta$ & 1 & 2 & 1 & 2 & 2 & 1 & 2 & 1 & & & \\
\hline & & $R_{c}$ & 1 & 2 & 2 & 1 & 2 & 1 & 1 & 2 & & & \\
\hline Exp. & $R_{c}$ & $m_{b}$ & 1 & 2 & 3 & 4 & 5 & 6 & 7 & 8 & & & \\
\hline 1 & 1 & 1 & $y_{11}$ & $y_{12}$ & $y_{13}$ & $y_{14}$ & $y_{15}$ & $y_{16}$ & $y_{17}$ & $y_{18}$ & & & \\
\hline 2 & 1 & 2 & $y_{21}$ & $y_{22}$ & $y_{23}$ & $y_{24}$ & $y_{25}$ & $y_{26}$ & $y_{27}$ & $y_{28}$ & $\mapsto \mu_{2}$ & $\sigma_{2}^{2}$ & $S / N_{2}$ \\
\hline 3 & 1 & 3 & $y_{31}$ & $y_{32}$ & $y_{33}$ & $y_{34}$ & $y_{35}$ & $y_{36}$ & $y_{37}$ & $y_{38}$ & $\mapsto \mu_{3}$ & $\sigma_{3}^{2}$ & $S / N_{3}$ \\
\hline 4 & 1 & 4 & $y_{41}$ & $y_{42}$ & $y_{43}$ & $y_{44}$ & $y_{45}$ & $y_{46}$ & $y_{47}$ & $y_{48}$ & $\mapsto \mu_{4}$ & $\sigma_{4}^{2}$ & $S / N_{4}$ \\
\hline 5 & 1 & 5 & $y_{51}$ & $y_{52}$ & $y_{53}$ & $y_{54}$ & $y_{45}$ & $y_{46}$ & $y_{57}$ & $y_{58}$ & $\mapsto \mu_{5}$ & $\sigma_{5}^{2}$ & $S / N_{5}$ \\
\hline 6 & 2 & 1 & $y_{61}$ & $y_{62}$ & $y_{63}$ & $y_{64}$ & $y_{65}$ & $y_{66}$ & $y_{67}$ & $y_{68}$ & $\mapsto \mu_{6}$ & $\sigma_{6}^{2}$ & $S / N_{6}$ \\
\hline 7 & 2 & 2 & $y_{71}$ & $y_{72}$ & $y_{73}$ & $y_{74}$ & $y_{75}$ & $y_{76}$ & $y_{77}$ & $y_{78}$ & $\mapsto \mu_{7}$ & $\sigma_{7}^{2}$ & $S / N_{7}$ \\
\hline 8 & 2 & 3 & $y_{81}$ & $y_{82}$ & $y_{83}$ & $y_{84}$ & $y_{85}$ & $y_{86}$ & $y_{87}$ & $y_{88}$ & $\mapsto \mu_{8}$ & $\sigma_{8}^{2}$ & $S / N_{8}$ \\
\hline 9 & 2 & 4 & $y_{91}$ & $y_{92}$ & $y_{93}$ & $y_{94}$ & $y_{95}$ & $y_{96}$ & $y_{97}$ & $y_{98}$ & $\mapsto \mu_{9}$ & $\sigma_{9}^{2}$ & $S / N_{9}$ \\
\hline 10 & 2 & 5 & $y_{101}$ & $y_{102}$ & $y_{103}$ & $y_{104}$ & $y_{105}$ & $y_{106}$ & $y_{107}$ & $y_{108}$ & $\mapsto \mu_{9}$ & $\sigma_{9}^{2}$ & $S / N_{9}$ \\
\hline 11 & 3 & 1 & $y_{111}$ & $y_{112}$ & $y_{113}$ & $y_{114}$ & $y_{115}$ & $y_{116}$ & $y_{117}$ & $y_{118}$ & $\mapsto \mu_{11}$ & $\sigma_{11}^{2}$ & $S / N_{11}$ \\
\hline 12 & 3 & 2 & $y_{121}$ & $y_{122}$ & $y_{123}$ & $y_{124}$ & $y_{125}$ & $y_{126}$ & $y_{127}$ & $y_{128}$ & $\mapsto \mu_{12}$ & $\sigma_{12}^{2}$ & $S / N_{12}$ \\
\hline 13 & 3 & 3 & $y_{131}$ & $y_{132}$ & $y_{133}$ & $y_{134}$ & $y_{135}$ & $y_{136}$ & $y_{137}$ & $y_{138}$ & $\mapsto \mu_{13}$ & $\sigma_{13}^{2}$ & $S / N_{13}$ \\
\hline 14 & 3 & 4 & $y_{141}$ & $y_{142}$ & $y_{143}$ & $y_{144}$ & $y_{145}$ & $y_{146}$ & $y_{147}$ & $y_{148}$ & $\mapsto \mu_{14}$ & $\sigma_{14}^{2}$ & $S / N_{14}$ \\
\hline 15 & 3 & 5 & $y_{151}$ & $y_{152}$ & $y_{153}$ & $y_{154}$ & $y_{145}$ & $y_{146}$ & $y_{157}$ & $y_{158}$ & $\mapsto \mu_{15}$ & $\sigma_{15}^{2}$ & $S / N_{15}$ \\
\hline$\vdots$ & $\vdots$ & $\vdots$ & $\vdots$ & $\vdots$ & $\vdots$ & $\vdots$ & $\vdots$ & $\vdots$ & $\vdots$ & $\vdots$ & $\vdots$ & $\vdots$ & $\vdots$ \\
\hline 46 & 10 & 1 & $y_{461}$ & $y_{462}$ & $y_{463}$ & $y_{464}$ & $y_{465}$ & $y_{466}$ & $y_{467}$ & $y_{468}$ & $\mapsto \mu_{46}$ & $\sigma_{46}^{2}$ & $S / N_{46}$ \\
\hline 47 & 10 & 2 & $y_{471}$ & $y_{472}$ & $y_{473}$ & $y_{474}$ & $y_{475}$ & $y_{476}$ & $y_{477}$ & $y_{478}$ & $\mapsto \mu_{47}$ & $\sigma_{47}^{2}$ & $S / N_{47}$ \\
\hline 48 & 10 & 3 & $y_{481}$ & $y_{482}$ & $y_{483}$ & $y_{484}$ & $y_{485}$ & $y_{486}$ & $y_{487}$ & $y_{488}$ & $\mapsto \mu_{48}$ & $\sigma_{48}^{2}$ & $S / N_{48}$ \\
\hline 49 & 10 & 4 & $y_{491}$ & $y_{492}$ & $y_{493}$ & $y_{494}$ & $y_{495}$ & $y_{496}$ & $y_{497}$ & $y_{498}$ & $\mapsto \mu_{49}$ & $\sigma_{49}^{2}$ & $S / N_{49}$ \\
\hline 50 & 10 & 5 & $y_{501}$ & $y_{502}$ & $y_{503}$ & $y_{504}$ & $y_{505}$ & $y_{506}$ & $y_{507}$ & $y_{508}$ & $\mapsto \mu_{50}$ & $\sigma_{50}^{2}$ & $S / N_{50}$ \\
\hline
\end{tabular}





\section{Resultados}

Para o projeto de dispositivos adequados para coleta de energia, o modelo em elementos finitos de viga apresentado no capítulo 2 foi utilizado, sendo o dispositivo estruturado para condições de incertezas inerentes no projeto. Os dispositivos são otimizados deterministicamente para máxima captação de energia, considerando o algoritmo de otimização SQP no software comercial Matlab. No entanto, previamente um estudo paramétrico para os valores admissíveis de rigidez elástica $k_{w}$ e $k_{\theta}$ foi conduzido, sendo os valores encontrados utilizados para a otimização. Uma análise de robustez foi implementada através da utilização de matrizes ortogonais e, por meio de análise de variância (ANOVA) foi realizada uma verificação estatística. O valor absoluto da sensibilidade de cada dispositivo foi comparado para garantia de menor variabilidade e maior robustez dos projetos. O estudo da monotonicidade ou aditividade dos parâmetros foi verificada juntamente com a aplicação do método de robustez. Com as análises realizadas e procedimentos de dimensionamento dos dispositivos, uma comparação em termos de potência gerada e robustez foi realizada diante das condições de incertezas.

Os resultados encontrados são referentes a um conjunto de cinco dispositivos dinâmicos para coleta de energia com dimensionamento adequado, considerando maximização de potência e robustez diante das incertezas de engastamento, amortecimento e tolerância de resistência elétrica. A entrada imposta é de deslocamento, embora a função de resposta em frequência (FRF) para potência seja medida em termos de entrada de aceleração ao quadrado, uma vez que esta é uma medida de referência em muitas situações de coleta de energia (ZHOU et al., 2012; YAN et al., 2017).

\subsection{Análise paramétrica de rigidez do engaste}

A rigidez das molas linear e de torção pode ser uma causa de variação da resposta, quando não se tem certeza do ajuste adequado do dispositivo na fixação do engaste. A partir de certos valores de rigidez, a resposta passa a ser pouco influenciada e, neste caso, esses valores são utilizados para a otimização determinística do dispositivo. Em um primeiro momento, o grau de liberdade referente à rigidez torcional do engaste é restringido para estudo unidimensional de $k_{w}$, permitindo verificar a variabilidade da resposta do dispositivo frente a rigidez linear. A resposta é analisada para o primeiro modo de vibração e como, nesta etapa, o interesse é a análise da variação da resposta, uma entrada $w_{0}$ harmônica de $100 \mathrm{~Hz}$ na base do dispositivo é imposta e verifica-se a mobilidade na extremidade da viga. Assim, dois casos são estudados: uma viga de $50 \mathrm{~mm}$ de comprimento e outra de $75 \mathrm{~mm}$. Nestes casos, o circuito elétrico é considerado aberto 
e sem massa sísmica, ou seja, o dispositivo está dessintonizado e o estudo da resistência elétrica não é realizado. Como não se conhece, previamente, o valor da massa sísmica, para um determinado comprimento de viga do dispositivo, que sintoniza a frequência deste com a frequência de excitação, a análise paramétrica é realizada desconsiderando a presença da massa sísmica. Com a otimização determinística se encontra o valor de massa, porém é necessário encontrar os valores de rigidez do engaste antecipadamente nesta análise paramétrica.

Para averiguação da resposta do dispositivo frente à entrada imposta, algumas considerações são previamente realizadas. Inicialmente, o modelo estudado é em elementos finitos conforme apresentado no capítulo 2. As seguintes propriedades geométricas são definidas: distância da camada piezelétrica até o engaste $d_{p}=5 \mathrm{~mm}$; largura da viga e camada piezelétrica com resina $b=25 \mathrm{~mm}$; espessuras da viga, camada piezelétrica e resina de $h_{v}=1,0 \mathrm{~mm}, h_{p}=0,25 \mathrm{~mm}$ e $h_{c}=0,1 \mathrm{~mm}$, respectivamente; camada piezelétrica com $80 \%$ do comprimento da viga $\left(h_{p}=0,8 h_{v}\right)$. As propriedades da viga, que é de alumínio são: densidade de $2790 \mathrm{~kg} / \mathrm{m}^{3}$ e módulo de elasticidade de 69 GPa. Para a Resina Epoxy são considerados os valores de densidade de $1126 \mathrm{~kg} / \mathrm{m}^{3}$ e módulo de elasticidade 2.5 GPa (SANTOS, 2012). O sensor piezelétrico é do tipo Titanato Zirconato de Chumbo (PIC-151) com densidade de $7800 \mathrm{~kg} / \mathrm{m}^{3}$, constante elástica $\bar{c}_{11}^{D}=101,24 \mathrm{GPa}$, constante de acoplamento piezelétrico $\bar{h}_{31}=-1,4862 \times 10^{9} \mathrm{NC}^{-1}$, constante dielétrica de $\bar{\beta}_{33}^{\epsilon}=76,435 \times 10^{6} \mathrm{mF}^{-1}$ e fator de correção de cisalhamento $k_{2}=0,83$. Além disso, um fator de amortecimento global com $\zeta=0,3 \%$ é utilizado para o dispositivo. Com as propriedades descritas, um modelo em elementos finitos é gerado conforme figura 26, considerando a viga com $50 \mathrm{~mm}$ de comprimento. A camada azul superior na figura 26 representa o elemento piezelétrico, enquanto a camada verde, a viga de alumínio, sendo que uma fina camada de cola existe entre estes elementos. Para outros comprimentos, o mesmo estudo em elementos finitos é conduzido com diferentes números de elementos.

Figura 26 - Viga em elementos finitos de $50 \mathrm{~mm}$ de comprimento.

A variação da resposta é possível de ser verificada pelo estudo de saída de velocidade no primeiro modo de vibração em função da variação do valor de $k_{w}$. Considerando uma aceleração $\ddot{\tilde{w}}_{0}=g=10 \mathrm{~m} / \mathrm{s}^{2}$ e a frequência de operação de $100 \mathrm{~Hz}$ na entrada da base do dispositivo, a resposta é plotada segundo figura 27 para o primeiro caso, ou seja, viga de $50 \mathrm{~mm}$ de comprimento.

Os gráficos da figura 27 possuem abscissas de rigidez linear em diferentes valores. No gráfico à esquerda, $k_{w}$ varia de 0 a $50 \mathrm{kN} / \mathrm{m}$, enquanto que no gráfico à direita, o valor 
Figura 27 - Resposta para primeiro modo de vibração em função da rigidez linear para viga de $50 \mathrm{~mm}$.

(a) Limites 0 e $50 \mathrm{kN} / \mathrm{m}$.

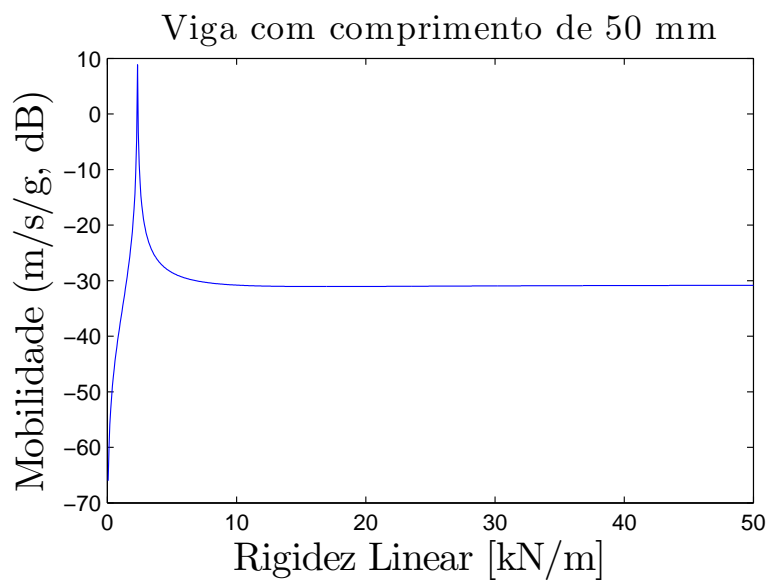

(b) Limites 50 e $18000 \mathrm{kN} / \mathrm{m}$.

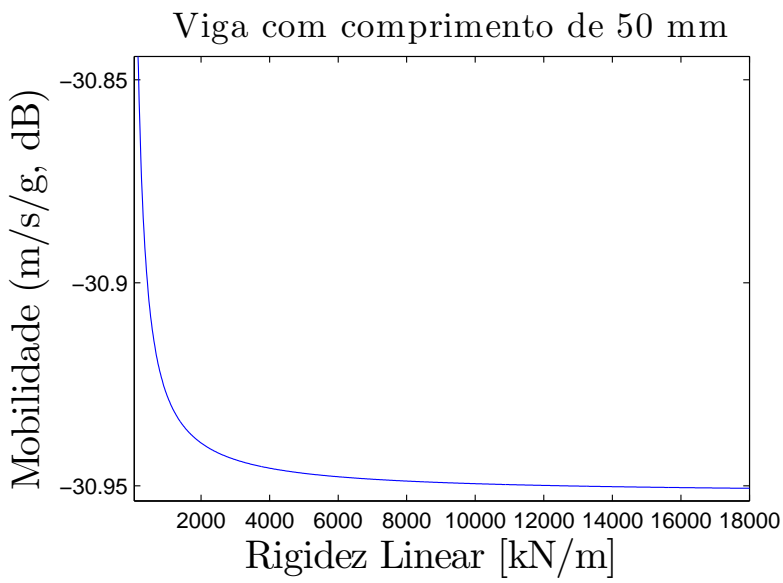

é de $50 \mathrm{kN} / \mathrm{m}$ a $18000 \mathrm{kN} / \mathrm{m}$. A partir de valores próximos a $18000 \mathrm{kN} / \mathrm{m}$, a resposta da ordenada varia muito pouco para o caso da viga de $50 \mathrm{~mm}$. Entre 0 e $10 \mathrm{kN} / \mathrm{m}$ existe um pico de ressonância, referente ao valor de $k_{w}$ em que o dispositivo entra em ressonância com a frequência de operação de $100 \mathrm{~Hz}$.

Como entre 15000 e $18000 \mathrm{kN} / \mathrm{m}$, a resposta do dispositivo tende a ficar constante, o valor de $15000 \mathrm{kN} / \mathrm{m}$ é utilizado para análise da resposta frente a uma variação de rigidez torcional. Com isso, o grau de liberdade referente a rotação é considerado irrestrito, nesta etapa, para esse propósito. Nas mesmas condições, a figura 28 representa a resposta de saída de velocidade na extremidade da viga para valores de rigidez da mola $k_{\theta}$.

Figura 28 - Resposta para primeiro modo de vibração em função da rigidez torcional para viga de $50 \mathrm{~mm}$.

(a) Limites 0 e $10 \mathrm{Nm} / \mathrm{rad}$.

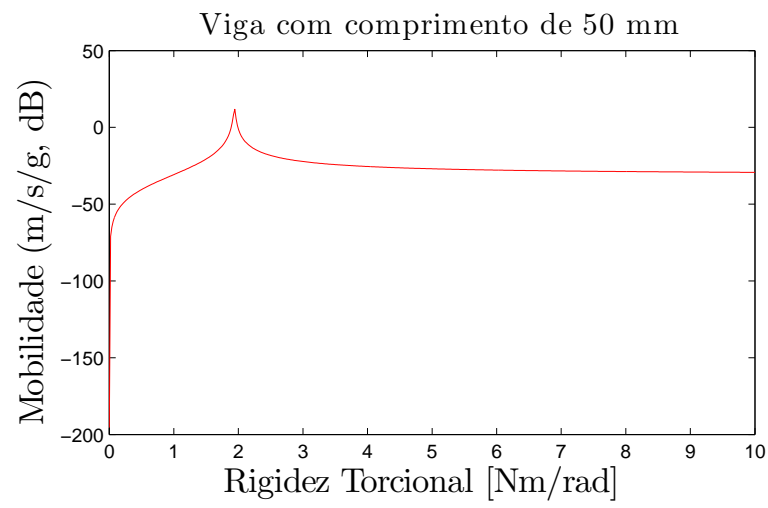

(b) Limites 10 e $1000 \mathrm{Nm} / \mathrm{rad}$.

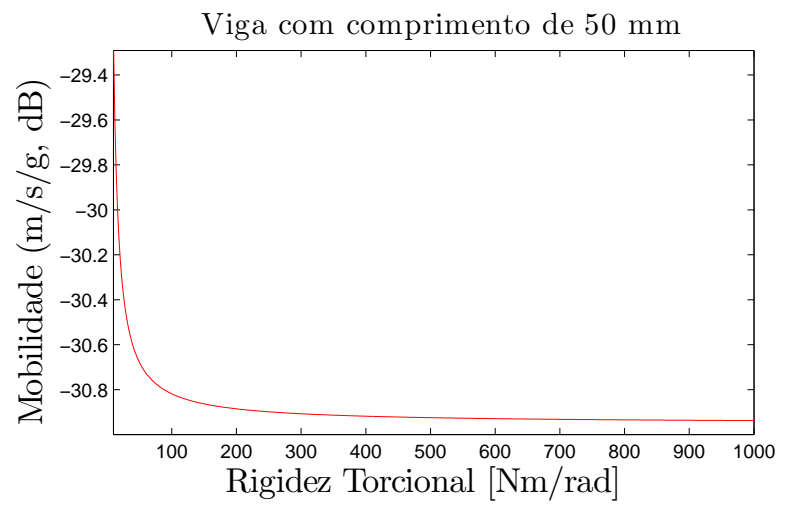

$\mathrm{Na}$ figura 28, a abscissa representa valores de rigidez entre 0 e $10 \mathrm{Nm} / \mathrm{rad}$ para o gráfico à esquerda e entre 10 e $1000 \mathrm{Nm} / \mathrm{rad}$ para o gráfico a direita. Com valores entre 800 e $1000 \mathrm{Nm} / \mathrm{rad}$, a resposta da ordenada tem uma variabilidade muito baixa, enquanto 
que em $2 \mathrm{Nm} / \mathrm{rad}$ o dispositivo entra em ressonância com a frequência de operação de $100 \mathrm{~Hz}$.

Levando em consideração as mesmas condições descritas anteriormente, exceto que o comprimento da viga seja $75 \mathrm{~mm}$, pode-se plotar os gráficos conforme figura 29 para analise dos valores de $k_{w}$, sendo o grau de liberdade referente a rotação no engaste restrito.

Figura 29 - Resposta para primeiro modo de vibração em função da rigidez linear para viga de $75 \mathrm{~mm}$.

(a) Limites 0 e $50 \mathrm{kN} / \mathrm{m}$.

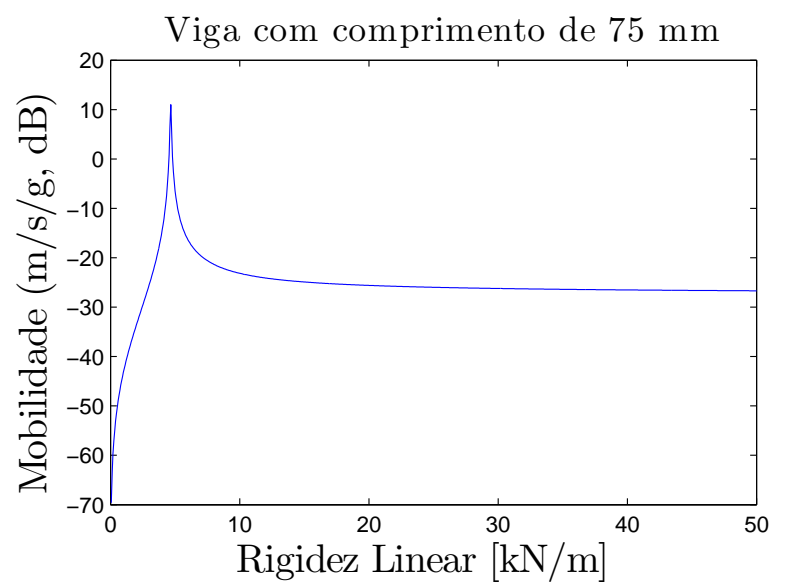

(b) Limites 50 e $18000 \mathrm{kN} / \mathrm{m}$.

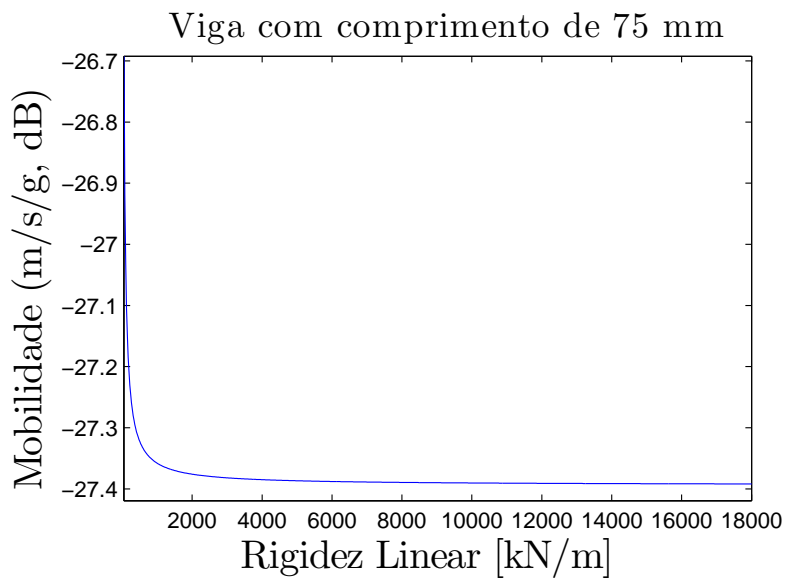

A mesma análise é elaborada em relação à viga de $75 \mathrm{~mm}$, sendo que o gráfico à esquerda da figura 29 varia de 0 a $50 \mathrm{kN} / \mathrm{m}$, com um pico de ressonância entre 0 e $10 \mathrm{kN} / \mathrm{m}$ e mantém-se praticamente constante entre 10000 e $18000 \mathrm{kN} / \mathrm{m}$, no gráfico à direita, que tem abscissa entre 50 e $18000 \mathrm{kN} / \mathrm{m}$.

Para $15000 \mathrm{kN} / \mathrm{m}$ é feito o estudo da influência da rigidez torcional da mola $k_{\theta}$, sendo o gráfico plotado conforme figura 30. Neste caso, a rigidez $k_{\theta}$ causa pouca influência entre 8000 e $10000 \mathrm{Nm} / \mathrm{rad}$, visto no gráfico à direita da figura, que possui abscissa entre 100 e $10000 \mathrm{Nm} / \mathrm{rad}$.

Figura 30 - Resposta para primeiro modo de vibração em função da rigidez torcional para viga de $75 \mathrm{~mm}$.

(a) Limites 0 e $100 \mathrm{Nm} / \mathrm{rad}$.

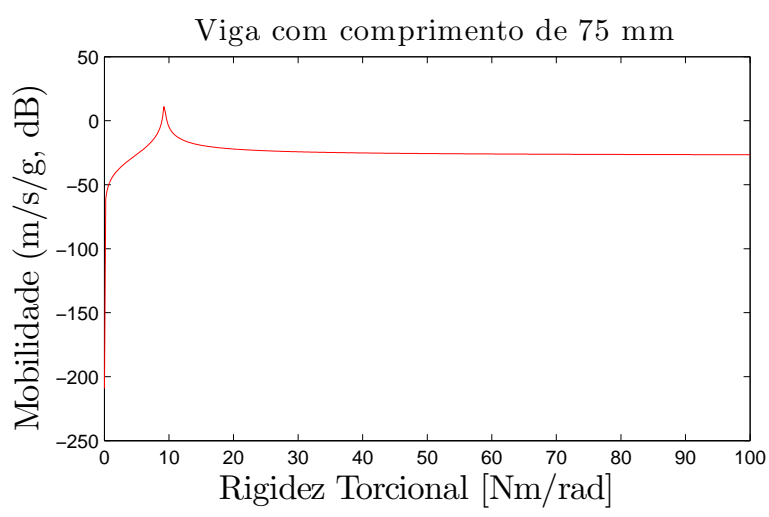

(b) Limites 100 e $10000 \mathrm{Nm} / \mathrm{rad}$.

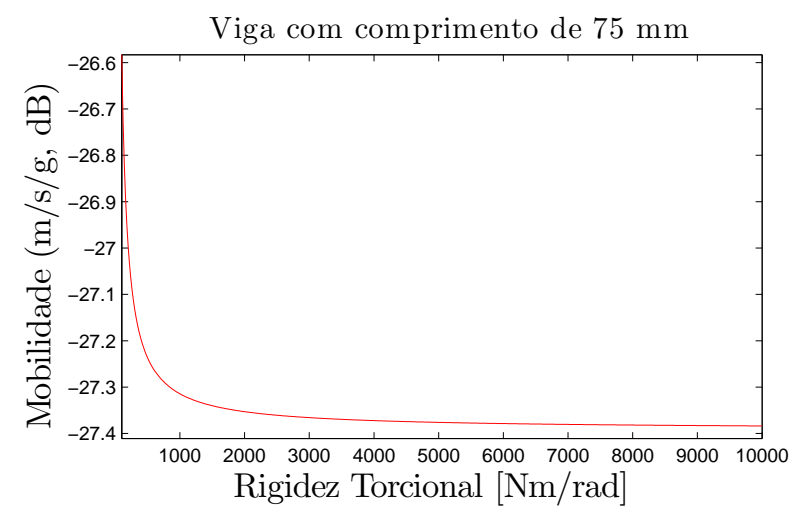


Pela análise das figuras é possível concluir que valores de $k_{w}$ entre 15000 e $18000 \mathrm{kN} / \mathrm{m}$ e $k_{\theta}$ entre 8 e $10 \mathrm{kNm} / \mathrm{rad}$ (viga de $75 \mathrm{~mm}$ ) causam pouca variação na ordenada dos gráficos. Deste fato, valores de $k_{w}$ e $k_{\theta}$ iguais a $15000 \mathrm{kN} / \mathrm{m}$ e $8 \mathrm{kNm} / \mathrm{rad}$ são utilizados para otimização do dispositivo.

Com respeito ao amortecimento do sistema $(\zeta)$, um valor de $0,3 \%$ é utilizado, sendo que tal valor diz respeito a todos os dispositivos, incluindo o amortecimento que pode existir no engaste. Para um estudo mais aprimorado, um modelo que inclua o amortecimento do engaste pode ser elaborado, como procedimento para trabalhos futuros. No presente caso, é considerado este valor e, na análise de robustez, uma certa incerteza é embutida neste parâmetro para o estudo da sensibilidade.

\subsection{Projeto do dispositivo}

Para o projeto dos dispositivos ressonantes, o passo é definir os valores desejados de comprimento das vigas, sendo que a camada piezelétrica é $80 \%$ deste valor $\left(l_{p}=0,8 l_{v}\right)$. Levando em consideração o estudo realizado na seção anterior e o introduzido, cinco tipos de dispositivos são projetados, conforme tabela 10 para uma excitação na base igual a $10 \mathrm{~m} / \mathrm{s}^{2}$.

Tabela 10 - Condições para projetos de dispositivos via otimização

\begin{tabular}{|c|c|c|c|}
\hline Dispositivos & $l_{v}[\mathrm{~mm}]$ & $m_{b}[g]$ & $R_{c}[k \Omega]$ \\
\hline 1 & $50 \leq l_{v 1} \leq 55$ & $3 \leq m_{b 1} \leq 45$ & $R_{c 1}$ \\
\hline 2 & $55 \leq l_{v 2} \leq 60$ & $3 \leq m_{b 2} \leq 45$ & $R_{c 2}$ \\
\hline 3 & $60 \leq l_{v 3} \leq 65$ & $3 \leq m_{b 3} \leq 45$ & $R_{c 3}$ \\
\hline 4 & $65 \leq l_{v 4} \leq 70$ & $3 \leq m_{b 4} \leq 45$ & $R_{c 4}$ \\
\hline 5 & $70 \leq l_{v 5} \leq 75$ & $3 \leq m_{b 5} \leq 45$ & $R_{c 5}$ \\
\hline
\end{tabular}

Pelo fato das condições de contorno para utilização de $k_{w}=15000 \mathrm{kN} / \mathrm{m}^{2} \mathrm{e}$ $k_{\theta}=8 \mathrm{kNm} / \mathrm{rad}$ serem formuladas para vigas de $50 \mathrm{~mm}$ e $75 \mathrm{~mm}$, os dispositivos são projetados dentro dessas regiões, conforme tabela 10. Neste caso, os valores de comprimento da viga $l_{v}$, massa sísmica $m_{b}$ e resistência elétrica $R_{c}$ são encontrados via otimização determinística, sendo que o comprimento do sensores piezelétricos são determinados diretamente pelo tamanho da viga.

Mais precisamente, a otimização determinística é considerada segundo o procedimento abaixo, em que os valores de resistência elétrica e massa sísmica possuem os limites 
conforme especificados.

$$
\begin{array}{cl}
\operatorname{maximize} & f\left(\mathbf{x}_{p}\right) \\
\text { sujeito a } & l_{v l} \leq l_{v} \leq l_{v u} \\
& 3 g \leq m_{b} \leq 45 g
\end{array}
$$

em que a função $f\left(\mathbf{x}_{p}\right)$ é a potência por unidade de aceleração quadrada a ser maximizada e $\mathbf{x}_{p}=\left[l_{v}, m_{b}, R_{c}\right]$. Os limites superior e inferior de comprimento da viga são representados por $l_{v l}$ e $l_{v u}$, respectivamente.

Para o projeto de cada dispositivo, o comprimento $l_{v}$ e massa sísmica $m_{b}$, recebem valores dentro da faixa imposta pela tabela 10. Na aplicação do algoritmo SQP, é importante escolher os pontos iniciais, uma vez que pode acontecer do valor maximizado da função ser um máximo local. Por isso, um primeiro passo foi dividir cada intervalo de comprimento e massa sísmica da tabela 10 em pontos adequados para aplicação do algoritmo SQP. Assim, a escolha dos pontos de partida é realizada considerando uma divisão de cada intervalo que gere 5 pontos, tanto para massa como comprimento, e todas as combinações possíveis são escolhidas. Para a resistência elétrica, um valor inicial de $R_{c}=50 \mathrm{k} \Omega$ é utilizado em todos os casos do intervalos da tabela 10, para aplicação do algoritmo.

Após otimização em cada intervalo de comprimento para os dispositivos, de acordo com a tabela 10, alguns valores são encontrados, no entanto, para o projeto se escolhe valores próximos aos encontrados via cálculo, para facilitar o dimensionamento. Na tabela, está uma divisão que mostra os valores encontrados via calculo determinístico e os escolhidos.

Após otimização em cada intervalo de comprimento, são encontrados os valores do parâmetros conforme tabela 11. Para as resistências elétricas são utilizados os seguintes valores na análise, considerando dispositivos 1 até 5: 215, 210, 200, 185 e $180 k \Omega$, respectivamente. No caso, os dispositivos ficam sintonizados com a frequência de operação em $100 \mathrm{~Hz}$ após otimizados e com os valores de resistências anteriores a frequência praticamente não é alterada.

Com os valores dos parâmetros de projeto de cada dispositivo e dados previamente apresentados nesta seção, é possível plotar os gráficos de saída de tensão elétrica por unidade de aceleração para o conjunto dos cinco dispositivos no primeiro modo de vibração, conforme pode ser visto na figura 31. No caso, a mesma análise para saída de potência elétrica por unidade de aceleração quadrada é mostrada no gráfico da figura 32.

É possível verificar dos gráficos um desempenho considerável no primeiro dispositivo frente aos demais, em relação a pico de respostas, tanto de tensão elétrica ou potência gerada, sendo que todos possuem frequência de ressonância bem próxima de $100 \mathrm{~Hz}$. 
Tabela 11 - Intervalos e parâmetros otimizados

\begin{tabular}{|l|c|c|c|c|c|c|}
\cline { 5 - 7 } \multicolumn{2}{c|}{} & \multicolumn{3}{c|}{ Resultados } \\
\hline disp. 1 & $50 \leq l_{v 1} \leq 55$ & $3 \leq m_{b 1} \leq 45$ & $R_{c 1}$ & 50 & 13,978 & 214981 \\
\hline disp. 2 & $55 \leq l_{v 2} \leq 60$ & $3 \leq m_{b 2} \leq 45$ & $R_{c 2}$ & 55 & 10,386 & 206906 \\
\hline disp. 3 & $60 \leq l_{v 1} \leq 65$ & $3 \leq m_{b 1} \leq 45$ & $R_{c 1}$ & 60 & 7,782 & 201641 \\
\hline disp. 4 & $65 \leq l_{v 2} \leq 70$ & $3 \leq m_{b 2} \leq 45$ & $R_{c 2}$ & 65 & 5,837 & 184572 \\
\hline disp. 5 & $70 \leq l_{v 1} \leq 75$ & $3 \leq m_{b 1} \leq 45$ & $R_{c 1}$ & 70 & 4,342 & 179428 \\
\hline
\end{tabular}

Figura 31 - Resposta para saída de tensão dos dispositivos projetados.

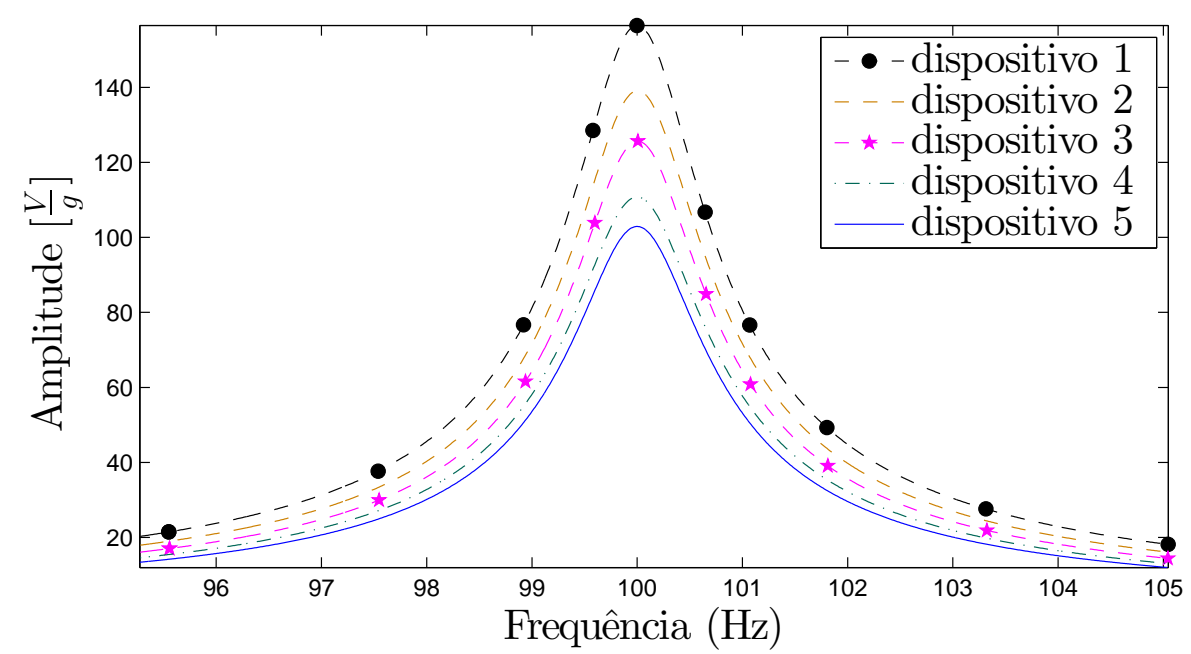

Figura 32 - Resposta para saída de potência elétrica dos dispositivos projetados.

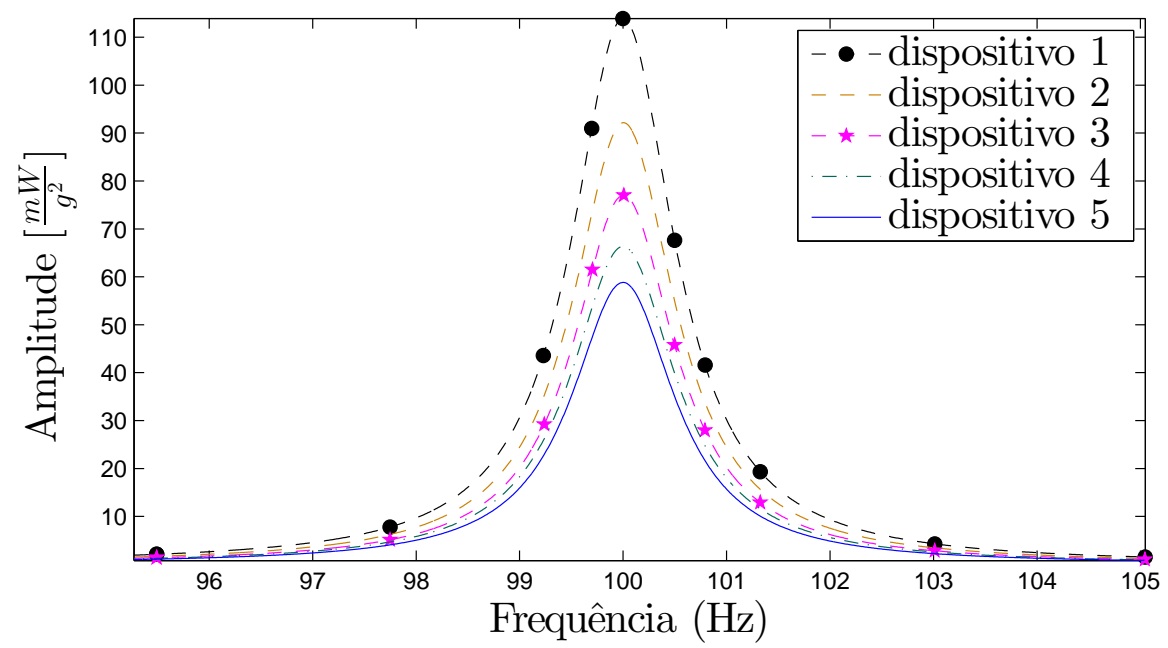

Para um estudo mais aprofundado e abrangente, as incertezas são introduzidas nos fatores de ruídos (rigidez linear, torcional e amortecimento) e resistência elétrica, o que implica em definições de condições de contorno, bem como prosseguimento com um 
estudo de robustez dos dispositivos.

\subsection{Projeto robusto e análise de incertezas dos dispositivos}

Com os dispositivos otimizados, uma tendência é escolher o dispositivo de maior desempenho para uma aplicação em coleta de energia, no entanto, ao se considerar as incertezas inerentes no projeto ou mesmo ruídos externos, um estudo mais aprofundado é necessário. Assim, para complementar e aprofundar a análise descrita até o momento, os dispositivos são avaliados diante da sensibilidade com as incertezas da rigidez do engaste, amortecimento e resistência efetiva do circuito elétrico. Por isso, o método de robustez através de matrizes ortogonais é utilizado, sendo que para essa utilização foi necessário uma otimização determinística, a fim de se encontrar os valores ótimos para captação de energia.

Partindo do introduzido na metodologia deste trabalho, no capítulo 4, é possível separar parâmetros de controle e fatores de ruído para a análise de robustez. No entanto, para determinar quais os valores de ruído utilizados e os parâmetros de controle, uma análise preliminar da resposta dos dispositivos foi realizada. Esse estudo é em relação a geração de tensão elétrica diante da variação dos valores de rigidez do engaste, pois permite determinar regiões de variabilidade que influenciam a resposta. Considerando que dispositivos podem estar trabalhando com engastamento não perfeitamente ajustados, uma dessintonização de frequência pode ocorrer. Por isso, estudar uma possível região que provoque a geração de incertezas é interessante do ponto de vista de potência produzida, diante das condições de robustez. Em relação ao amortecimento, um valor de tolerância é introduzido no valor global de $0,3 \%$ para a análise. Além do mais, o valor de resistência elétrica ótimo calculado para os dispositivos, proporcionando maior potência disponível, é comparado com outros valores diante da tolerâncias considerada. Neste caso, uma interessante análise é a verificação do gráfico de geração de potência pelo valor de resistência elétrica, permitindo escolher valores em regiões de proximidade com a máxima geração ou das resistências otimizadas, ou mesmo fazer comparação com valores em outros pontos de menor geração de energia.

Em um primeiro momento, a investigação dos valores de rigidez do engaste diante da tensão elétrica gerada por valor de aceleração pode ser analisado. Para a frequência de operação de $100 \mathrm{~Hz}$, as curvas de saída de tensão elétrica em função da rigidez linear $k_{w} \mathrm{e}$ torcional $k_{\theta}$ podem ser plotadas. Para a rigidez linear, a figura 33 representada as curvas para os cinco dispositivos, sendo que a escala da abscissas é limitada em $9000 \mathrm{kN} / \mathrm{m}$, que já é suficiente para a análise da variabilidade da resposta diante de incertezas.

Para os gráficos da figura 33, uma maior variabilidade na resposta ocorre até $4000 \mathrm{kN} / \mathrm{m}$, sendo que na faixa de 2000 a $4000 \mathrm{kN} / \mathrm{m}$, uma leve variabilidade ocorre e 
Figura 33 - Resposta para saída de tensão em função da rigidez linear para os dispositivos.

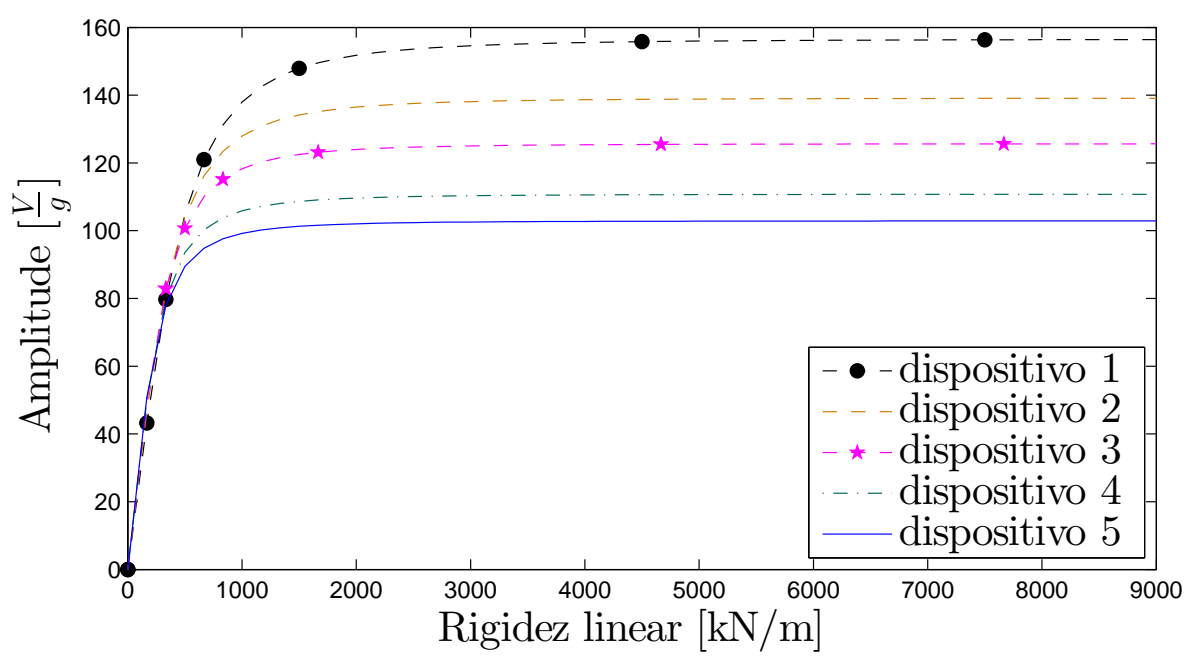

Figura 34 - Resposta para saída de tensão em função da rigidez torcional para os dispositivos.

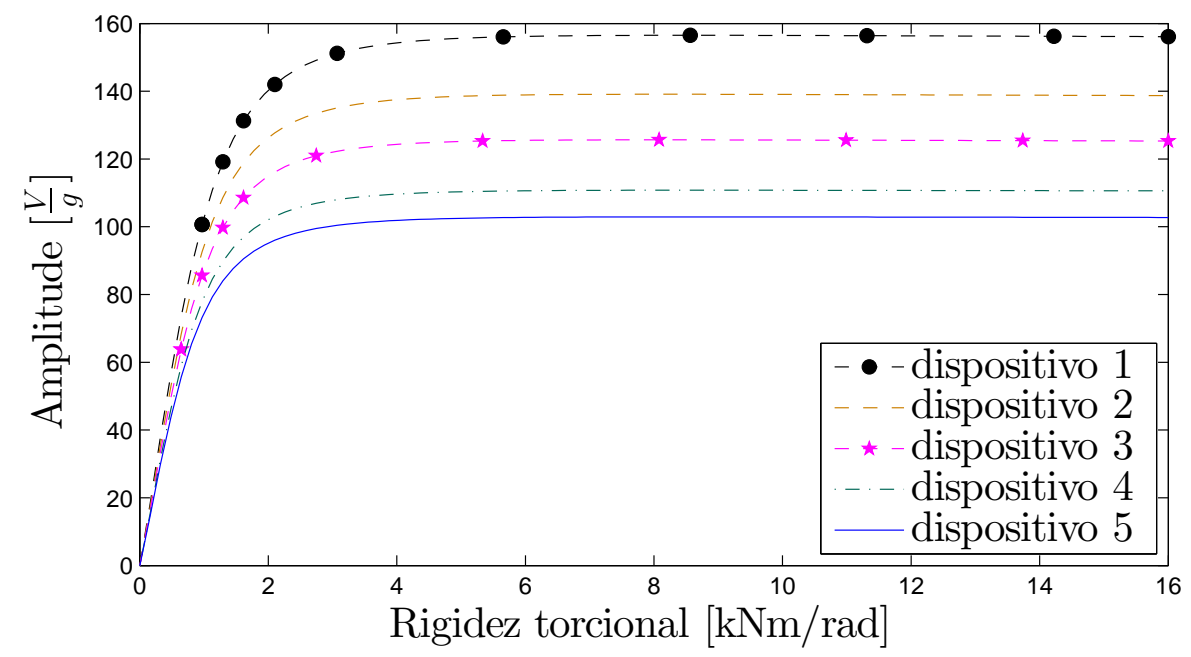

anterior a $2000 \mathrm{kN} / \mathrm{m}$ a resposta começa a ser influenciada consideravelmente pela diminuição da rigidez linear. Assim, para o estudo da robustez, os valores de $k_{w}$ são escolhidos a partir de $1000 \mathrm{kN} / \mathrm{m}$, supondo que o engaste não está completamente desajustado. A mesma investigação pode ser feita para o valor da rigidez torcional $k_{\theta}$, sendo assim, a figura 34 representa os valores com limite da abscissa em $16 \mathrm{kNm} / \mathrm{rad}$. Nesse caso, até $6 \mathrm{kNm} / \mathrm{rad}$ pode-se considerar que a resposta é influenciada pelos valores de rigidez torcional, sendo que a partir deste valor a influência é bem menor nos dispositivos. Definindo regiões de análise para a rigidez linear e de torção, é possível encontrar seus valores médios, desvios e tolerâncias. Assim, inicialmente definindo a região de estudo para a rigidez linear e utilizando as equações (4.7) e (4.8) do capítulo 4 é possível construir a tabela 12. Com intervalos pré-definidos, os valores médios, desvios e tolerâncias são encontrados e 
dados na mesma tabela.

Tabela 12 - Regiões de análise para rigidez linear

\begin{tabular}{|c|c|c|c|}
\hline Limites $(\mathrm{kN} / \mathrm{m})$ & Média $(\mathrm{kN} / \mathrm{m})$ & Desvio $(\mathrm{kN} / \mathrm{m})$ & tolerância $(\%)$ \\
\hline$[1000,2000]$ & 1500 & 500 & 33 \\
\hline$[2000,3000]$ & 2500 & 500 & 20 \\
\hline$[3000,4000]$ & 3500 & 500 & 14 \\
\hline
\end{tabular}

Pelo gráfico da figura 33, os limites de estudo são definidos para $k_{w}$, baseandose em condições de variabilidade e, nesse caso, os limites foram definidos entre 1000 e $4000 \mathrm{kN} / \mathrm{m}$, em três intervalos, absorvendo a região de 2000 a $4000 \mathrm{kN} / \mathrm{m}$. Para a rigidez torcional, raciocínio semelhante é utilizado, definindo assim três intervalos para estudo, com valores médios, desvios e tolerâncias. Partindo de um valor médio de $2,5 \mathrm{kNm} / \mathrm{rad}$ com $33 \%$ de tolerância, que é a mesma porcentagem utilizada para a rigidez linear, pode-se definir o intervalo e desvio de estudo. Os outros intervalos são definidos considerando valor de porcentagem semelhante a mola linear. A tabela 13 contém os valores dos intervalos da mola de torção com médias, desvio e tolerâncias.

Tabela 13 - Valores limites e tolerâncias para $k_{\theta}$

\begin{tabular}{|c|c|c|c|}
\hline Limites $(\mathrm{kNm} / \mathrm{rad})$ & Média $(\mathrm{kNm} / \mathrm{rad})$ & Desvio $(\mathrm{kNm} / \mathrm{rad})$ & tolerâncias $(\%)$ \\
\hline$[1,67,3,33]$ & 2,5 & 0,83 & 33 \\
\hline$[3,33,5,00]$ & 4,2 & 0,83 & 20 \\
\hline$[5,00,6,66]$ & 5,8 & 0,83 & 14 \\
\hline
\end{tabular}

Portanto, do exposto, três valores de rigidez são considerados para o estudo nos dispositivos, sendo que cada valor é utilizado para todos os dispositivos, considerando a mesma região de análise ou mesmo ajuste em relação a cada um deles. Com isso, é possível verificar o impacto que há na resposta com o ajuste do engaste, ou seja, verificar a variabilidade na resposta diante das incertezas.

Para o amortecimento, um fator $\zeta=0,003$ é utilizado para todos os dispositivos e este valor é global, ou seja, diz respeito ao conjunto com engaste, viga, camada piezelétrica com resina, massa sísmica e resistência elétrica. Como existem incertezas nesse valor, principalmente pelo desajuste do engaste, uma tolerância de $10 \%$ é escolhida em todos os casos dos dispositivos para verificação da robustez final.

Para o caso da resistência elétrica, uma análise da curva de potência para cada dispositivo é plotada e determinada região é escolhida para utilização, tendo como base a máxima potência gerada. Assim, valores de resistência que aumentem o pico de potência são escolhidos e outros fora da região são analisados para verificação do impacto na variabilidade da resposta. Na figura 35, estão os gráficos de potência em função da resistência elétrica para cada dispositivo. 
Figura 35 - Resposta para saída de potência versus resistência para os dispositivos na frequência de $100 \mathrm{~Hz}$.

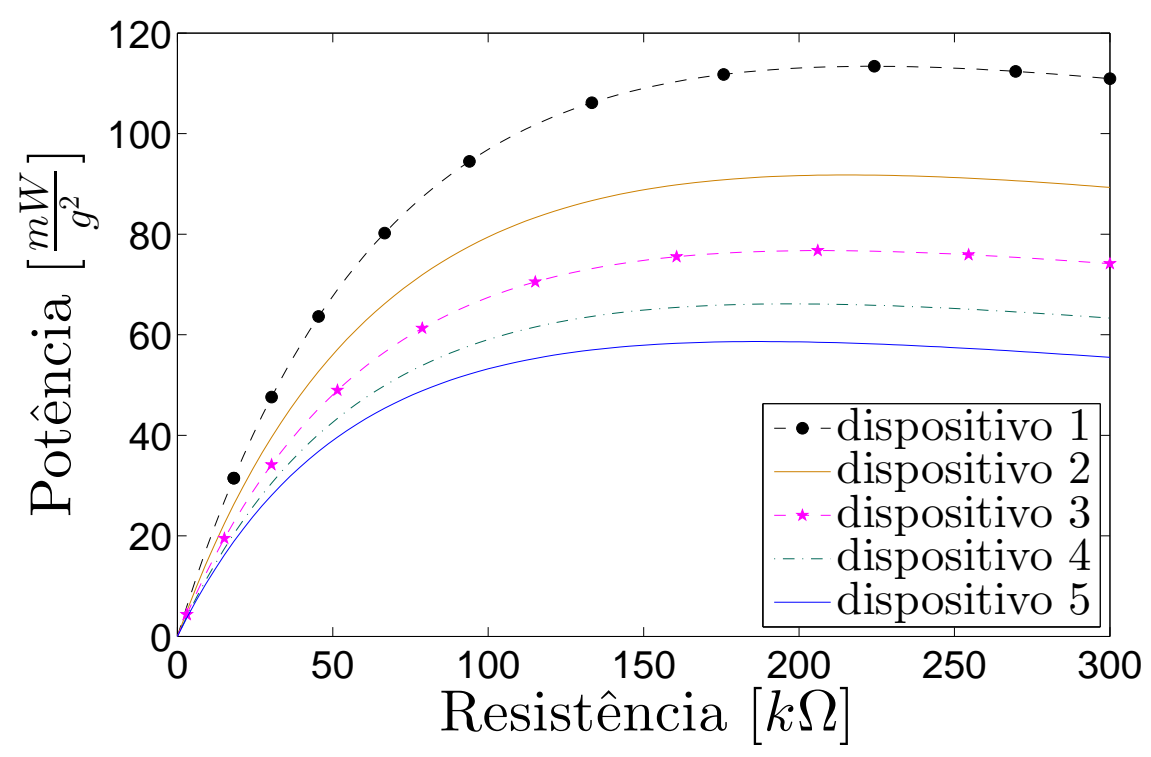

A figura 35 mostra os valores máximos de pico de potência para cada dispositivo, sendo que os valores ótimos via cálculo determinístico do primeiro ao quinto dispositivo são: 215, 210, 205, 185 e $180 k \Omega$, respectivamente. Para averiguação do comportamento da robustez frente a valores diferentes, são definidas 10 resistências elétricas, com $2 \%$ de tolerância cada, na proximidade dos valores otimizados. Dessa forma, pode-se definir o seguinte conjunto de resistências, mantendo os valores ótimos: 120, 140, 160, 180, 185, $200,210,215,240$ e $260 k \Omega$.

Para a realização da análise de robustez segundo o método por matrizes ortogonais é necessário separar fatores de ruído e parâmetros de controle, divididos em níveis. Assim, para cada entrada no diagrama dado na figura 24 do capítulo 4, uma resposta é esperada. De acordo com a tabela 9, para associação de matriz de controle e ruído, cada nível de massa sísmica e resistência elétrica produz uma resposta. Assim, a tabela 14 para massa sísmica $m_{b}$ e resistência elétrica $R_{c}$, com os níveis correspondentes é criada para facilitar a análise. Na tabela 14, cinco níveis são atribuído a $m_{b}$, que é representante de cinco dispositivos sintonizados para operação na frequência próxima a $100 \mathrm{~Hz}$. Os valores de $R_{c}$ são divididos em 10 níveis, para verificação do desempenho e robustez em relação a $100 k \Omega$, que é o valor de máxima potência gerada em relação aos outros níveis.

Os dispositivos estão sujeitos a ruídos, sendo assim, as mesmas condições de incertezas são consideradas para cada dispositivo, ou seja, o engaste atua de forma semelhante nos mesmos. Assim, as cinco condições das tabelas 12 e 13 são analisadas, individualmente nos dispositivos e os valores finais são comparados. As condições de atuação de ruídos são divididas em três casos, atuando em todos os dispositivos, segundo a tabela 15. 
Tabela 14 - Parâmetros de controle

\begin{tabular}{|ccccccccccc|}
\hline & \multicolumn{10}{c|}{ Níveis } \\
\cline { 2 - 12 } Notação & 1 & 2 & 3 & 4 & 5 & 6 & 7 & 8 & 9 & 10 \\
\hline$R_{c}(k \Omega)$ & 120 & 140 & 160 & 180 & 185 & 205 & 210 & 215 & 240 & 260 \\
$m_{b}(g)$ & 13,978 & 10,386 & 7,782 & 5,837 & 4,342 & & & & & \\
\hline
\end{tabular}

Tabela 15 - Fatores de ruídos

\begin{tabular}{ccccc}
\hline Fatores de ruído & \multirow{2}{*}{ Notação } & \multicolumn{3}{c}{ Casos } \\
\cline { 3 - 5 } & & 1 & 2 & 3 \\
\hline Rigidez linear & $k_{w}(k N / m)$ & 1500 & 2000 & 3000 \\
Rigidez de torção & $k_{\theta}(k N m / r a d)$ & 2,5 & 4,2 & 5,8 \\
\hline tolerância & $-(\%)$ & 33,3 & 20,0 & 14 \\
\hline amortecimento & $\zeta$ & 0,003 & 0,003 & 0,003 \\
\hline tolerância & $-(\%)$ & 10 & 10 & 10 \\
\hline
\end{tabular}

Para utilização dos fatores de ruído uma matriz do tipo $L_{8}\left(2^{7}\right)$, conforme descrito na metodologia e dada pela tabela 7 , com alocação de $k_{w}, k_{\theta}, \zeta$ e $R_{c}$ nas devidas colunas, é considerada. A resistência elétrica possui $2 \%$ de tolerância o que provoca um ruído na análise, embora seja um parâmetro de controle, isso faz com que uma matriz de ruído e outra de controle sejam utilizadas, conforme tabela 9.

Uma primeira análise pode ser realizada com os parâmetros $m_{b}$ e $R_{c}$ da tabela 14, tendo em vista o primeiro caso dos fatores de ruídos da tabela 15. Assim, o gráfico de efeito pode ser plotado, conforme figura 36, que permite analisar o desempenho dos dispositivos em relação a média (gráfico em vermelho) e robustez por meio da sensibilidade (gráfico em azul). Tanto para o gráfico de média como sensibilidade existem linhas com pontos discretos, sendo que a linha à esquerda representa a resistência elétrica com seus 10 níveis, enquanto que a linha à direita representa a massa sísmica com seus 5 níveis, ou cinco dispositivos.

Os gráficos anteriores são construídos levando em consideração $33 \%$ de tolerância em relação a rigidez do engaste e $10 \%$ para o amortecimento global. No entanto, os valores médios de rigidez estão localizados em regiões propensas a alta variabilidade da resposta com $k_{w}=1500 \mathrm{kN} / \mathrm{m}$ e $k_{\theta}=2,5 \mathrm{kNm} / \mathrm{rad}$, como pode ser visto nas figuras 33 e 34. Uma investigação preliminar mostra um desempenho melhor do primeiro dispositivo em relação a média, pois o nível 1 do gráfico para $m_{b}$ possui um efeito maior, e um menor para o dispositivo 5. Em relação a robustez, é interessante ter valores maiores de sensibilidade, uma vez que isso diminui o valor da variância da função perda de qualidade, por isso o dispositivo 5 é mais robusto, ou seja, tem uma menor variância frente aos ruídos impostos no problema, enquanto o primeiro é menos robusto. Por outro lado, o estudo da 
Figura 36 - Efeito com $k_{w}=1500 \mathrm{kN} / \mathrm{m}, k_{\theta}=2,5 \mathrm{kNm} / \mathrm{rad}$ e $\zeta$ com $10 \%$ de tolerância.
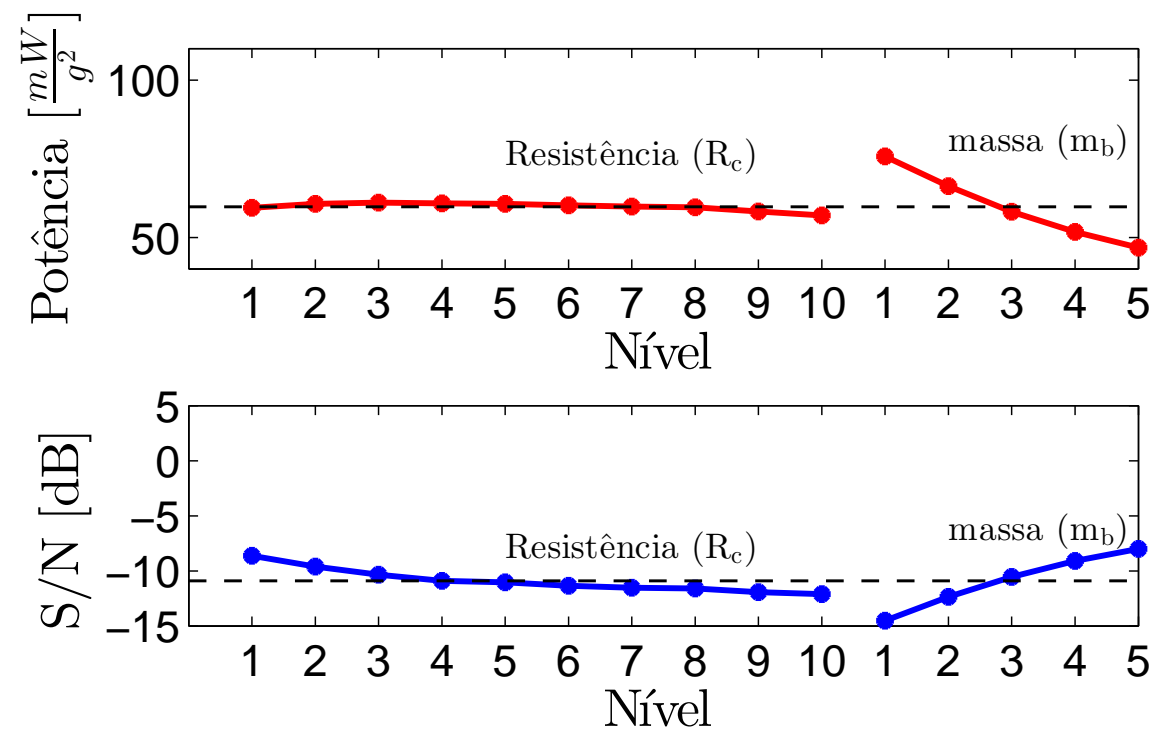

resistência mostra um valor de média praticamente constante, diminuindo um pouco nos níveis extremos, mais precisamente nos níveis 9 e 10, sendo que para a robustez, existe um crescente aumento da função sensibilidade nos níveis inferiores e, por consequência, uma diminuição da variância dos dispositivos ao diminuir o valor da resistência elétrica.

Prosseguindo com uma análise para o segundo caso de rigidez média da tabela 15, tal que a tolerância é $20 \%$, pode-se plotar os gráficos da figura 37. Nesse caso, a linha referente à média de potência (gráfico em vermelho) se tornou um pouco diferente em relação ao gráfico da figura 36 para os efeitos de resistência elétrica, além do valor de sensibilidade média aumentar do gráfico em azul, o que pode ser constatado pelo deslocamento da linha tracejada. O fato da região de análise se mostrar mais comportada em relação à variabilidade dos valores de rigidez nos gráficos das figuras 33 e 34 em relação a $k_{w}=2000 \mathrm{kN} / \mathrm{m}$ e $k_{\theta}=3,5 \mathrm{kNm} / \mathrm{rad}$, influenciam no gráfico de efeito.

Para o caso de ruído com $k_{w}=3000 \mathrm{kN} / \mathrm{m}, k_{\theta}=5.8 \mathrm{kNm} / \mathrm{rad}$ e tolerância de $14 \%$, a figura 38 é apresentada para os gráficos de efeito. Nesse caso, os gráficos passam a ser semelhantes ao da figura 37, pois as regiões de análise possuem baixa variabilidade, que pode ser constatado observando as figuras 33 e 34 .

Dos gráficos anteriores, é possível observar um aumento da média com o aumento da massa sísmica, ou seja dispositivos com menores comprimento de viga e maior massa sísmica tendem a ter mais desempenho nesse sentido. Quanto à sensibilidade, dispositivos com maior comprimento de viga e menor massa sísmica têm um maior valor de $S / N$, sendo menos suscetíveis à variabilidade. A resistência elétrica promove o aumento da robustez com valores menores, ou seja, nos níveis mais baixos. No entanto, os valores de resistências elétricas foram escolhidos próximos aos valores otimizados, pois é perceptível 
Figura 37 - Efeito com $k_{w}=2000 \mathrm{kN} / \mathrm{m}, k_{\theta}=4,2 \mathrm{kNm} / \mathrm{rad}$ e $\zeta$ com $10 \%$ de tolerância.
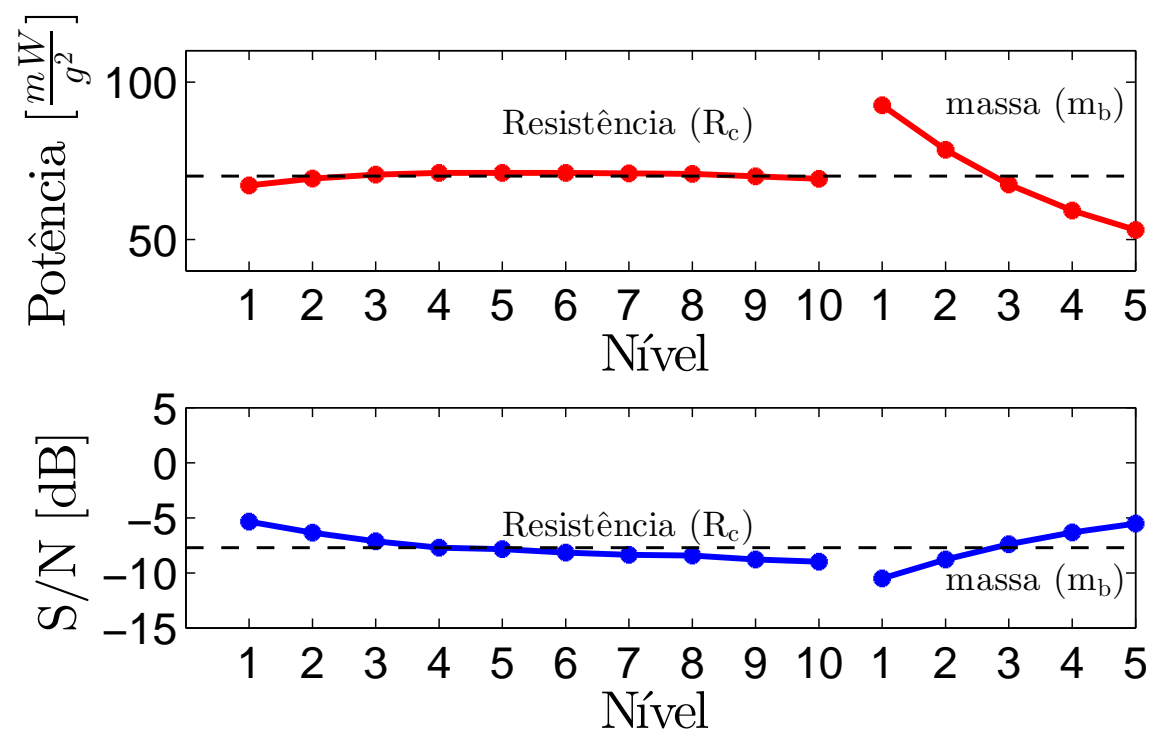

Figura 38 - Efeito com $k_{w}=3000 \mathrm{kN} / \mathrm{m}, k_{\theta}=5,8 \mathrm{kNm} / \mathrm{rad}$ e $\zeta$ com $10 \%$ de tolerância.
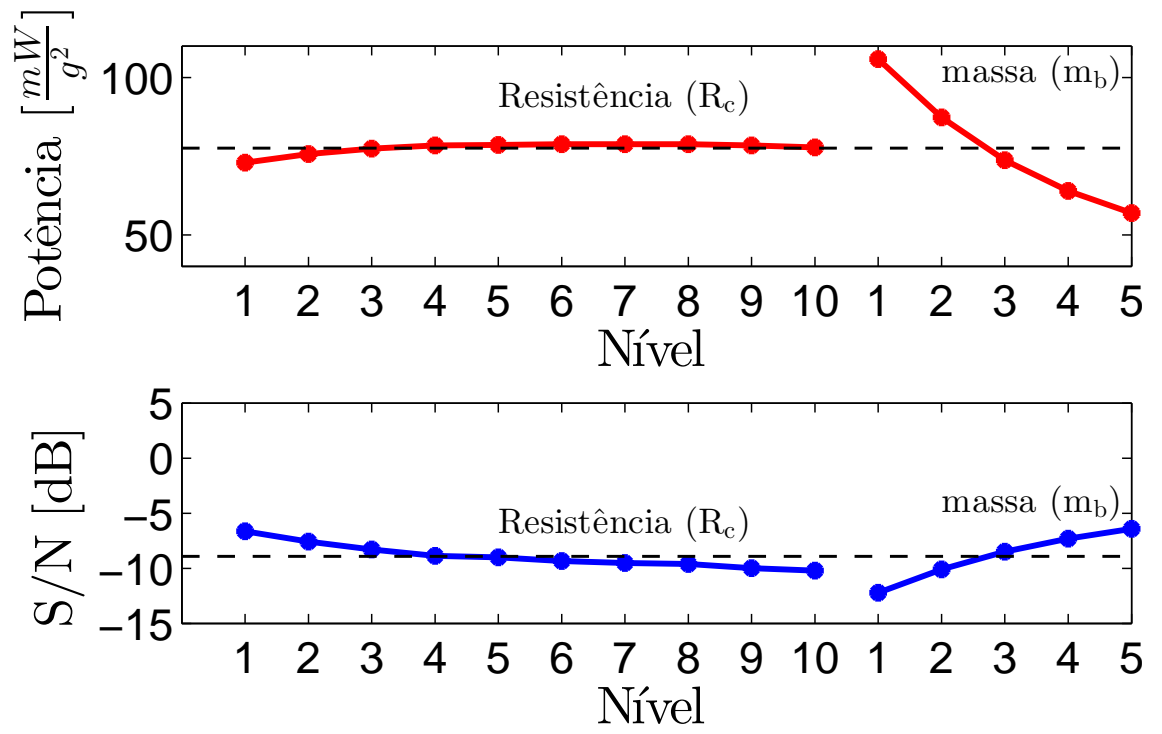

pelos gráficos de média que níveis mais baixos tendem a causar diminuição da média, embora a robustez aumente. Por isso, a otimização determinística foi fundamental, uma vez que propiciou a escolha desses valores de resistências próximos aos pontos ótimos.

Para averiguação do desempenho de cada dispositivo frente às incertezas do projeto, o último caso para a rigidez linear é investigado com um valor maior de incertezas, garantindo assim a escolha de um dispositivo adequado, mesmo em condições com alta variabilidade. Tomando o valor nominal para $k_{w}=3000 \mathrm{kN} / \mathrm{m}$ e $k_{\theta}=5.0 \mathrm{kNm} / \mathrm{rad}$, porém com tolerância de $50 \%$, sendo esta considerada como três desvios padrão, os valores de média, variância e sensibilidade podem ser encontrados. Cada linha da matriz 
de controle fornece esses valores, conforme explicado diante da tabela 9 na metodologia. Com isso, os resultados podem ser encontrados em cada experimento, conforme mostrado na tabela 16 .

Tabela 16 - Valores média, variância e sensibilidade para os níveis dos parâmetros

\begin{tabular}{|c|cccc|}
\hline & & média & variância \\
Exp. & $R_{c}$ & $m_{b}$ & $m W g^{-2}$ & $\left(m W g^{-2}\right)^{2}$ \\
\hline 1 & 1 & 1 & 97,65 & 10,15 \\
2 & 1 & 2 & 81,16 & 6,14 \\
3 & 1 & 3 & 69,22 & 4,25 \\
4 & 1 & 4 & 60,69 & 3,25 \\
5 & 1 & 5 & 54,65 & 2,69 \\
\hline 6 & 2 & 1 & 101,81 & 12,55 \\
7 & 2 & 2 & 84,42 & 7,62 \\
8 & 2 & 3 & 71,77 & 5,28 \\
9 & 2 & 4 & 62,71 & 4,03 \\
10 & 2 & 5 & 56,24 & 3,33 \\
\hline 11 & 3 & 1 & 104,58 & 14,88 \\
12 & 3 & 2 & 86,52 & 9,05 \\
13 & 3 & 3 & 73,36 & 6,27 \\
14 & 3 & 4 & 63,90 & 4,77 \\
15 & 3 & 5 & 57,11 & 3,91 \\
\hline 16 & 4 & 1 & 106,27 & 17,08 \\
17 & 4 & 2 & 87,76 & 10,38 \\
18 & 4 & 3 & 74,24 & 7,17 \\
19 & 4 & 4 & 64,49 & 5,43 \\
20 & 4 & 5 & 57,46 & 4,42 \\
\hline 21 & 5 & 1 & 106,55 & 17,59 \\
22 & 5 & 2 & 87,96 & 10,69 \\
23 & 5 & 3 & 74,37 & 7,38 \\
24 & 5 & 4 & 64,56 & 5,58 \\
25 & 5 & 5 & 57,48 & 4,54 \\
\hline & & & & \\
\hline & & \\
15 &
\end{tabular}

\begin{tabular}{|c|cccc|}
\hline & & & média & variância \\
Exp. & $R_{c}$ & $m_{b}$ & $m W g^{-2}$ & $\left(m W g^{-2}\right)^{2}$ \\
\hline 26 & 6 & 1 & 107,26 & 19,57 \\
27 & 6 & 2 & 88,42 & 11,86 \\
28 & 6 & 3 & 74,60 & 8,16 \\
29 & 6 & 4 & 64,61 & 6,14 \\
30 & 6 & 5 & 57,37 & 4,97 \\
\hline 31 & 7 & 1 & 107,34 & 20,03 \\
32 & 7 & 2 & 88,45 & 12,13 \\
33 & 7 & 3 & 74,59 & 8,34 \\
34 & 7 & 4 & 64,57 & 6,27 \\
35 & 7 & 5 & 57,29 & 5,06 \\
\hline 36 & 8 & 1 & 107,39 & 20,48 \\
37 & 8 & 2 & 88,46 & 12,39 \\
38 & 8 & 3 & 74,57 & 8,51 \\
39 & 8 & 4 & 64,51 & 6,39 \\
40 & 8 & 5 & 57,21 & 5,15 \\
\hline 41 & 9 & 1 & 107,19 & 22,52 \\
42 & 9 & 2 & 88,17 & 13,57 \\
43 & 9 & 3 & 74,17 & 9,28 \\
44 & 9 & 4 & 64,01 & 6,92 \\
45 & 9 & 5 & 56,60 & 5,54 \\
\hline 46 & 10 & 1 & 106,63 & 23,91 \\
47 & 10 & 2 & 87,62 & 14,36 \\
48 & 10 & 3 & 73,59 & 9,78 \\
49 & 10 & 4 & 63,40 & 7,26 \\
50 & 10 & 5 & 55,95 & 5,78 \\
\hline
\end{tabular}

Em relação a média e sensibilidade, uma análise de variância pode ser feita para o caso anterior, permitindo verificar a contribuição de cada parâmetro no resultado final. As tabelas 17 e 18 representam os resultados do exposto anteriormente. Nas tabelas, GL representa os graus de liberdade, SQ a soma dos quadrados, QM os quadrados médios ou variância e F o resultado do teste estatístico de Fisher (Teste F). É possível notar a grande contribuição que cada dispositivo possui na geração de potência, ao olhar o fator $m_{b}$ na análise da média. A sensibilidade é afetada pela resistência elétrica e escolha do dispositivo, ou seja os fatores $m_{b}$ e $R_{c}$ influenciam na robustez.

Utilizando os casos ótimos de resistência elétrica, obtidos via otimização determinística, que geram maior valor de média, e os menores valores, que garantem a maior robustez dos dispositivos, é possível plotar os gráficos da figura 39 com intervalos de con- 
Tabela 17 - ANOVA para média $\left(m W / g^{2}\right)$

\begin{tabular}{|c|c|c|c|c|}
\hline & $R_{c}$ & $m_{b}$ & Erro & Total \\
\hline Nível 1 & 72,10 & 104,07 & & \\
Nível 2 & 74,78 & 86,08 & & \\
Nível 3 & 76,45 & 72,85 & & \\
Nível 4 & 77,37 & 63,29 & & \\
Nível 5 & 77,50 & 56,36 & & \\
Nível 6 & 77,72 & & & \\
Nível 7 & 77,73 & & & \\
Nível 8 & 77,71 & & & \\
Nível 9 & 77,28 & & & \\
Nível 10 & 76,67 & & & \\
\hline GL & 9 & 4 & 36 & 50 \\
\hline SQ & 145,96 & 14456,26 & 32,63 & 14634,85 \\
\hline QM & 16,22 & 3614,06 & 0,91 & 292,70 \\
\hline F & 17,89 & 3987,48 & & \\
\hline Contribuição (\%) & 1 & 99 & & \\
\hline
\end{tabular}

Tabela 18 - ANOVA para sensibilidade $\mathrm{S} / \mathrm{N}(\mathrm{dB})$

\begin{tabular}{|c|c|c|c|c|}
\hline & $R_{c}$ & $m_{b}$ & Erro & Total \\
\hline Nível 1 & $-6,95$ & $-12,71$ & & \\
Nível 2 & $-7,87$ & $-10,45$ & & \\
Nível 3 & $-8,60$ & $-8,77$ & & \\
Nível 4 & $-9,17$ & $-7,51$ & & \\
Nível 5 & $-9,30$ & $-6,57$ & & \\
Nível 6 & $-9,63$ & & & \\
Nível 7 & $-9,82$ & & & \\
Nível 8 & $-9,91$ & & & \\
Nível 9 & $-10,28$ & & & \\
Nível 10 & $-10,51$ & & & \\
\hline GL & 9 & 4 & 36 & 50 \\
\hline SQ & 55,74 & 238,56 & 0,13 & 294,4 \\
\hline QM & 6,20 & 59,63 & 0,004 & 5,88 \\
\hline F & 1754,78 & 16900 & & \\
\hline Contribuição (\%) & 19 & 81 & & \\
\hline
\end{tabular}

fiança de menos e mais três desvios padrão, considerando os valores de média e variância obtidos na tabela 16 .

O dispositivo 1 é nominalmente melhor em termos de geração de potência do que os outros. No entanto, levando-se em conta as incertezas e o intervalo de confiança 
Figura 39 - Valor de média e intervalo de confiança com $6 \sigma$ para saída de potência dos cinco dispositivos para energy harvesting quando usando (a) Valor de resistência ótima e (b) Valor menor de resistência.

(a) Caso determinístico.

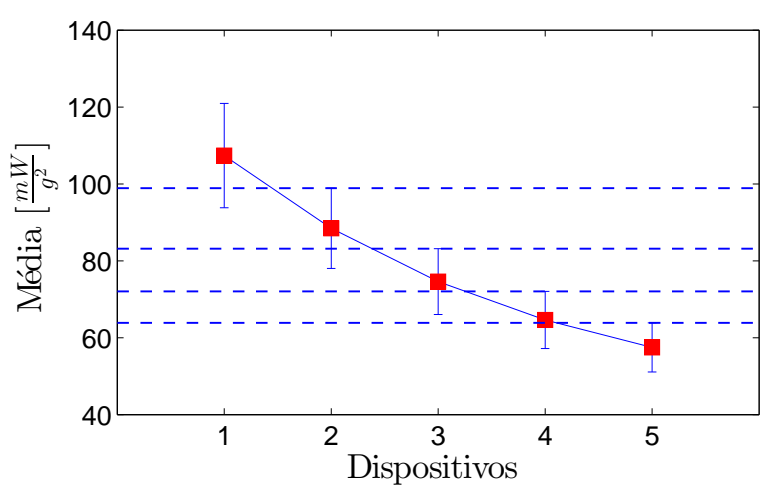

(b) Caso Robusto.

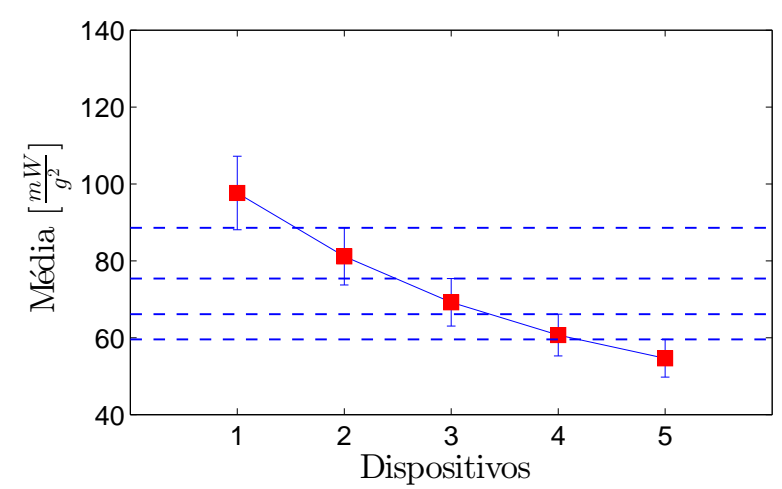

considerado, o segundo dispositivo pode chegar a ser melhor que o primeiro. O dispositivo 2 se comporta da mesma forma ao se fazer a comparação com o dispositivo 3 , bem como os outros dispositivos com seus anteriores para o caso da figura 39a. Por outro lado, na condição mais robusta de menor resistência elétrica, em que os dispositivos têm uma menor variabilidade, o dispositivo 1 é praticamente sempre superior aos outros. Destes resultados, pode-se concluir que ao reduzir a variância do dispositivo 1, através de uma redução no valor da resistência do circuito, em relação à ótima, este dispositivo passa a ser sempre a melhor escolha mesmo considerando-se as incertezas no engaste, no amortecimento e na resistência do circuito.

\subsection{Análise de Interações}

Em relação ao projeto estudado, uma análise da interação entre os parâmetros deve ser feita para confirmar se são monotônicos ou se a interação é do tipo sinergética. Nesse caso, uma análise com 3 níveis é suficiente para estudar o paralelismo entre os parâmetros. Portanto, escolhendo $k_{w}=3000 \mathrm{kN} / \mathrm{m}, k_{\theta}=5.0 \mathrm{kNm} / \mathrm{rad}$ com tolerância de $50 \%$ e amortecimento global com 10\%, é possível verificar a interação entre $m_{b}$ e $R_{c}$. Uma divisão em 3 níveis é realizada com base nos valores extremos de $m_{b}$ (nível 1 e nível $5)$ e $R_{c}$ (nível 1 e nível 10), além do nível central, nível 3 para $m_{b}$ na tabela 14 com seu valor otimizado de resistência $R_{c}$. Assim os níveis para análise de interação são dados através da tabela 19 a seguir.

Na tabela anterior, a massa sísmica está representada pelo parâmetro A, enquanto que a resistência elétrica por B. Como apenas 3 níveis por parâmetros são analisados, uma matriz do tipo $L_{9}\left(3^{4}\right)$, que pode ser vista na tabela 1 do capítulo 3 , é suficiente para $m_{b}$ e $R_{c}$. Para os fatores de ruído a mesma matriz $L_{8}\left(2^{7}\right)$ pode ser utilizada, uma vez que não houve modificação na quantidade de fatores estudados. Com isso o gráfico de interação 
Tabela 19 - Parâmetros de controle para análise de interação

\begin{tabular}{ccccc}
\hline Parâmetros de controle & Notação & \multicolumn{3}{c}{ Níveis } \\
\cline { 3 - 5 } & & 1 & 2 & 3 \\
\hline Massa sísmica & $A(g)$ & 13.978 & 7.782 & 4.342 \\
Resistência elétrica & $B(k \Omega)$ & 120 & 200 & 260 \\
\hline
\end{tabular}

entre os parâmetros é representado através da figura 40.

Figura 40 - Gráfico de interação.

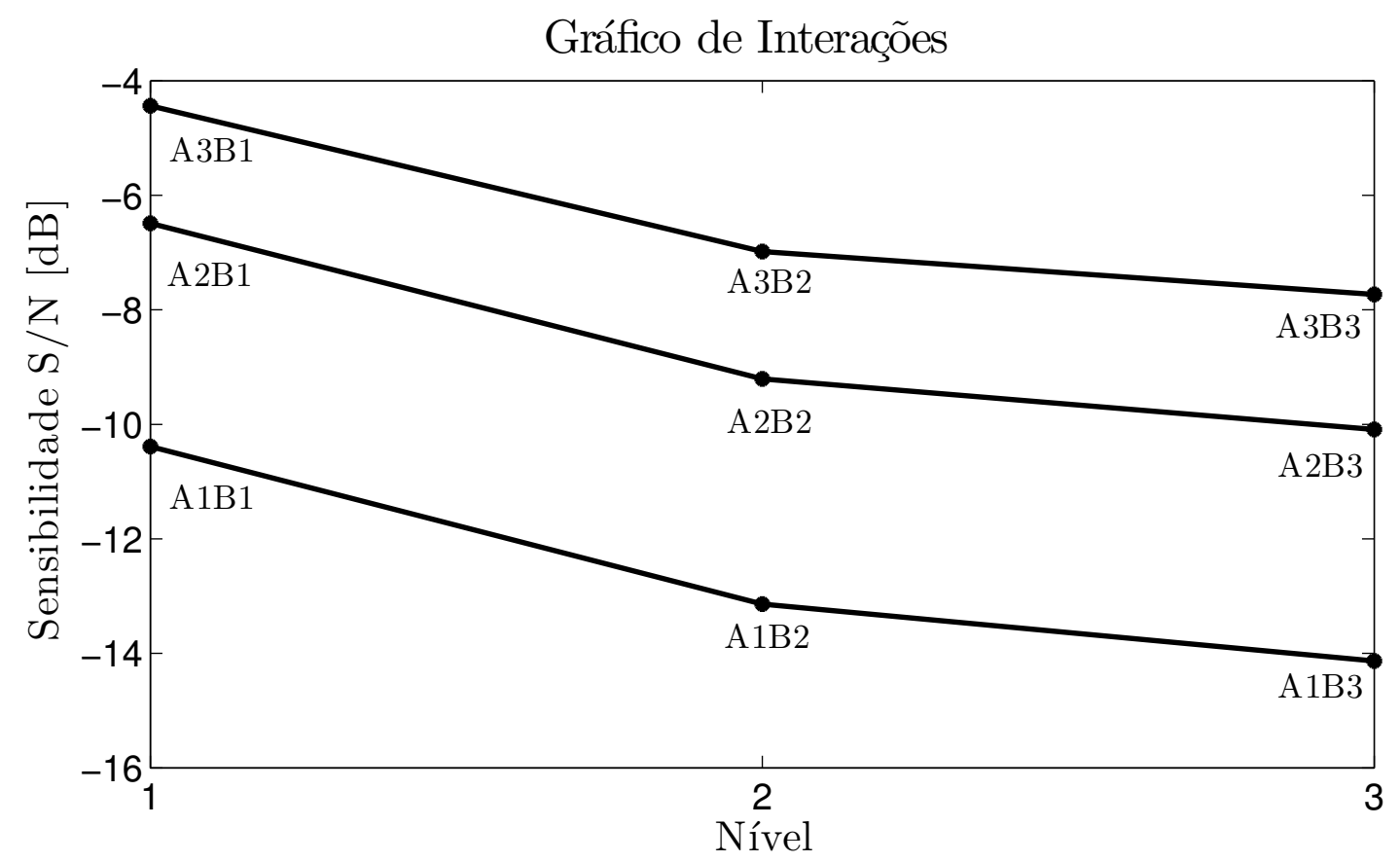

Da figura 40, é possível verificar que as linhas são praticamente paralelas umas às outras e, assim, os parâmetros são monotônicos, garantindo a potencialidade de aplicação do método via matrizes ortogonais para o presente projeto, de acordo com todo o exposto anteriormente, nos níveis escolhidos. Caso ocorresse o contrário e os parâmetros interagissem fortemente, a análise deveria ser voltada para estudo de outros parâmetros ou mesmo limitar a região de análise em relação aos níveis. Além do mais, a interação poderia ser avaliada do ponto de vista de impacto no resultado. Nesse caso, estudos têm sido realizados no sentido de verificação de interações entre parâmetros e pode ser uma proposta para futuros trabalhos (ANDERSON; WHITCOMB, 2016).

Para um estudo complementar, além da análise do amortecimento inserido diretamente no engaste do dispositivo, métodos de análise de robustez alternativos e inserção de indutância no circuito elétrico podem ser avaliados para aprofundamento do caso de coleta de energia. A metodologia utilizando matrizes ortogonais pode também ser aplicada em outros problemas para aprofundamento de casos. 


\section{Considerações Finais e Conclusões}

Esta dissertação esteve focada no processo de coleta de energia em dispositivos apropriados, que convertem a energia mecânica proveniente da vibração em energia elétrica. Os dispositivos estudados foram vigas do tipo cantilevers de alumínio, com engaste simulados por molas (linear e de torção), massa sísmica na extremidade livre, sensores piezelétricos colados nas vigas e acoplados a resistências elétricas. Além disso, uma entrada de deslocamento harmônico no engaste foi considerada. Pelo fato da energia disponível para conversão ser pequena, foi necessário garantir para os dispositivos: desempenho, eficiência e baixa variabilidade com incertezas inerentes ao projeto.

O dispositivo estudado foi modelado em elementos finitos usando um modelo já desenvolvido em dissertação de mestrado anterior. Assim, foi possível encontrar a FRF para saída de potência e entrada de aceleração ao quadrado, que a princípio dever ser maximizada para garantir maior energia coletada e projeto adequado do dispositivo. Com a maximização da potência, as frequências de ressonância do dispositivo e de operação tendem a sintonização.

Antes do projeto dos dispositivos, um estudo paramétrico para encontrar valores de rigidez do engaste foi conduzido, verificando a saída de velocidade na extremidade da viga, com entrada de deslocamento vertical no engaste. Os valores ideais de rigidez foram aqueles a partir dos quais a saída de velocidade passou a ser pouco influenciada. Partindo desses valores, uma otimização do tipo determinística para máxima potência gerada, utilizando o algoritmo de Programação Sequencial Quadrática (SQP), foi realizada para faixas de comprimento das vigas. Isso permitiu encontrar dispositivos criteriosamente otimizados, com valores adequados de massas sísmicas que propiciaram uma sintonização com a frequência de operação.

Com os dispositivos projetados via otimização determinística, incertezas foram inseridas no engaste, na resistência elétrica e no amortecimento. Desse fato, a análise de robustez foi conduzida através do método com matrizes ortogonais, estudado por Taguchi. O método foca em parâmetros de controle, que, no caso, foram o valor de massa sísmica, para dispositivos sintonizados com a frequência de operação, e resistência elétrica, além de fatores de ruído, que são aqueles com incertezas e que afetam a resposta. Com isso, uma análise de sensibilidade foi realizada para estudar média e variância do desempenho em geração de potência.

Para a situação em que os dispositivos são encontrados deterministicamente, via otimização SQP, o dispositivo com maior massa e menor comprimento de viga gera mais energia em comparação aos outros quatro dispositivos. Considerando incertezas nos dispo- 
sitivos com as respectivas resistências encontradas via cálculo determinístico, o dispositivo com maior massa é melhor que os outros. Devido às incertezas, no entanto, um dispositivo com massa menor pode chegar a ser melhor dentro do intervalo de confiança considerado. De forma geral, massas e resistências menores geram dispositivos com maior robustez. Quando se considera o caso em que todos os dispositivos estão com uma menor resistência elétrica, uma maior robustez é encontrada para os dispositivos. Por isso, escolher valores de resistências menores, mesmo que próximas aos valores otimizados, pode ser uma alternativa interessante sob o ponto de vista de aumento de robustez. Neste caso, com valores menores de resistência para os dispositivos, o de menor comprimento e maior massa apresenta um desempenho melhor em relação aos outros, praticamente em todos os casos de geração de energia, mesmo considerando a variabilidade.

Além disso, uma análise de interação entre os parâmetros de controle foi realizada a fim de garantir a eficiência do método através de matrizes ortogonais e não houve interação entre os mesmos.

Como trabalhos futuros, as seguintes sugestões são propostas:

1. Introdução do amortecimento no engaste do dispositivo;

2. Aplicação de outros métodos de otimização robusta e determinística, em dispositivos distintos ou mesmo semelhantes para estudo de coleta de energia, bem como em estruturas inteligentes com outras finalidades;

3. Inclusão de indutância elétrica no dispositivo;

4. Análise de incertezas da camada adesiva entre sensor piezelétrico e viga. 


\section{Referências}

ABDELKEFI, A. Aeroelastic energy harvesting: A review. International Journal of Engineering Science, Elsevier, v. 100, p. 112-135, 2016. Citado 2 vezes nas páginas 25 e 26 .

ANDERSON, M. J.; WHITCOMB, P. J. DOE simplified: practical tools for effective experimentation. [S.1.]: CRC Press, 2016. Citado 2 vezes nas páginas 71 e 106.

BARBETTA, P. A.; REIS, M. M.; BORNIA, A. C. Estatística: para cursos de engenharia e informática. [S.l.]: Atlas São Paulo, 2004. Citado na página 68.

BEEBY, S. P.; TUDOR, M. J.; WHITE, N. M. Energy harvesting vibration sources for microsystems applications. Measurement science and technology, IOP Publishing, v. 17, n. 12, p. R175, 2006. Citado na página 26.

BRAND, O. et al. Micro energy harvesting. [S.l.]: John Wiley \& Sons, 2015. Citado 2 vezes nas páginas 31 e 33 .

CHEN, W.-H.; HUANG, S.-R.; LIN, Y.-L. Performance analysis and optimum operation of a thermoelectric generator by taguchi method. Applied Energy, Elsevier, v. 158, p. 44-54, 2015. Citado na página 59.

CHEN, Z. et al. Metamaterials-based enhanced energy harvesting: A review. Physica B: Condensed Matter, Elsevier, v. 438, p. 1-8, 2014. Citado na página 26.

CRAIG, R. R. Structural dynamics: an introduction to computer methods. [S.1.]: John Wiley \& Sons Inc, 1981. Citado na página 50.

DEHNAD, K. Quality control, robust design, and the Taguchi method. [S.l.]: Springer Science \& Business Media, 2012. Citado na página 60.

DOLTSINIS, I.; KANG, Z. Robust design of structures using optimization methods. Computer Methods in Applied Mechanics and Engineering, Elsevier, v. 193, n. 23, p. 2221-2237, 2004. Citado 2 vezes nas páginas 61 e 73.

ELVIN, N.; ERTURK, A. Advances in energy harvesting methods. [S.l.]: Springer Science \& Business Media, 2013. Citado 2 vezes nas páginas 31 e 32.

ERTURK, A.; INMAN, D. J. Piezoelectric energy harvesting. [S.l.]: John Wiley \& Sons, 2011. Citado 2 vezes nas páginas 28 e 30.

ESEN, H.; TURGUT, E. Optimization of operating parameters of a ground coupled heat pump system by taguchi method. Energy and Buildings, Elsevier, v. 107, p. 329-334, 2015. Citado na página 59.

FRANCO, V.; VAROTO, P. Parameter uncertainty and stochastic optimization of cantilever piezoelectric energy harvesters. In: Proceedings of the International Conference on Noise and Vibration Engineering (ISMA), Leuven. [S.l.: s.n.], 2012. p. 4537-4548.

Citado na página 32. 
GODOY, T.; TRINDADE, M.; DEÜ, J. Topological optimization of piezoelectric energy harvesting devices for improved electromechanical efficiency and frequency range. In: Proceedings of 10th World Congress on Computational Mechanics (WCCM), São Paulo. [S.l.: s.n.], 2012. p. 4003-4016. Citado 2 vezes nas páginas 26 e 30.

GODOY, T. C. d. Projeto, otimização e análise de incertezas de um dispositivo coletor de energia proveniente de vibrações mecânicas utilizando transdutores piezelétricos e circuito ressonante. Tese (Doutorado) - Escola de Engenharia de São Carlos, Universidade de São Paulo, 2012. Citado 3 vezes nas páginas 47, 48 e 53.

GODOY, T. C. d.; TRINDADE, M. A. Effect of parametric uncertainties on the performance of a piezoelectric energy harvesting device. Journal of the Brazilian Society of Mechanical Sciences and Engineering, SciELO Brasil, v. 34, n. SPE2, p. 552-560, 2012. Citado na página 26.

GONÇALVES, T. R. S. Colheita piezoeléctrica de energia. Dissertação (Mestrado) Faculdade de Ciências e Tecnologia da Universidade de Nova de Lisboa, 2011. Citado 2 vezes nas páginas 25 e 26.

GUIDO, F. et al. Aln-based flexible piezoelectric skin for energy harvesting from human motion. Microelectronic Engineering, Elsevier, v. 159, p. 174-178, 2016. Citado na página 26.

HWANG, K.-H.; LEE, K.-W.; PARK, G.-J. Robust optimization of an automobile rearview mirror for vibration reduction. Structural and Multidisciplinary Optimization, Springer, v. 21, n. 4, p. 300-308, 2001. Citado na página 65.

KACKER, R. N.; LAGERGREN, E. S.; FILLIBEN, J. J. Taguchi's orthogonal arrays are classical designs of experiments. Journal of Research of the National Institute of Standards and Technology, National Institute of Standards and Technology, v. 96, n. 5, p. 577, 1991. Citado na página 62.

KALYANI, V. L.; PIAUS, A.; VYAS, P. Harvesting electrical energy via vibration energy and its applications. Journal of Management Engineering and Information Technology, v. 2, p. 9-14, 2015. Citado na página 27.

LEE, H. J. et al. Piezoelectric energy harvesting in internal fluid flow. Sensors, Multidisciplinary Digital Publishing Institute, v. 15, n. 10, p. 26039-26062, 2015. Citado na página 26.

LEO, D. J. Engineering analysis of smart material systems. [S.1.]: John Wiley \& Sons, 2007. Citado na página 28.

LESIEUTRE, G. A.; OTTMAN, G. K.; HOFMAnN, H. F. Damping as a result of piezoelectric energy harvesting. Journal of Sound and Vibration, Elsevier, v. 269, n. 3, p. 991-1001, 2004. Citado na página 25.

LOPES JR, V.; STEFFEN JR, V.; SAVI, M. A. Dynamics of Smart Systems and Structures: Concepts and Applications. [S.l.]: Springer, 2016. Citado na página 28.

Mide Technology. Energy Harvesting Kit: VLT-9001. 1989. Disponível em: < http: //www.mide.com/collections/vibration-energy-harvesting-with-protected-piezos/ products/vlt-9001-piezoelectric-energy-harvesting-kit>. Citado na página 78. 
MOHEIMANI, S. R.; FLEMING, A. J. Piezoelectric transducers for vibration control and damping. [S.l.]: Springer Science \& Business Media, 2006. Citado na página 28.

NAIR, V. N. et al. Taguchi's parameter design: a panel discussion. Technometrics, Taylor \& Francis Group, v. 34, n. 2, p. 127-161, 1992. Citado 2 vezes nas páginas 71 e 74.

OSTASEVICIUS, V. et al. Peculiarities of the third natural frequency vibrations of a cantilever for the improvement of energy harvesting. Sensors, Multidisciplinary Digital Publishing Institute, v. 15, n. 6, p. 12594-12612, 2015. Citado na página 26.

PARK, G.-J. et al. Robust design: an overview. AIAA journal, v. 44, n. 1, p. 181-191, 2006. Citado 5 vezes nas páginas 59, 61, 74, 75 e 76.

PHADKE, M. S. Quality engineering using robust design. [S.l.]: Prentice Hall PTR, 1995. Citado 11 vezes nas páginas 58, 60, 62, 63, 67, 69, 70, 71, 74, 75 e 84.

RAMADAN, K. S.; SAMEOTO, D.; EVOY, S. A review of piezoelectric polymers as functional materials for electromechanical transducers. Smart Materials and Structures, IOP Publishing, v. 23, n. 3, p. 033001, 2014. Citado na página 29.

RAO, S. S. Engineering optimization: theory and practice. [S.l.]: John Wiley \& Sons, 2009. Citado 2 vezes nas páginas 34 e 35.

ROUNDY, S. On the effectiveness of vibration-based energy harvesting. Journal of Intelligent Material Systems and Structures, Sage Publications Sage CA: Thousand Oaks, CA, v. 16, n. 10, p. 809-823, 2005. Citado 2 vezes nas páginas 25 e 26.

SANTOS, H. Controle de vibrações estruturais usando cerâmicas piezoelétricas em extensão e cisalhamento conectadas a circuitos híbridos ativo-passivos. Dissertação (Mestrado) - Escola de Engenharia de São Carlos, Universidade de São Paulo, 2008. Citado 7 vezes nas páginas 15, 42, 43, 44, 45, 48 e 78 .

SANTOS, H. Controle ativo-passivo de vibrações estruturais usando materiais piezelétricos: Otimização e quantificação de incertezas. Tese (Doutorado) — Escola de Engenharia de São Carlos, Universidade de São Paulo, 2012. Citado na página 90.

SANTOS, H. F. dos; TRINDADE, M. A. Structural vibration control using extension and shear active-passive piezoelectric networks including sensitivity to electrical uncertainties. Journal of the Brazilian Society of Mechanical Sciences and Engineering, SciELO Brasil, v. 33, n. 3, p. 287-301, 2011. Citado na página 29.

SCHUËLLER, G. I.; JENSEN, H. A. Computational methods in optimization considering uncertainties-an overview. Computer Methods in Applied Mechanics and Engineering, Elsevier, v. 198, n. 1, p. 2-13, 2008. Citado na página 35.

SEKI, K.; ISHII, K.; ESTERMAN, M. Robust design for dynamic performance: optical pick-up example. In: Proceedings of the $199^{7}$ ASME Design Engineering Technical Conference and Design Automation Conference, Sacrament, CA, Paper No. 97-DETC/DAC3978. [S.l.: s.n.], 1997. Citado na página 62.

SODANO, H. A.; INMAN, D. J.; PARK, G. A review of power harvesting from vibration using piezoelectric materials. Shock and Vibration Digest, Washington, DC: The Center, v. 36, n. 3, p. 197-206, 2004. Citado na página 26. 
STEPHEN, N. On energy harvesting from ambient vibration. Journal of Sound and Vibration, Elsevier, v. 293, n. 1, p. 409-425, 2006. Citado 2 vezes nas páginas 25 e 26.

TIKANI, R. et al. Optimization of spiral-shaped piezoelectric energy harvester using taguchi method. Journal of Vibration and Control, SAGE Publications Sage UK: London, England, p. 1-8, 2017. Citado na página 38.

TRINDADE, M. A.; BENJEDDOU, A. Finite element characterisation of multilayer d31 piezoelectric macro-fibre composites. Composite Structures, Elsevier, v. 151, p. 47-57, 2016. Citado na página 30.

TSUI, K.-L. An overview of taguchi method and newly developed statistical methods for robust design. Iie Transactions, Taylor \& Francis, v. 24, n. 5, p. 44-57, 1992. Citado na página 37.

YAN, X. et al. Composition-driven phase boundary and its energy harvesting performance of bczt lead-free piezoelectric ceramic. Journal of the European Ceramic Society, Elsevier, v. 37, n. 7, p. 2583-2589, 2017. Citado na página 89.

ZANG, C.; FRISWELL, M.; MOTTERSHEAD, J. A review of robust optimal design and its application in dynamics. Computers $\&$ structures, Elsevier, v. 83, n. 4, p. 315-326, 2005. Citado 4 vezes nas páginas 35, 36, 37 e 38 .

ZHOU, L. et al. A model for the energy harvesting performance of shear mode piezoelectric cantilever. Sensors and Actuators A: Physical, Elsevier, v. 179, p. 185-192, 2012. Citado na página 89. 